SAND 74-0252

Unlimited Release

A80006098

\title{
Free-Field Ground Motion Induced by Underground Explosions
}

William R. Perret, Robert C. Bass






\section{DISCLAIMER}

This report was prepared as an account of work sponsored by an agency of the United States Government. Neither the United States Government nor any agency Thereof, nor any of their employees, makes any warranty, express or implied, or assumes any legal liability or responsibility for the accuracy, completeness, or usefulness of any information, apparatus, product, or process disclosed, or represents that its use would not infringe privately owned rights. Reference herein to any specific commercial product, process, or service by trade name, trademark, manufacturer, or otherwise does not necessarily constitute or imply its endorsement, recommendation, or favoring by the United States Government or any agency thereof. The views and opinions of authors expressed herein do not necessarily state or reflect those of the United States Government or any agency thereof. 


\section{DISCLAIMER}

Portions of this document may be illegible in electronic image products. Images are produced from the best available original document. 
Issued by Sandia Laboratories, operated for the United States Atomic Energy Commission by Sandia Corporation.

\section{NOTICE}

This report was prepared as an account of work sponsored by the United States Government. Neither the United States nor the United States Atomic Energy Commission, nor any of their employees, nor any of their contractors, subcontractors. or their employees, makes any warranty, express or implied, or assumes any legal liability or responsibility for the accuracy. completeness or usefulness of any information, apparatus, product or process disclosed, or represents that its use would not infringe privately owned rights.

SF $1004-0 F(2-74)$ 
SAND74-0252

Unlimited Release

Printed February 1975

\author{
William R. Perret \\ Robert C. Bass \\ Underground Physics Division \\ Sandia Laboratories \\ Albuquerque, NM 87115
}

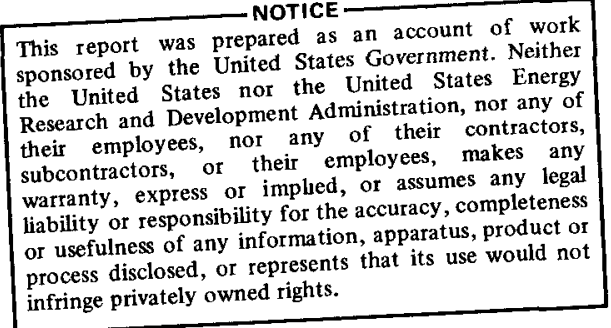

ABSTRACT

Free-field ground motion induced by 60 contained underground nuclear explosions and one underground chemical explosion detonated by the U.S. Atomic Energy Commission at the Nevada Test Site and elsewhere was measured, and data from recorded motion have been collated and analyzed for effects of geologic environment on attenuation of the motion. These data include those derived from hydrodynamic, nonlinear, and linear response of the rock. This study involved nearly 1100 peak stress and motion data, of which 116 were of stress and particle velocities from within the hydrodynamic response region and the remainder were accelerations, particle velocities, and displacements from the nonlinear and beginning of the linear response regions. Data from the latter two regions included 183 in a dry alluvium environment, 198 in dry tuff, 215 in wet tuff, and 425 in hard rock, i. e., granite, salt, dolomite, and similar sedimentaries.

Log-linear regression of these data normalized to explosive energy release equivalent to that of one kiloton of TNT for each motion parameter in each environment indicate such facts as no differentiation between dry alluvium, dry tuff, wet tuff, or granite, in particle velocities in the hydrodynamic response regime where stress is attenuated as the inverse 
2.96-power of distance from the source and particle velocity as the inverse 1.87-power. Scaled accelerations are generally represented by two-branched attenuation in both the nonlinear and linear domains, but except for dry alluvium this appears to become a single attenuation pattern in the other motion parameters. Scaled accelerations and particle velocities are of similar magnitude in saturated tuff and hard rock but are lower in dry tuff and still lower in alluvium. Scaled displacements are of roughly similar amplitude except in dry alluvium where they are lower by factors ranging from 5 to 10.

Analysis of all particle velocities from the hydrodynamic region and from wet tuff and hard rock in the nonlinear region shows a single linear trend over a range of 5 orders of magnitude, for which the regression equation is

$$
u=1.85 \times 10^{4}\left(\mathrm{R} / \mathrm{W}^{1 / 3}\right)^{-1.76 \pm 0.02}
$$

where $u$ is particle velocity in meters per second and $R / W^{1 / 3}$ is scaled radial range in meters per cube-root yield in (kilotons) $1 / 3$. 


\section{ACKNOWLEDGMENTS}

A study such as the following analysis of free-field stress and ground motion in the immediate vicinity of 60 underground nuclear explosions over a period of 15 years necessarily involved the efforts of a great many very capable people in the execution of these numerous programs. The authors recognize their indebtedness to all of these people, for without their successful accomplishment of difficult tasks, this study could not have been made.

The authors realize that even a simple listing of those who have contributed directly to this work would be pages long and, unintentionally, incomplete. Those to whom we are indebted include many who through sponsorship and support of the measurement programs ensured the basis for this study. Probably most significant to the full scope of our undertaking were the numerous scientists, engineers, and technicians whose painstaking and consciencious efforts yielded data of consistently excellent quality. Their work was frequently performed under adverse field conditions which ranged from desert heat and sandstorms to subfreezing blizzards and Aleutian williwaws and from Nevada flashfloods to a waning Mississippi hurricane. And finally in the chain of experts who gave us our basic data are the mathematicians and data processors who converted field records from signals on magnetic tapes to plots and listings of time and motion and who aided in the analysis of these data.

We acknowledge a special indebtedness to those from other laboratories and agencies who either sponsored Sandia programs or provided us with data from their programs. Among these we place particular value on the contributions of Robert C. Campbell, Arthur N. Cox, the late Alvin C. Graves, Robert W. Newman, and William E. Ogle of Los Alamos Scientific Laboratory; Roger G. Preston, Phillip L. Randolph, and Vernon E. Wheeler of Lawrence Livermore Laboratory; John G. Lewis of the Defense Nuclear Agency; Lawrence M. Swift of Stanford Research Institute, Fred M. Sauer of Physics International Company, and Leo Ingram of the Waterways Experiment Station.

A list of Sandia Laboratories personnel who participated in ground motion programs would include over 50 names; however, we owe special recognition to those who held direct responsibility for successful operations in the field. These include Dale R. Breding, James I. Greenwoll,

Harry R. Holmes, Kenneth B. Kimball, the late Dean B. List, Darwin G. Palmer, A. Dean Thornbrough, and Joe W. Wistor. Most of the data processing was accomplished by Robert J. Beyatte and Gilbert E. Larsen.

We also acknowledge with gratitude the sponsorship and support of the U. S. Atomic Energy Commission which made possible the acquisition of most of the ground motion data used in this study as well as the study itself. 

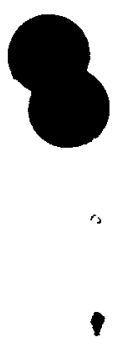


\section{CONTENTS}

$\begin{array}{lll}\text { Chapter 1. INTRODUCTION } & 11\end{array}$

1. 1 Background 11

1.2 Environment 12

1.3 Techniques $r$

Chapter 2. STRESS AND MOTION WITHIN THE REGIONS OF HYDRODYNAMIC AND PLASTIC RESPONSE

2. 1 Principles of Shock Front Parameter Measurements in Rock 19

2.2 Measurement Techniques for Alluvium 21

2. 3 Measurement Techniques for Tuff 22

2.4 Measurement Techniques for Granite 23

2.5 Measurement Techniques in the Region of Plastic Deformation 23

2. 6 Analysis of Data 23

Chapter 3. GROUND MOTION IN REGION OF NONLINEAR RESPONSE

3.1 Measurement of Ground Motion $\quad 27$

3.2 Free-Field Ground Motion in Alluvium 28

3.2. 1 Scaled Acceleration Analysis 28

3.2.2 Particle Velocity Analysis 30

3. 2. 3 Scaled Displacement Analysis

3.2.4 Discussion $\quad 32$

3. 3 Free-Field Ground Motion in Dry Tuff 34

3.3. 1 Scaled Acceleration Analysis $\quad 35$

3. 3.2 Particle Velocity Analysis 37

3.3. 3 Scaled Displacement Analysis $\quad 37$

3.4 Free-Field Ground Motion in Wet Tuff 37

3.4. 1 Scaled Acceleration Analysis $\quad 40$

3.4.2 Particle Velocity Analysis $\quad 42$

3.4. 3 Scaled Displacement Analysis $\quad 42$

3. 5 Free-Field Ground Motion in Hard Rock 42

3.5.1 Scaled Acceleration Analysis $\quad 45$

3.5.2 Particle Velocity Analysis $\quad 45$

3.5.3 Scaled Displacement Analysis 48

$\begin{array}{lll}3.6 & \text { General Discussion } & 48\end{array}$ 


\section{CONTENTS (cont)}

\section{PART I}

Chapter 4. COMPARISONS

4. 1 Comparison of Free-Field Motion in Regions of Hydrodynamic and Nonlinear Response

4. 2 Comparison of Motion in Different Rocks

4.2. 1 Scaled Acceleration

4.2.2 Particle Velocity

PART II

Chapter 5. RECORDS

5.1 General Comments

5. 2 Stress Records

5. 3 Records from the Salmon Event

5. 4 Records from the Plle Driver Event

5. 5 Records from the Merlin Event

5. 6 Records from the Handcar Event

Figure 3.1 Attenuation of scaled acceleration-dry alluvium

Figure 3.3 Attenuation of scaled displacement-dry alluvium

Figure 3.5 Attenuation of particle velocity-dry tuff

Figure 3.6 Attenuation of scaled displacement-dry tuff

Figure 3.7 Attenuation of scaled acceleration-wet tuff

Figure 3.8 Attenuation of particle velocity-wet tuff

Figure 3.9 Attenuation of scaled displacement-wet tuff

Figure 3.10 Attenuation of scaled acceleration-hard rock 
FIGURES (cont)

\section{PART I}

Figure 3.11 Attenuation of particle velocity-hard rock

Figure 3.12 Attenuation of scaled displacement-hard rock

Figure 4.1 Attenuation of particle velocity in the regions of hydrodynamic and nonlinear response

Figure 4.2 Attenuation comparison-scaled acceleration 56

Figure 4.3 Attenuation comparison-particle velocity 57

Figure 4. 4 Attenuation comparison-scaled displacement 59

PART II

Figure 5.1 Stress records $\quad 66$

Figure 5.2 Salmon instrumentation scheme-Sandia 67

Figure 5.3 Radial acceleration records-Borings 14 and $14 \mathrm{C}$

Figure 5.4 Radial particle velocity records-Borings 14 and 14C 69

Figure 5.5 Radial particle velocity records-Borings 6 and $11 \quad 70$

Figure 5.6 Radial displacement records-Borings 14 and $14 \mathrm{C}$

Figure 5.7 Radial displacement records-Borings 6, 11, and 5

Figure 5.8 Pile Driver free-field instrument stations 73

Figure 5.9 Pile Driver radial motion and stress records-Station B-SL

Figure 5.10 Pile Driver radial motion records-Station 16-SL 75

Figure 5.11 Pile Driver radial motion records-Station 16-SL 76

$\begin{array}{lll}\text { Figure 5.12 Merlin instrumentation } & 77\end{array}$

Figure 5.13 Merlin free-field ground motion, Station U3; slant range: 350 feet 78

Figure 5. 14 Merlin free-field ground motion, Station U4; slant range: 700 feet 79

Figure 5.15 Merlin free-field ground motion, Station U5; slant range: 1100 feet 80

Figure 5.16 Merlin free-field ground motion, Station U6; slant range: 1602 feet 81

Figure 5.17 Merlin free-field ground motion, Station U7; slant range: 2503 feet 82

Figure 5.18 Handcar instrumentation plan and geophysical cross section 83

Figure 5.19 Handcar horizontal radial particle velocity records on geologic section 84

Figure 5.20 Handcar vertical particle velocity records on geologic section 85

Figure 5.21 Handcar radial vector particle velocity records-Boring U10b-2 86

Figure 5.22 Handcar radial vector particle velocity records-Boring U10b-4 87

Figure 5.23 Handcar radial vector particle velocity records-Boring U10b-5 88

Figure 5. 24 Handcar radial vector displacement-Boring U10b-2 89

Figure 5.25 Handcar radial vector displacement-Boring U10b-4 90

Figure 5.26 Handcar radial vector displacement-Boring U10b-5 91 


\section{TABLES}

PART I

Table 1.1 Geophysical Properties of Typical Rocks 14

Table 2.1 Hugoniot Parameters 21

Table 3.1 Regression Parameters for Free-Field Ground Motion 51

Table 4.1 Scaled Acceleration in Nonlinear and Linear Regions 56

Table 4.2 Particle Velocity in Nonlinear and Linear Regions 57

Table 4.3 Scaled Displacement in Nonlinear and Linear Regions 59

PART II

Table 6.1 Scaled Free-Field Ground Motion and Pressure 96

Table 6.2 Scaled Free-Field Ground Motion and Pressure 97

Table 6.3 Scaled Free-Field Ground Motion--Alluvium 98

Trable 6.4 Scaled Free-Field Ground Motion--Alluvium 99

Table 6.5 Scaled Free-Field Ground Motion--Alluvium 100

Table 6.6 Scaled Free-Field Ground Motion--Tuff 101

Table 6.7 Scaled Free-Field Ground Motion--Tuff 102

T rb!e 6.8 Scaled Free-Field Ground Motion--Tuff 103

J'ablo 9.9 Scaled Free-Field Ground Motion - -Wet Tuff 104

Thite 6.10 Scaled Free-Field Ground Motion --Wet Tuff 105

Table 5. 11 Scaled Free-Field Ground Motion --Wet Tuff 106

Fahlc 6.12 Scaled Free-Field Ground Motion --Wet Tuff 107

Table 6.13 Scaled Free-Field Ground Motion --Wet Tuff 108

Tahle 6.14 Scaled Free-Field Ground Motion --Granite 109

Tabie 6.15 Scaled Free-Field Ground Motion --Granite and Dolomite 110

Table 6.16 Scaled Free-Field Ground Motion --Granite 111

Tiable 6.17 Scaled Free-Field Ground Motion --Volcanic Breccia and Lava 112

Table 6.18 Scaled Free-Field Ground Motion --Lava 113

Table 6.19 Scaled Free-Field Ground Motion --Shale and Rhyolite 114

Table 0.20 Sealed Free-Field Ground Motion --Bedded Salt 115

Table 6.21 Scaled Free-Field Ground Motion --Dome Salt 116 
FREE-FIELD GROUND MOTION INDUCED BY UNDERGROUND EXPLOSIONS

\author{
PART I \\ Chapter 1 \\ INTRODUCTION
}

\title{
1.1 Background
}

During a period of more than 15 years beginning with the Rainier underground nuclear explosion in 1957, the Atomic Energy Commission (AEC) has detonated a considerable number of nuclear devices underground in connection with weapon tests, Plowshare program objectives, and Vela Uniform seismic detection studies. Observation of the ground motion caused by many of these explosions has been undertaken by various agencies for numerous purposes.

Ground motion induced by underground explosions involves four typical domains of mechanical response of the rock to energy released. In the immediate vicinity of an underground explosion, within a few meters to a few tens of meters depending on the energy released and the rock, stresses induced in the rock are extremely high, a megabar and greater, the macro and crystalline structure of rocks exert little influence on their reaction to the stress, and the result is hydrodynamic response. Energy lost or trapped in this region and spherical divergence results in decreased stresses at increased distance so that beyond the hydrodynamic regime rock structure begins to control response. However, where stresses are still high, tens of kilobars to hundreds of bars, energy is lost to dissipative processes and the response to loading is nonlinear. At still more remote regions as stress levels decrease to a few bars and less, response of the rock becomes linear or quasi-linear and continues in this mode to the limits of detection. The fourth response is characterized by the influence of the free surface on motion; it includes ballistic effects at the ground surface directly above the explosion and the generation of surface waves near that area.

Ground motion measurements are generally segregated into two regional classes, free-field and surface motions. The domain of free-field motion is defined, optimistically, as the region within the earth surrounding an explosion but sufficiently remote from both the free ground surface and other major rock interfaces or fault zones that perturbations of the motion by such discontinuities is either negligible or affects only late portions of the motion. The degree of approximation of any real shot environment to this definition ranges from good in relatively uniform massive geologic formations to very poor in highly stratified formations which include appreciable thicknesses of alluvium, tuff, and carbonate rocks. However, in the domain of hydrodynamic response, these differences have little or no influence on the motion. 
Surface motion measurements are considered to represent motion of the free surface of the earth. However, for practical reasons of gage installation and general classification, such motion is characteristic of a surface layer a few meters thick.

This study considers only data from free-field motion measurements made following 61 underground detonations, on-site at the AEC Nevada Test Site (NTS) and off-site at Supplemental Test Sites in Central Nevada, on Amchitka Island, or at special Plowshare or Vela Uniform locations in Nevada, New Mexico, and Mississippi. These data were derived from the hydrodynamic and nonlinear response regions and from that portion of the quasi-linear response domain adjacent to the nonlinear region. They include nearly all such measurements of which we have knowledge through 1972 and in the tabulations are credited to the agency which recorded them. Where these data have been reported, in open literature, the reports are identified.

\subsection{Environment}

The geologic environment of an underground explosion exercises considerable control over the character of ground motion within the more remote regions where response is either nonlinear or linear. Specific differences in characteristics of the rock surrounding an explosion are not particularly significant to motion in the hydrodynamic region, with the possible exception of the degree of water saturation of porous rocks. However, because mechanical properties of the rock in the more remote regions influence energy absorption and transmission strongly at the lower stress levels, the geologic environment will affect ground motion there significantly.

Those underground events from which free-field data were derived occurred in a variefy of geologic environments which have been classified into four general geological types: dry alluviurn, dry tuff, wet tuff, and hard rock. All four of these are present at $\mathrm{NTS}$, and several exist at the Supplemental and special event sites. These specific environments are lescribed in some detail in the following paragraphs.

Dry alluvium applies to the valley fill in the Yucca Flat valley at VTS. It consists of sinds and gravelly detritus from the surrounding mountains composed principally of tulls and carlionatr. rocks. It forms about $300 \mathrm{~m}$ or more of surface lill and is gentrally well above the water lathle. Within this alluvium there may occur masses of unweathered tuft ranging in size from cobbles to boulders. In this valley alluvium lies over various tulf strata, ranging from welded tuff to extremely friable ash flows and varying in thickness from 300 to 700 meters. Water tahle depths vary from 500 to $600 \mathrm{~m}$, and consequently tuffs occur in both dry and saturated states. Beneath the tuffs lie formations of paleozoic shale and carbonate rocks. This cross section is roughly characteristic of those portions of NTS designated as Areas 1, 3, 4, 7, 8, 9, and 10 . 
Rainier Mesa, NTS Area 12, is composed almost entirely of tuffaceous strata of which the top consists of 10 to $50 \mathrm{~m}$ of a dense welded tuff overlying nearly $600 \mathrm{~m}$ of relatively soft tuff strata which in turn lie upon thick paleozoic carbonate rocks. Several localized perched water tables occur in this mesa, and the degree of saturation in some parts of the mesa is highly variable.

Hard rocks at NTS include the paleozoic carbonates mentioned above, granitic intrusive rock in Area 15, and some of the rhyolitic flows among the volcanic rock of Pahute Mesa, Areas 19 and 20. The Climax Stock in Area 15 outcrops and, as an intrusive mass, extends to great depth. It is comprised of large masses of granodiorite and quartz monzonite bordered by metamorphosed carbonates. It includes several nearly vertical fault zones of significant thickness as well as at least three uniformly developed fissure systems. Pahute Mesa includes over a thousand meters of volcanic ash and lava flows within a large caldera, with the consequent pattern of numerous and extensive vertical faults.

At the AEC Supplemental Test Sites, the geologic environments are roughly similar to some areas at NTS. The Central Nevada Supplemental Test Site (CNSTS) includes part of a caldera in which several hundred meters of typical alluvium overlie tuff, andesites, rhyolites, and sedimentaries to a depth of more than two kilometers. At this site the water table is about $100 \mathrm{~m}$ deep and normal underground shot depths imply a saturated tuff environment.

Amchitka Island is composed of numerous lava and ash flows and thick volcanic breccia strata, essentially all of submarine origin and extending to a depth of more than 2 kilometers. The lavas are primarily basaltic or andesitic.

The geologic environments of those Plowshare and Vela Uniform events from which data in this study were derived differ considerably from those at NTS. Gnome was a Plowshare experiment detonated within a thick series of evaporites in southern New Mexico. These flat-lying salt strata range from less than $10 \mathrm{~cm}$ to several meters in thickness and are composed principally of halite, sylvite, and polyhalite, with thin brine-saturated clay seams in bedding planes. The evaporites are overlain by about $150 \mathrm{~m}$ of anhydrite and red bed strata and about $60 \mathrm{~m}$ of alluvium.

Gasbuggy, another Plowshare event, occurred in the San Juan Basin of northwest New Mexico. It was detonated near the top of the $500-\mathrm{m}$ thick Lewis shale within a $1600 \mathrm{~m}$ series of Cretaceous sandstones and shales. These are overlain by $1200 \mathrm{~m}$ of Tertiary and Recent sedimentary rocks.

The Vela Uniform event Shoal was located in a tunnel within the Sand Spring Range of Central Nevada. This range consists of an intrusive granitic mass cut by numerous dikes and thick fault zones filled with wet clay gouge. 
The second Vela Unıform experiment, Salmon, was detonated within the Tatum Salt Dome in central Mississippi. This dome, composed of more than 90 percent halite, is about $1.5 \mathrm{~km} 1 \mathrm{n}$ diameter at shot depth, extended to a depth of about $8 \mathrm{~km}$ and was capped by $200 \mathrm{~m}$ of anhydrite and limestone beneath about $250 \mathrm{~m}$ of Recent sediments.

These descriptions of the sites suggest the multiplicity of environments possible, and in one sense it has appeared that there might be nearly as many specific environments as events. However, various characteristics of the free-field motion data and theoretical studies suggest that the four geologic categories chosen provide a reasonable division of source environments for this study. There are a few exceptions in which the best geological description of an explosion site differs from that in which the data fit most readily. Such cases are noted, and an attempt is made to rationalize differences in discussion of the data.

The dry alluvium category includes principally those events which occurred at depths between 300 and $500 \mathrm{~m}$ within Yucca Flat at NTS. The dry tuff classification includes some events in Rainier Mesa and in the outer edges of Yucca and Frenchman Flats. The third group--wet tuff--1ncludes events detonated at the CNSTS, in Yucca Flat below the water table, and some in Rainier Mesa. Finally, the fourth category, hard rock, covers all those events which were detonated in granitic, volcanic, or carbonate rocks or in sandstone, shale, or salt.

Geophysıcal properties of the varıous rocks are particularly significant to their response to explosive loading in the linear and nonlinear region. The values listed in Table 1.1 are generally applicable to the rock types described here and serve to indicate differences in response of such rocks. The wave velocity quoted for bedded salt is probably high as is the density because of a layer of dense polyhalite directly below the shot point.

TABLT 1.1 Geophysical Properties of Typical Rocks

\begin{tabular}{|c|c|c|c|c|c|c|}
\hline \multirow[b]{2}{*}{ Rock } & \multirow{2}{*}{$\begin{array}{l}\text { Natural } \\
\text { Density } \\
\left(\mathrm{gm} / \mathrm{cm}^{3}\right) \\
\end{array}$} & \multirow{2}{*}{$\begin{array}{l}\text { Porosity } \\
(\% \text { Vol })\end{array}$} & \multirow{2}{*}{$\begin{array}{c}\text { Water } \\
\text { Saturation } \\
(\%) \\
\end{array}$} & \multicolumn{2}{|c|}{$\begin{array}{c}\text { Compressive Wave } \\
\text { Velocity }\end{array}$} & \multirow{2}{*}{$\begin{array}{l}\text { Selsmic } \\
\text { Impedance } \\
\left.\text { (gm/m } / \mathrm{m}^{2} \mathrm{sec}\right)\end{array}$} \\
\hline & & & & $(\mathrm{m} / \mathrm{sec})$ & $(\mathrm{ft} / \mathrm{sec})$ & \\
\hline Alluvium (NTS) & $1.78 \pm 0.19$ & $36 \pm 6$ & $61 \pm 16$ & $1800 \pm 310$ & $5900 \pm 1000$ & $32.0 \pm 8.9$ \\
\hline Dry Tuff (NTS) & $1.78 \pm 0.19$ & $36 \pm 6$ & $61 \pm 16$ & $1800 \pm 310$ & $5900 \pm 1000$ & $32.0 \pm 8.9$ \\
\hline Wet Tuff (NTS) & $1.86 \pm 0.05$ & $38 \pm 3$ & $92 \pm 6$ & $2350 \pm 440$ & $7700 \pm 1450$ & $43.7 \pm 9.4$ \\
\hline $\begin{array}{l}\text { Raimer Mesa } \\
\text { Tuff (NTS) }\end{array}$ & $1.90 \pm 0.12$ & $35 \pm 7$ & $96 \pm 9$ & $2500 \pm 275$ & $8203 \pm 900$ & $47.5 \pm 8.2$ \\
\hline $\begin{array}{l}\text { Dry Volcames } \\
\text { Pahute Mesa } \\
\text { (NTS) }\end{array}$ & $2.06 \vdash 0.22$ & $23 \pm 5$ & 50 (est) & $3091 \pm 793$ & $10,142 \pm 2600$ & $63.7 \pm 23.1$ \\
\hline $\begin{array}{l}\text { Wet Volcanics } \\
\text { Pahute Mesa } \\
\text { (NTS) }\end{array}$ & $2.25 \pm 0.19$ & $20.1 \pm 6$ & $100(\mathrm{est})$ & $3374 \pm 743$ & $11,070 \pm 2440$ & $75.9 \pm 23.1$ \\
\hline Bedded Salt & $2.30 \pm 0.16$ & $2.9 \pm 2.2$ & $79 \pm 65$ & $4839 \pm 968$ & $15,877 \pm 3175$ & $111.3 \pm 30$ \\
\hline Dome Salt & $2.23 \pm 0.10$ & $\mathrm{mll}$ & $\mathrm{nil}$ & $4669 \pm 25$ & $15,319 \pm 82$ & $104.1 \pm 5.2$ \\
\hline $\begin{array}{l}\text { Breccia } \\
\qquad(\Lambda \text { mchitka })\end{array}$ & $2.30 \pm 0.2$ & 22.5 & 100 (est) & $3833 \pm 201$ & $12,577 \pm 659$ & $88.2 \pm 12.3$ \\
\hline $\begin{array}{l}\text { Lava } \\
\qquad(\Lambda \text { mehitka) }\end{array}$ & $2.48 \vdash 0.2$ & 8.1 & 100 (est) & $4677 \pm 53$ & $15,346 \pm 174$ & $116.0 \pm 9.5$ \\
\hline Granite & $2.67 \pm 0.04$ & $0.76 \pm 0.66$ & 100 (est) & $5722 \pm 430$ & $18,774 \pm 1410$ & $152.8 \pm 13.8$ \\
\hline
\end{tabular}




\subsection{Techniques}

Mechanical effects of an underground explosion include transient pressure, strain, and particle motion. Observation of any of these parameters must depend upon compatibility of a measuring system with conditions in the vicinity of the observation point. In the region of hydrodynamic response pressure levels, rise times and temperatures restrict such measuring systems to those responsive to shock front velocities, from which pressure levels may be deduced. Near the outer limits of the hydrodynamic region where rocks begin to respond plastically, gages have been devised which yield a signal relatable to the whole transient disturbance. The primary limiting factor in this region is the very brief survival of instruments and communications, i. e., cables, through the very high stress levels and large mass velocities behind the shock front. These conditions prevent acquisition of data after shock arrival within the hydrodynamic regime and often terminate data during later portions of the stress transient in the plastic regime.

Communication survival, i. e., maintenance of cable integrity, is also a limiting factor in the forward portion of the nonlinear response region. This problem is generally limited to stress levels above one kilobar, although catastrophic cable damage may occur at lower stress levels where gross displacements occur at bedding planes or faults intersected by the cables. There is, however, a very different restraint imposed on measuring techniques in the lower stress regions as a consequence of impedance matching problems between the rock and the instruments. As a consequence of this problem, it has been found that measurement of motion in terms of particle acceleration or its time integrals is more reliable than observation of either stress or strain. Response of instrumentation for measuring either of the latter appears to be much more sensitive to disturbance of the environment by gage emplacement or to mismatch of rock and gage impedance than is response of motion gages. Consequently, data from the hydrodynamic domain are shock front velocities translated to peak pressure levels by means of experimentally determined rock properties, and data from the nonlinear and linear or quasi-linear domain are motion data recorded as time-histories of acceleration or particle velocity. Correlation of these data will be developed in later portions of this report.

Contained underground nuclear explosions, which were the source of all but one set of data used in this study, are placed at depths of the order of $250 \mathrm{~m}$ or deeper. Emplacement is either in a deep vertical borehole from the ground surface or in a horizontal tunnel or drift extending either from the face of a mesa or from the bottom of a vertical access shaft, depending upon the terrain and specific objectives of the event. Regardless of the type of explosive emplacement, the preferred pattern of free-field ground motion instrument stations is in a radial line from the explosive at distances dependent upon instrumentation and feasible positions. Such instrument arrays are generally on horizontal radii at shot depth or on the vertical radius through surface zero directly above the explosive. In special cases vertical arrays may also be offset horizontally from surface zero at various distances and horizontal arrays may be above or below shot level. 
Emplacement of the explosive in a deep vertical hole requires that horizontal instrument arrays be emplaced in a series of vertical holes drilled at specified distances along a radius and that vertical arrays be located in a boring offset about $10 \mathrm{~m}$ or more from the shot hole. The Merlin event in NTS Area 3 included instrument arrays of this type, Figure 5.12. Events for which distant offset vertical arrays were required, such as Salmon, Figure 5.2, and Handcar, Figure 5. 18 , used similar series of instrumentation borings; but these borings usually extended to depths appreciably below shot level.

Free-field instrumentation arrays for nuclear explosions emplaced in tunnels were usually installed at or near shot level in borings extending from the floor or walls of the tunnel to depths of 3 or more tunnel diameters and in vertical borings from surface zero, Figure 5. 8 . In tunnel installations where stations were required at distances or in directions beyond the tunnel complex, offset vertical borings were also used for shot level stations.

Peculiarities of the environment in the hydrodynamic and nonlinear response regions dictate differences in instrumentation and techniques of installing these instruments. Specifics of these gages and techniques will be considered in the chapters which deal separately with results of such measurements. However, it is pertinent here to describe the method of handling data from these measurements for the analysis which forms the basis for this report.

Peak values of stress and particle velocity were derived from measurements made in the hydrodynamic region, and corresponding peak values of acceleration, particle velocity, and displacement were derived from ground motion measurement records obtained within the nonlinear response domain. These peak data were from numerous events involving explosively released energy which ranged over several orders of magnitude and from gages placed at distances ranging from a few meters to a few kilometers. Comparison of such data requires normalization to some logical base by means of dimensional analysis. Such analysis has shown that, normalized to an energy release equivalent to that of one kiloton of TNT explosive, pressure or stress and particle velocity vary inversely with the $n^{\text {th }}$ power of the distance from source to measurement station reduced by the cube root of the yield or energy released in equivalent kilotons of TNT. Similar power law relationships are derived from accelerations normalized by multiplying by the culs root of yield and for displacement divided by the cube root of yield. Ceneral equations for these normalization or scaled relationships are:

$$
\begin{aligned}
\mathrm{p} & =\mathrm{p}_{\mathrm{o}}\left(\mathrm{R} / \mathrm{W}^{1 / 3}\right)^{-\mathrm{m}}, \\
\mathrm{u} & =\mathrm{u}_{\mathrm{o}}\left(\mathrm{R} / \mathrm{w}^{1 / 3}\right)^{-\mathrm{n}}, \\
\mathrm{a} \cdot \mathrm{w}^{1 / 3} & =\left(\mathrm{a} \cdot \mathrm{w}^{1 / 3}\right)_{\mathrm{o}}\left(\mathrm{R} / \mathrm{w}^{1 / 3}\right)^{-\mathrm{q}},
\end{aligned}
$$

and

$$
\delta / \mathrm{W}^{1 / 3}=\left(\delta / \mathrm{W}^{1 / 3}\right)_{0}\left(\mathrm{R} / \mathrm{W}^{1 / 3}\right)^{-\mathrm{r}}
$$


where $\mathrm{p}, \mathrm{u}, \mathrm{a}$ and $\delta$ are respectively pressure, particle velocity, acceleration, and displacement, $R$ is the distance or range between source and measurement station, and $W$ is the energy yield in equivalent kilotons of TNT. The subscript zero refers to the value of the normalized quantity for $\left(\mathrm{R} / \mathrm{W}^{1 / 3}\right)$ equal to one.

Consequently, all free-field ground motion data used in this study are normalized to a value of $\mathrm{W}$ equal to $1 \mathrm{kt}$ and are tabulated, fitted by $\mathrm{log}$-linear regression, and plotted in this form. The resulting linear fits and plots are compared and discussed in the remainder of this part of the report. Tabulated data, a few typical pressure and motion records from the events studied, and brief descriptions of each event are included in Part II of the report. 
8

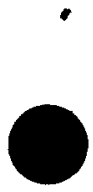




\section{Chapter 2 \\ STRESS AND MOTION WITHIN THE REGIONS OF HYDRODY NAMIC AND PLASTIC RESPONSE}

\section{1 Principles of Shock Front Parameter Measurements in Rock}

It has been noted previously that in the immediate vicinity of underground explosions temperatures and pressures are so great that rock responds hydrodynamically to the load. Such response is more strongly dependent upon the chemical elements in the rock than upon its crystalline or macrostructure. Only limited means exist for experimental studies of shock front characteristics under these conditions. Conventional instruments or systems for measuring stress or motion in the rock would be destroyed under the extremely high stress levels and large mass velocities which exist behind the shock front in this region. It is feasible, however, to derive certain parameters of the shock front which, combined with the equation of state for the geologic material which surrounds an explosion, can yield information concerning maximum stress in the shock front and particle velocities immediately behind it.

In an environment of hydrodynamic shock, the equation of state of a material may be described by the Hugoniot equation. This is a special form of the equation of state which involves neither temperature nor volume directly but is formulated in terms of the dynamic characteristics of a shock front or jump. These parameters include initial pressure and density, $p_{0}$ and $\rho_{0}$, ahead of the shock, velocity with which the shock is propagated, $U_{s}$, and pressure and particle velocity immediately behind the shock front, $p$ and $u_{p}$. The Hugoniot equation for this jump condition (Rice et al 1958) is

$$
p-p_{o}=\rho_{o} U_{s} u_{p}
$$

In addition to this equation, a second relationship expresses the shock front velocity as a linear function of particle velocity behind the front as

$$
U_{s}=C+S u_{p}
$$

where $C$ and $S$ are respectively the intercept and slope of a linear segment of a plot of $U_{S}$ versus $u_{p}$ for a specific span of pressure levels. For some materials, the full range of pressure levels within the hydrodynamic region may be represented by a single linear plot; for others, such as alluvium, Figure 2.1, the curve is not linear, but several linear segments serve as a practical approximation for application to the Hugoniot equation of state. 


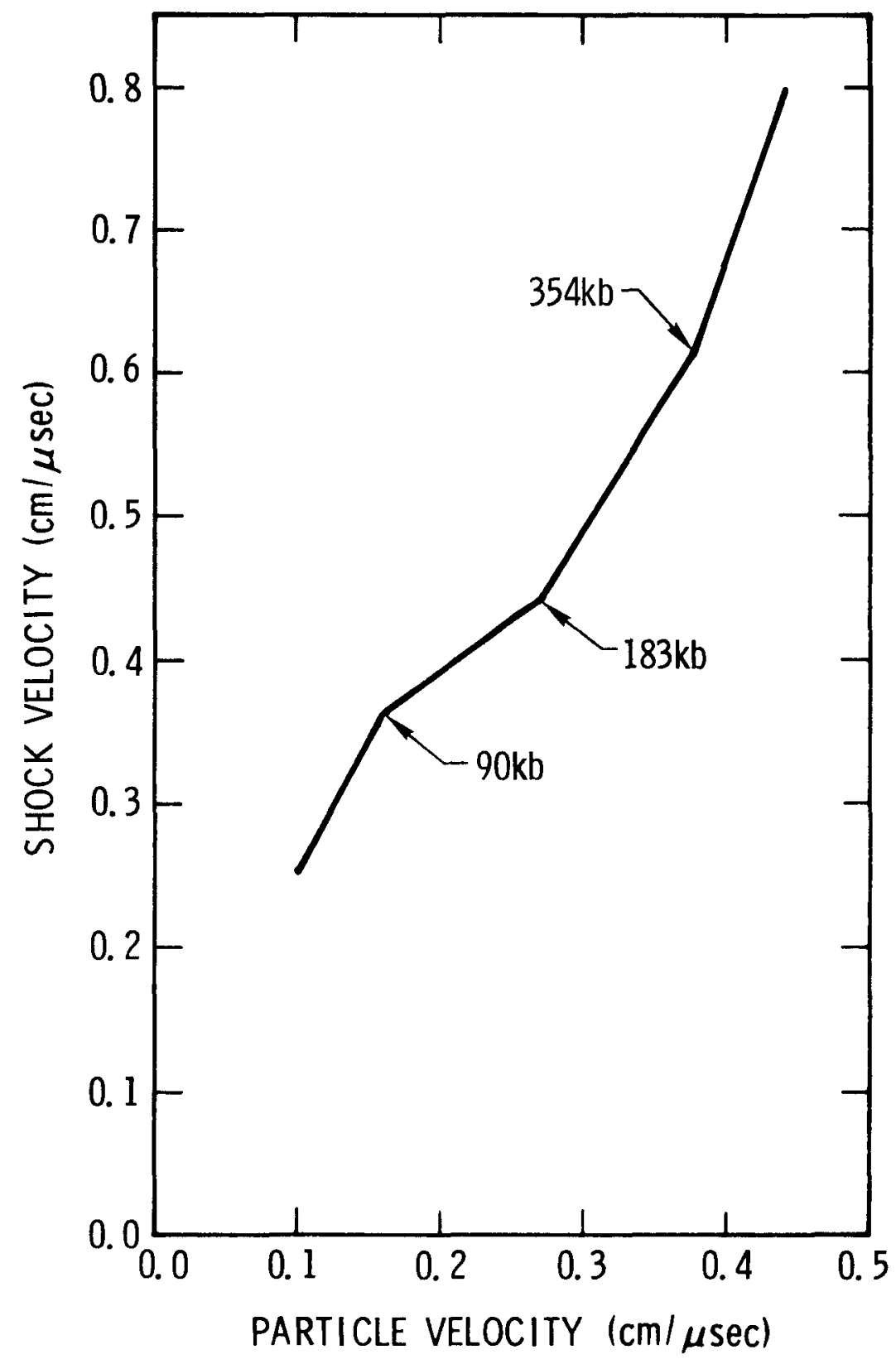

l'igure 2.1. Ilugoniot parameters for dry alluvium 
Laboratory atudies of a particular rock within which an explosion is planned provide values of $C$ and $S$ characteristic of the material over the applicable range of pressures, and it is sufficient to determine only the velocity with which the shock front is propagated from field measurements at a point near the explosion in order that both pressure level and particle velocity there may be determined. Such field measurements are customarily made by recording the times at which the shock arrives at two closely spaced and accurately positioned detectors. These shock front arrival measurements may be made either through part of the rock itself or within a sample of a different material, the Hugoniot parameters for which have been experimentally established.

Data reported in this study were obtained by Sandia Laboratories and include results of measurements near 30 underground nuclear explosions in alluvium, tuff, and granite. Hugoniot parameters used in reduction of these data were derived from laboratory experiments reported elsewhere (Bass 1966; Bass et al 1963; Lombard 1961), and are listed in Table 2. 1. Different field measurement schemes were, of necessity, devised for different geometries of explosive emplacement. These techniques are described briefly in conjunction with the types of rock to which each was best adapted. More detailed descriptions of gages are ayailable in reports of specific events.

TABLE 2.1 Hugoniot Parameters

\begin{tabular}{|c|c|c|c|c|}
\hline Rock & $\begin{array}{c}\text { Pressure } \\
\text { Range } \\
\text { (kilobars) }\end{array}$ & $\begin{array}{l}\text { Density } \\
\left(\mathrm{gm} / \mathrm{cm}^{3}\right)\end{array}$ & $\begin{array}{c}\mathrm{C} \\
(\mathrm{cm} / \mu \mathrm{sec}) \\
\end{array}$ & $\mathrm{S}$ \\
\hline Alluvium & $\begin{aligned} & <90 \\
>90 & -<183 \\
>183 & -<354 \\
& >354\end{aligned}$ & $\begin{array}{l}1.54 \\
1.54 \\
1.54 \\
1.54\end{array}$ & $\begin{array}{c}0.062 \\
0.247 \\
0.016 \\
-0.46\end{array}$ & $\begin{array}{l}1.875 \\
0.722 \\
1.577 \\
2.84\end{array}$ \\
\hline Dry Tuff & $\begin{array}{c}<85 \\
>85-<210\end{array}$ & $\begin{array}{l}1.46 \\
1.46\end{array}$ & $\begin{array}{l}0.068 \\
0.22\end{array}$ & $\begin{array}{l}1.80 \\
0.86\end{array}$ \\
\hline Partially Saturated Tuff & $<108$ & 1.74 & 0.34 & 0.74 \\
\hline Saturated Tuff & $>20-<86$ & 2.00 & 0.223 & 1.328 \\
\hline Granite & $>350$ & 2. 65 & 0.41 & 0.96 \\
\hline
\end{tabular}

\subsection{Measurement Techniques for Alluvium}

Underground nuclear explosion tests in alluvium are typically conducted in deep, vertical drill holes. Emplacement of gages for shock front measurements in the hydrodynamic region for these explosions must be accomplished from the surface, which is often more than a thous and feet above the prescribed gage position. Three techniques for these deep hole measurements have been employed by Sandia Laboratories. The first system used as the shock front velocity gage a 
plexiglass slab about $5 \mathrm{~cm}$ thick with PZT (lead zirconate titanate) ferroelectric crystals mounted on opposite surfaces. This slab was oriented by remote control so that the path of the shock front through it corresponded to that between the PZT crystals. A remote indicating gyroscope system permitted orientation of the gage with an angular precision of $\pm 1^{\circ}$ at depths of $1000 \mathrm{ft}$, and configuration of the arrival-time matrix was such that positioning error always resulted in positive error in derived pressures. Each hole containing a gage was backfilled with alluvium after final orientation of the gage to minimize perturbation of the shock front. Shock velocities observed within the plexiglass were related to pressures by means of known Hugoniot parameters for plexiglass. This pressure corresponded essentially to the driving pressure in the alluvium because Hugoniot parameters for alluvium and plexiglass are very similar.

Difficulty and expense of gage orientation at depth led to development of a ring-type or "nondirectional" gage (Chabai et al 1963). Active elements of these gages were a pair of PZT crystal rings about $5 \mathrm{~cm}$ and $10 \mathrm{~cm}$ in diameter, each having square cross sections about $6 \mathrm{~mm}$ on a side. The rings were mounted $10 \mathrm{~cm}$ apart coaxially on the axis of a thin-walled plexiglass tube which was filled with alluvium. The gage was placed at shot horizon with its axis vertical. Arrival of the shock front at each ring produced a signal from which shock front velocity was deduced. A third, rarely used technique utilized a quartz crystal embedded in a plexiglass blank. This type of gage required precise orientation similar to that for slab gages.

Proper uniform backfill of gage emplacement holes with local alluvium and special care to prevent bridged voids in the backfill is essential to successful operation of all three types of gage. All three systems also required precise time and high speed oscilloscopic recording of shock arrival signals.

\section{3 Measurement Techniques for Tuff}

Underground nuclear detonations in tuff have been conducted both in deep vertical borings and in tunnel and drift complexes mined into mesas surrounding some of the broad valleys at the Nevada Test Site. Those tests conducted in vertical wells were instrumented in the hydrodynamic region in the manner described for explosions in alluvium. Those tests conducted in tunnel complexes permitted more sophisticated measurement systems.

In tunnel systems it is usually feasible to reach desired gage positions within the hydrodynamic region by means of horizontal instrument borings $30 \mathrm{~m}$ or less in length. In such configurations, gage orientation is readily and accurately controllable and measurement of the range from shot point to gage is accurate to a few centimeters in several meters. This type of installation also permits bonding gages to the surrounding rock with a cement grout which is matched to the rock in pertinent physical characteristics. Gages of significantly larger size may be used in such tunnel installations.

Shock velocity data for shots in tuff were obtained primarily with PZT-ring gages. It was also found feasible to obtain some direct pressure-history data in lower pressure regions with 
piezoresistive gages formed of manganin wire grids embedded in C-7 epoxy. ${ }^{*}$ These gages have a useful pressure range of from 10 to 500 kilobars.

\section{4 Measurement Techniques for Granite}

The region of hydrodynamic response in granite is considerably smaller than in alluvium or tuff, with the consequent requirement that shock arrival gage systems for explosions in granite must be emplaced much closer to the shot point. Fortunately, nuclear explosion tests in granite have been located in deep tunnel complexes which permit precise close-in gage emplacement. The applicable improved gage installation procedures also permit use of other, more precise devices, such as impedance-match gages with which pressures ranging from a megabar to 100 kilobars may be measured. This system relates transit velocities measured in calibrated samples of two materials which are driven by the shock in granite to the shock velocity in granite. Sample materials are chosen for well established shock response characteristics and are typically aluminum and brass. This technique generates in situ Hugoniot data for granite and is capable of highly accurate pressure determinations. However, its use is limited by a required complex transmission and recording system.

\subsection{Measurement Techniques in the Region of Plastic Deformation}

Stress histories may be measured more readily in the lower pressure region just beyond the hydrodynamic region where rock is deformed plastically. Gages have been devised for use in this region which, though stronger than the surrounding rock and capable of withstanding passage of the shock front, do not severely distort the front and develop a signal relatable to the driving disturbance. Gaging systems for such measurements include active elements of ytterbium, quartz or PZT. Ytterbium gages, "which employ a foil of ytterbium embedded in C-7 epoxy, are suitable for recording pressures between 1 and 15 kilobars. In regions of somewhat lower stress, PZT gages were found suitable. Quartz gage systems (Chabai et al 1963) also have been used for stress measurements in granite. Typical stress history records from explosions in tuff and granite are included as Figure 5.1 in the second part of this report.

\section{6 Analysis of Data}

Data derived from measurements of shock front velocity in the hydrodynamic region surrounding nuclear explosions in alluvium are listed in Table 6.1 of the second part of this report and similar data for explosions in tuff and granite are listed in Table 6.2. These data which are listed with the scaled range in the tables are plotted versus that quantity in Figure 2. 2. In this figure, solid lines represent linear regression fits to the data and dashed lines represent 90 -percent confidence limits for these fits. Two sets of pressure data, identified as Tuff (nonlinear) and Granite (nonlinear) in the figure, were omitted from regression analysis for reasons discussed later.

*Manufactured by Pulsar, Inc., Redwood City, California. **Obtained from Gulf General Atomic, Inc., San Diego, California. 


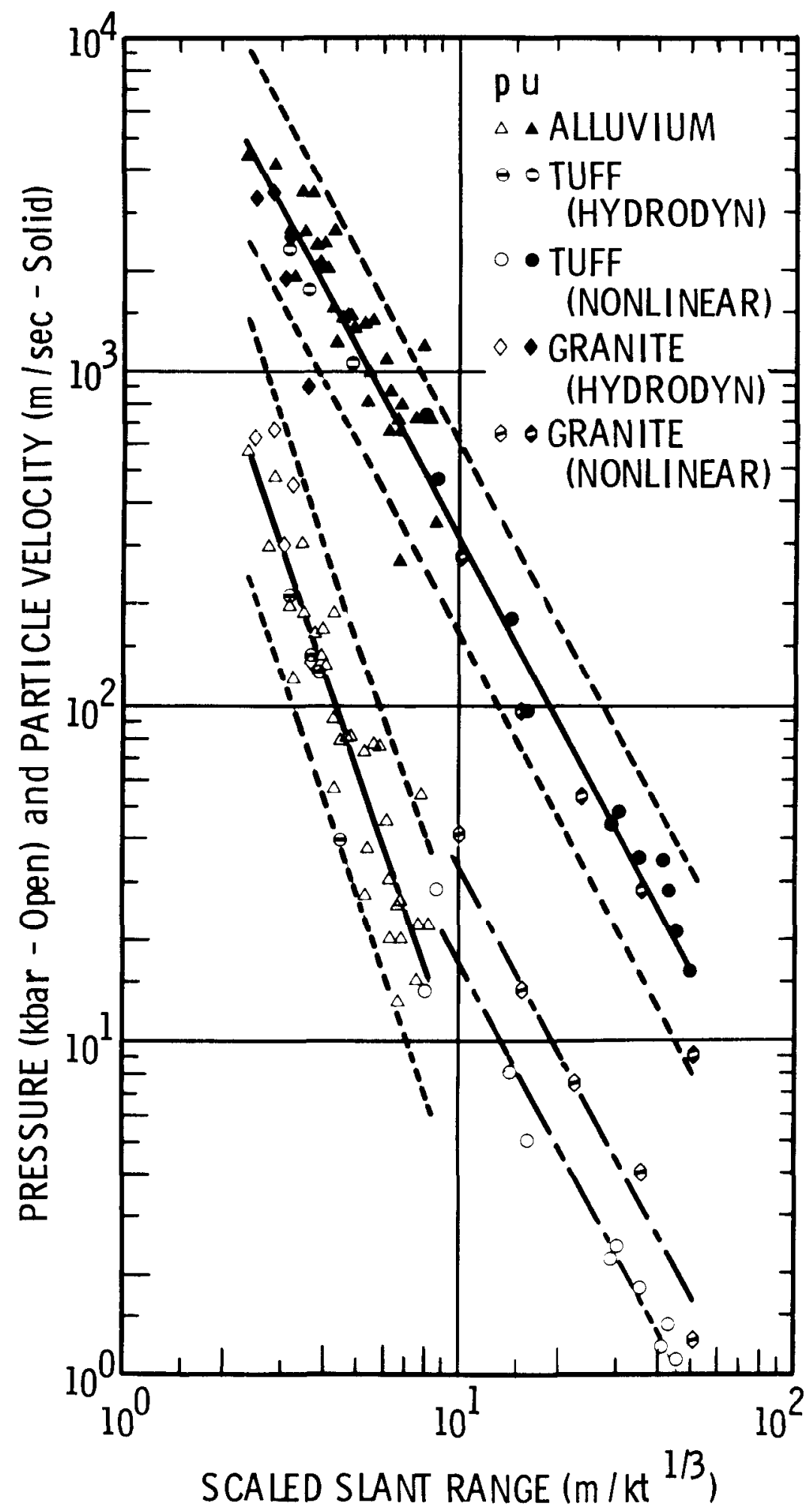

Figure 2.2. Pressure and particle velocity attenuation 
Regression equations for these data are

$$
p=7.71 \times 10^{3}\left(\mathrm{R} / \mathrm{W}^{1 / 3}\right)^{-2.96 \pm 0.19}
$$

where $\mathrm{p}$ is pressure in kilobars, $\mathrm{R}$ radial distance in meters, and $\mathrm{W}$ explosively released energy in equivalent kilotons of TNT; and

$$
u=2.43 \times 10^{4}\left(\mathrm{R} / \mathrm{W}^{1 / 3}\right)^{-1.87 \pm 0.05}
$$

where $u$ is particle velocity in $\mathrm{m} / \mathrm{sec}$ and $R$ and $\mathrm{W}$ are as defined above. The fractional standard deviation for the exponent in Eq. 2.3 is 6.4 percent; in Eq. 2.4 it is 2.7 percent. Variance factors for the coefficients are 1.34 and its reciprocal for Eq. 2.3 and 1.11 and its reciprocal for Eq. 2.4. The variance of the coefficient is defined by the standard deviation of the common logarithm of the coefficient. The antilog of this deviation and the reciprocal antilog are the applicable variance factors.

This analysis of pressure data indicates that in the range from 700 to about 10 or 20 kilobars pressure decreases as the inverse 2.96 power of scaled distance in good agreement with the theoretical attenuation for hydrodynamic response as the inverse cube of distance. It also indicates that particle velocity derived from hydrodynamic region pressures by the Hugoniot equation of state is attenuated as the inverse 1.87 power of range or roughly as the inverse square of range.

Pressure data from both the transition region between hydrodynamic and plastic response and from the plastic response region are represented in Figure 2.2 by the points below 10 kilobars. Of these data,those from explosions in granite are greater than those from shots in tuff by a factor of about 2.2, but the attenuation rate is essentially the same as that for all particle velocity data as indicated by the dash-dot lines which have been drawn through these pressure data parallel to the velocity regression curve. Evidently, pressures below 10 kilobar must be related to particle velocities by a constant factor, but above that stress level there is a variable relationship which changes with pressure. However, both the Hugoniot equation of state for the hydrodynamic region, i. e. , at pressures above 10 to 20 kilobars, and the relationship between shock front velocity and particle velocity indicate that, in hydrodynamic shock, pressure and particle velocity are not related by a simple factor because the propagation velocity, $U_{s}$, varies with pressure, and density behind the shock front must also depend on pressure.

Beyond the hydrodynamic response region and in fact into the region of nonlinear and linear response, both the propagation velocity and the density remain constant at least through the initial peak levels, and stress throughout this region is related to particle velocity by a constant factor, the seismic impedance, which is the product of density and propagation velocity. It should be noted that in the more dispersive rocks such as dry alluvium, the applicable propagation velocity for this conversion is that characteristic of the material under the effective stress loading. 
The differences in pressure levels in different types of rock previously noted in data below 10 kilobars are absent in the higher pressure data. Corresponding differences for particle velocity data from the nonlinear response region will be noted in later chapters. The explanation of these phenomena lies in the different porosities and strengths of the rocks and in the fact that at stress levels sufficiently high to cause hydrodynamic response to the loading, neither porosity nor strength which derive from the crystalline and macrostructure of the rock exist to differentiate response of the rock to hydrodynamic shock. However, in the regions of lower stress beyond that of hydrodynamic response, these properties of the rocks do exercise strong control over response to transient loading. 
Chapter 3

\section{GROUND MOTION IN REGION OF NONLINEAR RESPONSE}

\section{1 Measurement of Ground Motion}

It was noted in the first chapter that, in regions of nonlinear and linear response of rock, measurement of motion rather than stress yields more reliable results. Measurement of transient stress in a rock environment requires a continuous, good bonding between the gage and rock and a good match of seismic impedance as well. In the region of hydrodynamic response, this requirement must be met for extremely short periods during an early portion of the rise to the shock wave peak for time-of-arrival measurements. In the transition zone between hydrodynamic and nonlinear response where stress-history gages may survive passage of part or all of the transient, the duration time is still very short and gross motions produced by the stress wave have only a minor effect on the match between gage and rock impedance during the period.

However, in the regions of nonlinear and linear response, rise times increase from fractional milliseconds to tens of milliseconds, and both dispersive effects and absorption of high frequency components broaden peaks and decay portions of the transient. A consequence of this is that gross motions, which can be adequately registered by motion sensitive gages bonded securely to the rock, result in variations in gage-rock bonding and impedance match with, at best, questionable stress gage response. In general, motion-histories derived from the more sophisticated theoretical calculations agree reasonably with records from motion gages such as accelerometers or particle velocity gages. This discussion does not imply that impedance matching between rock, bonding material, and gage may be ignored in free-field motion measurements in the regions of nonlinear or linear response, but simply that such measurements are much less sensitive to mechanical consequences of passage of the broadened stress wave than are stress measurements.

Both accelerometers and particle velocity gages used in the measurements for this study were simple mass-spring or pendulum systems suitably damped to produce the desired response and equipped with electronic devices to translate motion to electric output which corresponded directly to the motion within a frequency band broader than that of the relevant motion. Accelerometer mass-spring systems were damped to about 0.7 times critical and responded with constant sensitivity over a frequency range bounded by zero $\mathrm{Hz}$ and half the natural frequency of the massspring system. This latter gage parameter ranged from about $50 \mathrm{~Hz}$ for low range (about $1-\mathrm{g}$ full scale) to more than $10 \mathrm{kHz}$ for high range (more than $10^{3} \mathrm{~g}$ full scale) accelerometers. Particle velocity gages employed pendulums grossly overdamped, about 100 times critical, and capable of gensitivity adjustment from $15 \mathrm{~cm} / \mathrm{sec}$ to more than $30 \mathrm{~m} / \mathrm{sec}$ full scale over a frequency range from about $0.3 \mathrm{~Hz}$ to $200 \mathrm{~Hz}$ (Perret 1968a Appendix A). 
Each type of gage was operated through a carrier-amplifier system, the output of which was demodulated and then converted to a frequency modulated signal which was recorded on magnetic tape. In a few cases, different but comparable signal conditioning systems were used.

Reduction of these data consisted of direct digitization of the analog FM signal at a scan rate of one or two $\mathrm{kHz}$. These digital data were recorded on a master data tape as time-answer information and were converted by one or two integration processes to final displacement-time data. In some cases, velocity gage data were reduced to acceleration by differentiation, but this procedure was used rarely. Baseline adjustments were necessary in most cases to yield reasonable integral records because of drift, or offset problems which were often introduced in the analog-todigital conversion. The final acceleration, particle velocity, and displacement data from this reduction procedure, listed and plotted by machine, was the source of tables in Part II and of the various plots of normalized peak motion versus scaled slant range presented in this chapter.

\section{2 Free-Field Ground Motion in Alluvium}

Free-field ground motion has been recorded for seven contained underground nuclear explosions in desert alluvium at the Nevada Test Site and for one underground chemical cratering explosion at NTS. Scaled peak motion data from these events are listed in Tables 6. 3, 6.4, and 6.5 in Part II of this report.

Horizontal shot level instrument arrays were used for five of these events - Scooter (Perret et al 1963), Fisher, Hognose, Haymaker (Perret 1965), and Merlin - and vertical radius arrays were used in four of them - Merlin (Perret 1971), Vulcan, Hupmobile (Preston, Wheeler 1969), and Packard (Wheeler, Preston 1971). In two cases, Hognose and Haymaker, gage arrays were near but not at shot depth. Because alluvium events all involved emplacement of explosives at the bottom of deep borings or shafts, the vertical instrument arrays nearest surface zero were in borings offset about $10 \mathrm{~m}$ from the emplacement boring.

\subsubsection{Scaled Acceleration Analysis -- Scaled acceleration data from alluvium events are} plotted in Figure 3.1. Data from each event is distinguished by a specific symbol. Data from the Mud Pack event (Perret 1970c) Table 6.8 are included in this and the corresponding alluvium plots of particle velocity and displacement for apparent reasons which are discussed later. The Mud Pack event was detonated in a dry tuff environment.

In Figure 3.1 and the succeeding data plots, linear regression fits to the data are plotted as solid lines and 90 percent confidence limits for the fit are shown as dashed lines. In many cases, certain data were omitted from the regression analysis because of anomalous conditions either in the instrumentation or the recorded motion. Such omitted points are indicated by underlining.

*Each table includes a reference to the basic publication, if any, which concerns specific events and includes the data, except as the unclassified nature of this report prevents such reference. 


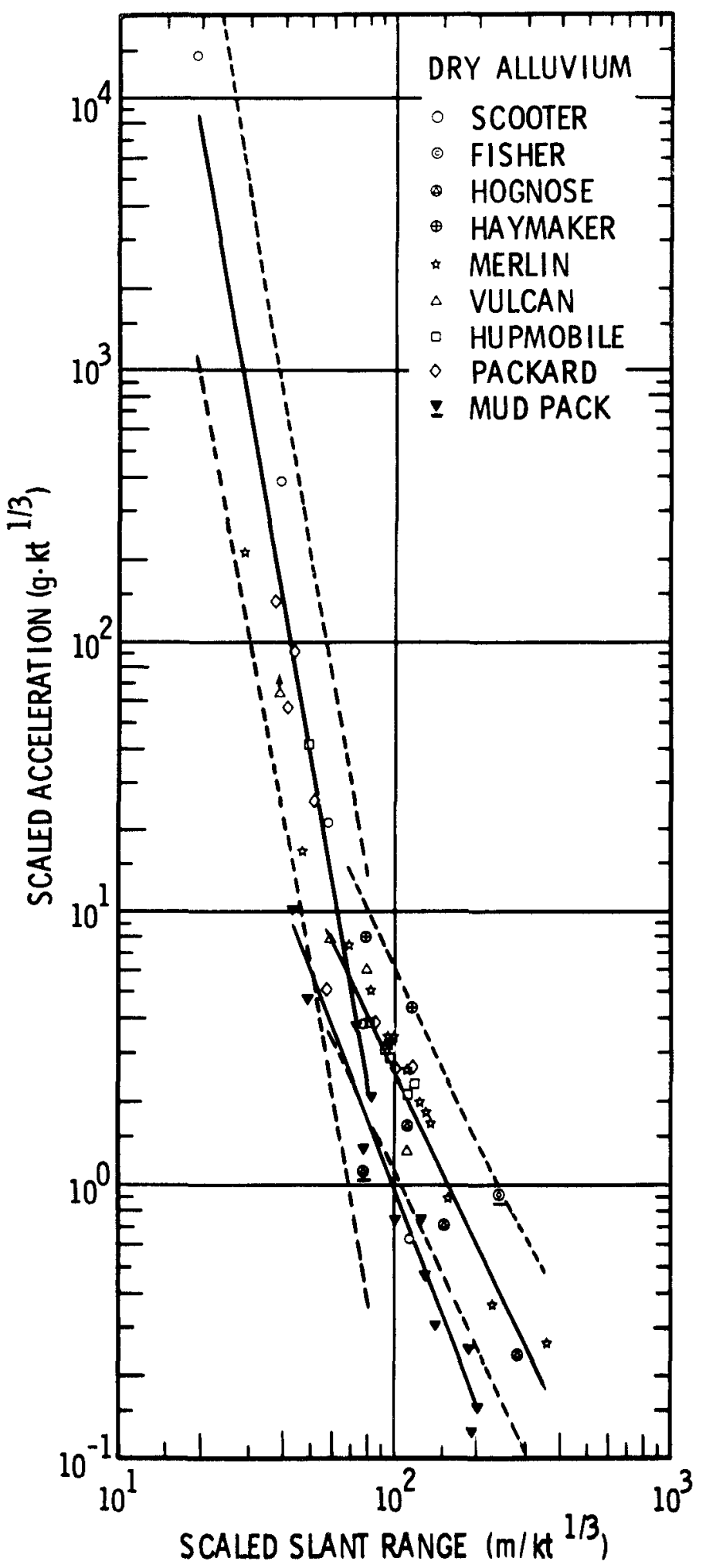

Figure 3.1. Attenuation of scaled acceleration-dry alluvium 
Where a complete set of data have been omitted from analysis, as were the Mud Pack data in Figure 3.1, the symbol in the legend block has been underlined. In some cases, a separate regression fit for an omitted event is plotted without confidence limits, as in Figure 3 。 1 .

Alluvium acceleration data in Figure 3.1 fall into two groups; those at scaled distances less than $80 \mathrm{~m} / \mathrm{kt}^{1 / 3}$ are attenuated at a much faster rate than those at scaled distances greater than $60 \mathrm{~m} / \mathrm{kt}^{1 / 3}$. The overlap recognizes that any transition in attenuation pattern is not a discontinuous process and that the use of linear fits to the data represent a simplifying approximation. Over a scaled range interval from 20 to $80 \mathrm{~m} / \mathrm{kt}^{1 / 3}$, scaled acceleration peaks fall off according to the equation

$$
a \cdot W_{I}^{1 / 3}=2.24 \times 10^{11}\left(R / W^{1 / 3}\right)^{-5.78 \pm 0.47}
$$

where scaled acceleration, $\mathrm{a} \cdot \mathrm{w}_{1}^{1 / 3}$, is in $\mathrm{g} \cdot \mathrm{kt} \mathrm{1}^{1 / 3}$, scaled slant range, $\mathrm{R} / \mathrm{w}^{1 / 3}$, is in $\mathrm{m} / \mathrm{kt} \mathrm{t}^{1 / 3}$, and $\mathrm{W}$ is the explosive energy yield in equivalent kilotons of TNT. The coefficient of this equation, which represents the intercept of the fit at $\mathrm{R} / \mathrm{W}^{1 / 3}$ equal to unity, has a variance defined by the factors 6.39 and its reciprocal; hereafter in quotation of variance factors the reciprocal is understood. The exponent has a fractional standard deviation of 8.1 percent.

Over the interval from 60 to $350 \mathrm{~m} / \mathrm{kt}^{1 / 3}$ in slant range, the regression equation is

$$
\mathrm{a} \cdot \mathrm{W}_{2}^{1 / 3}=4.79 \times 10^{4}\left(\mathrm{R} / \mathrm{W}^{1 / 3}\right)^{-2.13 \pm 0.18} \text {. }
$$

Variance of the coefficient is described by the factor 2.34. Fractional standard deviation of the exponent is 8.4 percent.

3.2.2 Particle Velocity Analysis -- Particle velocity data from the alluvium events are plotted as a function of scaled slant range in Figure 3.2. Here, some individual Mud Pack data were not included in the analysis so that only omitted points are underscored rather than the legend symbol. These underscored Mud Pack points represent data recorded at stations in carbonate rock beneath the tuff shot environment.

In this plot there are again two phases in the regression fit. In the first, at scaled ranges between 30 and $150 \mathrm{~m} / \mathrm{kt}^{1 / 3}$, the least-squares fit is represented by the equation

$$
u_{1}=1.52 \times 10^{6}\left(\mathrm{R} / \mathrm{W}^{1 / 3}\right)^{-3.27 \pm 0.16}
$$

where $u$ represents particle velocity in $\mathrm{m} / \mathrm{sec}$ and other terms are as previously defined. The variance of the coefficient, is given by the multiplier 1.96. Fractional standard deviation of the exponent is 4.9 percent. 


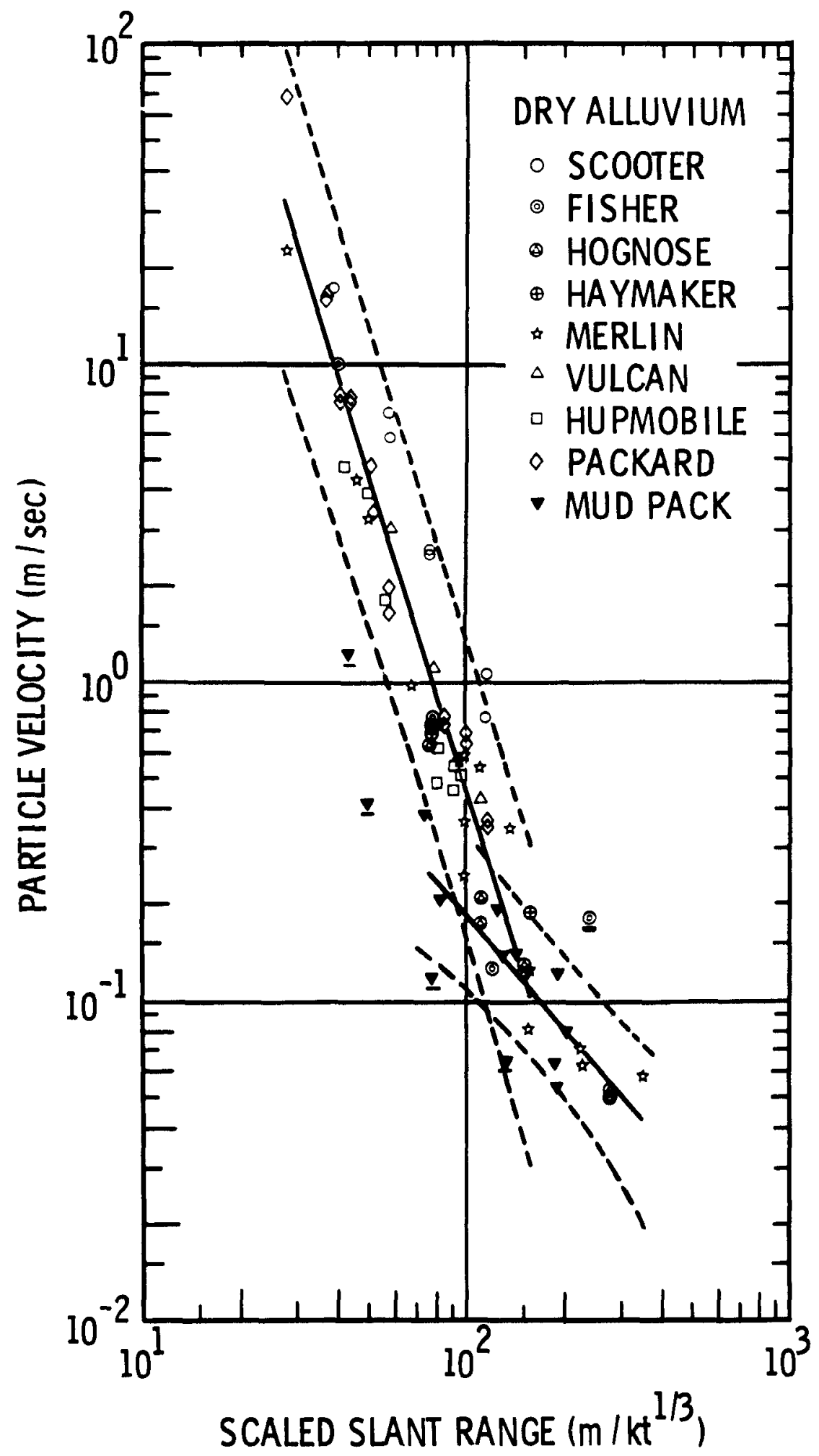

Figure 3.2. Attenuation of particle velocity-dry alluvium 
The second segment of these data, which covers the scaled slant range interval from 100 to $350 \mathrm{~m} / \mathrm{kt}^{1 / 3}$ and includes some of the Mud Pack data in the analysis, is described by the regression equation

$$
u_{2}=3.86 \times 10^{1}\left(R / W^{1 / 3}\right)^{-1.16 \pm 0.14}
$$

where the coefficient variance multiplier is 2.09 and fractional standard deviation of the exponent is 12 percent.

3.2. 3 Scaled Displacement Analysis -- Scaled displacement data from the alluvium events are plotted against scaled range in Figure 3.3. In this plot, all Scooter scaled displacements and specific Mud Pack data have been excluded from the regression analyses. Again, there are two phases in the analysis, of which the first, representing scaled ranges between 40 and 150 $\mathrm{m} / \mathrm{kt}^{1 / 3}$, fits the equation

$$
\delta / \mathrm{W}_{1}^{1 / 3}=3.44 \times 10^{6}\left(\mathrm{R} / \mathrm{W}^{1 / 3}\right)^{-3.04 \pm 0.20}
$$

where $\delta / \mathrm{W}^{1 / 3}$ is the scaled displacement peak in $\mathrm{cm} / \mathrm{kt}^{1 / 3}$. Variance of the coefficient is defined by the factor 2.42 and fractional standard deviation of the exponent is 6.6 percent.

The more remote scaled displacement data for alluvium within scaled ranges between 100 and $350 \mathrm{~m} / \mathrm{kt}^{1 / 3}$ and including more than half of the Mud Pack data yield the equation

$$
\delta / \mathrm{W}_{2}^{1 / 3}=2.22 \times 10^{2}\left(\mathrm{R} / \mathrm{W}^{1 / 3}\right)^{-1.11 \pm 0.11}
$$

where the variance factor for the coefficient is 1.72 and fractional standard deviation of the exponent is 9.9 percent.

3. 2. 4 Discussion - - A few pertinent facts which are evident in these plots and analyses merit discussion at this point. It is evident that Scooter accelerations fall among those observed during the other events, that Scooter particle velocities are in general higher near the upper 90 percent confidence limit, and that scaled displacements from Scooter exceed all others at the same slant range by a factor of at least two and fall well beyond the confidence limit plotted in 


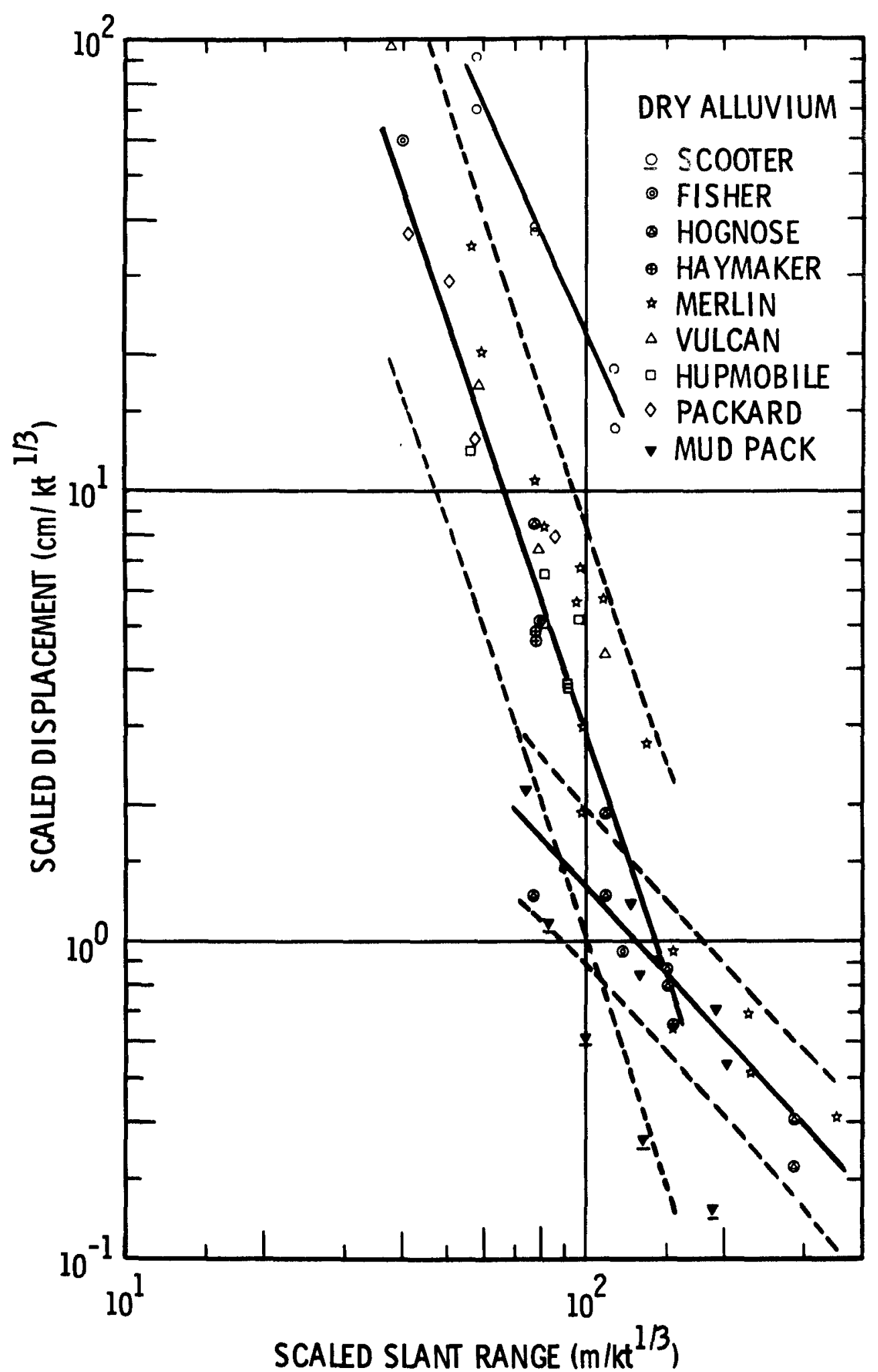

Figure 3.3. Attenuation of scaled displacement-dry alluvium 
Figure 3. 3. The explanation of this probably is related to the fact that Scooter depth of burst is roughly 10 percent of that of the contained explosions. Consequently, for Scooter geostatic pressure is considerably less, bulk density is low and in the looser particulate material greater particle velocities and displacements may develop. Scaled rise times quoted in Tables 6.3, 6.4, and 6.5 show that, in general, for accelerations this parameter is roughly the same for all events, for particle velocities it is greater for Scooter, and for displacements scaled rise times are even greater for the shallow event. It is also possible that the difference in explosives may have contributed to this difference, because of residual gases from the TNT explosion, but this effect would be somewhat mitigated by venting of Scooter as it cratered.

Mud Pack data do not belong in the alluvium analysis because that explosive was placed in dry tuff $30 \mathrm{~m}$ above the paleozoic rock in Area 8 at NTS. However, cores from instrument borings adjacent to the Mud Pack shot hole included several units of extremely friable, porous ash-flow tuff which probably responds much more like alluvium in the nonlinear domain than would the more common zeolitized tuffs of NTS. These very weak tuff cores were from the vicinity of the Mud Pack shot depth. Scatter in Mud Pack data is large, but it tends to correlate with geologic materials at specific instrument locations. Thus, stations in the carbonate paleozoic rock show motions much smaller than those in tuff at comparable scaled range, in keeping with both rock response and with energy losses due to reflection at the tuff-carbonate interface. The Mud Pack data appear to follow a pattern similar to those from Scooter in that scaled accelerations are all distinctly lower than those from the other alluvium events, and particle velocities and scaled displacements fall generally among the alluvium data from the other nuclear events.

\section{3 Free-Field Ground Motion in Dry Tuff}

Seven events from which free-field ground motion data were obtained were considered to have been detonated in "dry tuff." This definition of the shot environment is at best arbitrary. The category might more precisely have been called "not very wet tuff" since laboratory and theoretical studies of response of porous rocks to high stress transients differs little as moisture content is increased up to about 90 percent of saturation but changes radically between 90 and 100 percent saturation, where saturation implies that all pores are filled with liquid water. Dry tuffs may therefore be within the moist zone but well above the water table.

Examination of cores and outcrops of tuff at NTS indicates that this type of rock ranges from extremely friable grainy material hardly distinguishable mechanically from weakly cemented or consolidated sandy alluvium through varying degrees of cementation and vitreous bonding to dense welded tuffs which have seismic impedance similar to that of limestone and dolomite. Consequently, events assigned to the dry tuff category are limited to those detonated in tuff well above the water table, and none was located in high impedance welded tuff. 
All dry tuff events were detonated at NTS either in Area 12, Rainier Mesa, or in Area 8. All three types of instrument station array were used: shot level, vertical radius, and offset vertical arrays. Scaled peak motion data from these events are included in Tables 6.6, 6.7, and 6.8 in Part II, where brief descriptions of each installation accompany the tables.

Classification of the Discus Thrower shot environment as dry tuff prompts some explanation as a consequence of the Baneberry event. The latter explosion was much more effectively coupled to the rock than expected and produced much more vigorous motion. Subsequent investigation indicated the presence of a significant quantity of saturated montmorillonite within the tuff surrounding the Baneberry explosion. It is noted, however, that Discus Thrower, in addition to being some $300 \mathrm{~m}$ north of and deeper than the Baneberry shot, was in tuff appreciably beyond the limits of the montmorillonite bearing formation and that water content of the tuff at and near the Discus Thrower shot point was significantly below the 95 percent saturation which would have influenced rock response toward that typical of the wet tuff classification.

Classification yields of some events have required that their identification be limited to a letter rather than the event name to permit unclassified use of the scaled data in this report.

\section{3. 1 Scaled Acceleration Analysis -- Scaled acceleration data were available from only} four of the dry tuff events because only velocity gages were employed at free-field motion stations for the other three. These acceleration data are plotted versus scaled range in Figure 3.4. Data from the Rainier (Perret 1961), Evans (Perret 1959), and Discus Thrower (Perret, Kimball 1971) events are treated separately from those from the Mud Pack event because the latter are generally lower by an order of magnitude.

Regression analysis of the data from the first three events was performed in two linear phases. The first, applied to the scaled slant range interval between 40 and $150 \mathrm{~m} / \mathrm{kt}$, $\mathrm{re-}$ sulted in the equation

$$
\mathrm{a} \cdot \mathrm{w}_{1}^{1 / 3}=4.90 \times 10^{10}\left(\mathrm{R} / \mathrm{W}^{1 / 3}\right)^{-4.77 \pm 0.33}
$$

where variance of the coefficient is given by the factor 4.33 and fractional standard deviation of the exponent is 6.9 percent.

The second phase linear regression to these data covers the scaled range interval from 100 to $500 \mathrm{~m} / \mathrm{kt}^{1 / 3}$ and is described by the equation

$$
\mathrm{a} \cdot \mathrm{W}_{2}^{1 / 3}=7.71 \times 10^{4}\left(\mathrm{R} / \mathrm{W}^{1 / 3}\right)^{-1.92 \pm 0.14}
$$

where the multiplier 2.12 defines variance of the coefficient and 7.4 percent is the fractional standard deviation of the exponent. 


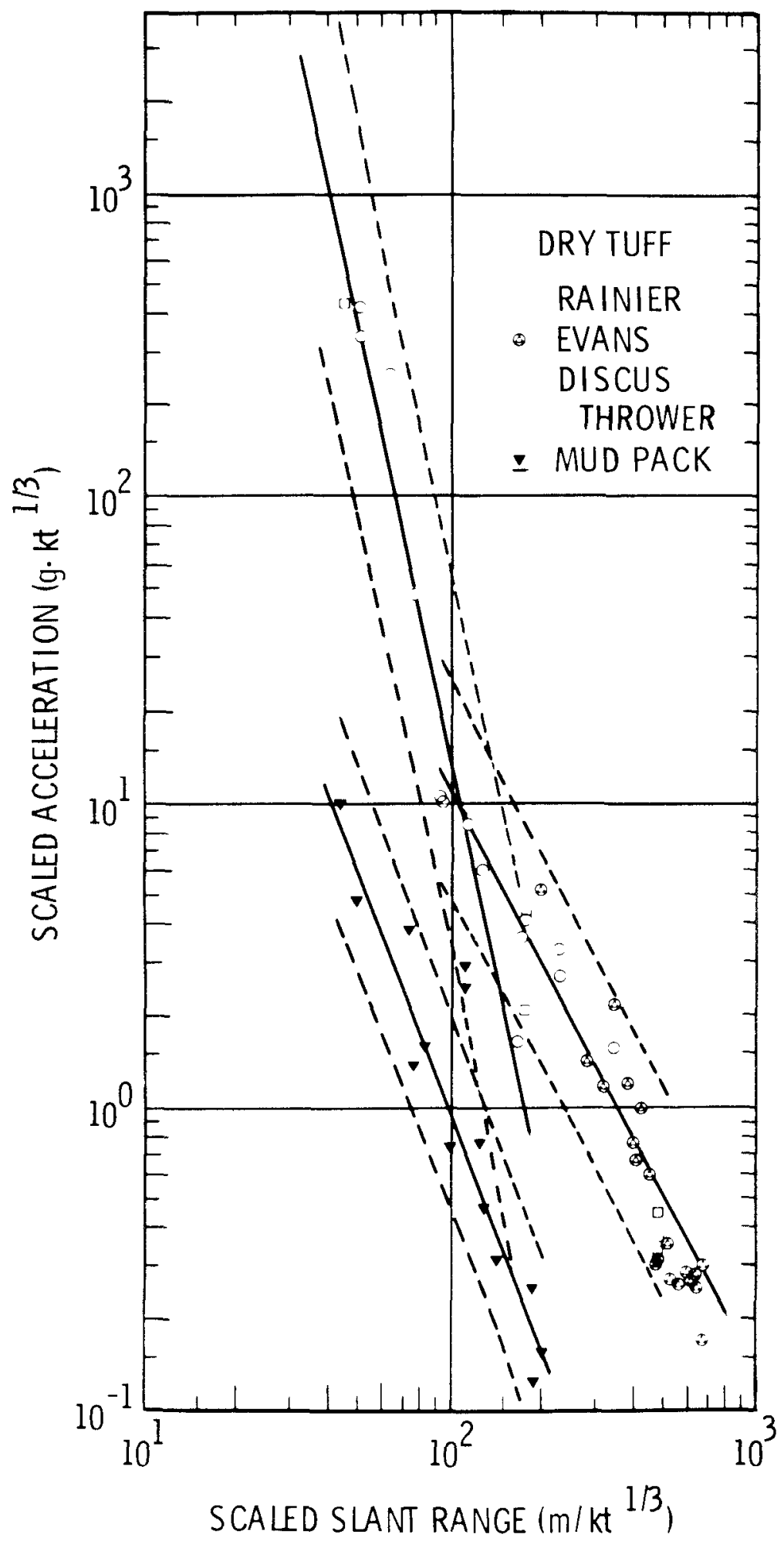

Figure 3.4. Attenuation of scaled acceleration-dry alluvium 


\section{3.2 Particle Velocity Analysis -- Particle velocity data plotted in Figure 3. 5, are avail-} able from all seven dry tuff events, but those from Mud Pack are again about an order of magnitude below those from the other events and are analyzed separately. Linear regression of data from the remaining six dry tuff events yielded the equation

$$
u=1.85 \times 10^{4}\left(\mathrm{R} / \mathrm{W}^{1 / 3}\right)^{-1.98 \pm 0.11}
$$

over the full span of scaled range from 40 to $500 \mathrm{~m} / \mathrm{kt}^{1 / 3}$. The multiplier 1.81 defines variance of the coefficient and fractional standard deviation of the exponent is 5.6 percent.

\section{3. 3 Scaled Displacement Analysis -- Data plotted in Figure 3.6 represent all available} peak displacements from the underground explosions in dry tuff. Scatter is unusually great, as indicated by the 90 percent confidence limits which span about an order of magnitude near the midpoint of the slant range data. Mud Pack data are again low by an order of magnitude and are analyzed separately.

Linear regression of scaled displacement data from the dry tuff events, omitting Mud Pack, leads to the equation

$$
\delta / \mathrm{W}^{1 / 3}=3.80 \times 10^{5}\left(\mathrm{R} / \mathrm{W}^{1 / 3}\right)^{-2.20 \pm 0.21}
$$

where the fractional standard deviation of the exponent is 9.6 percent and variance of the coefficient is encompassed by the multiplier 3.11 and its reciprocal. This applies to the span of scaled slant range between 100 and $500 \mathrm{~m} / \mathrm{kt}^{1 / 3}$.

Displacement data from six of the Discus Thrower stations are lower by a factor of nearly 10 than those from either the other Discus Thrower stations at about the same scaled range or from other events in dry tuff. These low data points represent motion within the carbonate rock below the tuff or from the tuff-carbonate interface and reflect the decreased pore volume and greater rigidity in the underlying paleozoic rock. This effect is hardly discernible in the acceleration data, Figure 3.4, and is considerably smaller by a factor of about 1.5 in the particle velocity plot, Figure 3.5, than in the scaled displacement data, Figure 3.6. These differences also reflect the relatively shorter scaled rise times, Tables 6.6,6.7, and 6.8, for displacements at the Discus Thrower paleozoic rock stations than at stations in tuff. The very distant Discus Thrower stations in tuff show rise times similar to those in the denser rocks, probably because early portions of the signal are transmitted over a refracted path through the underlying, higher impedance carbonate rocks.

\section{4 Free-Field Ground Motion in Wet Tuff}

Of the 14 contained underground nuclear explosions in wet tuff for which free-field ground motion data are available, Tables 6.9,6.10,6.11,6.12, and 6.13, eight were detonated in deep borings in tuff below the water table in Areas 2 and 9 and at CNSTS, one was above the water table in drier tuff and the remainder were in tunnel complexes within Rainier Mesa. In one case, Event L, the water content was probably at or just below the critical range, and data suggest response more 


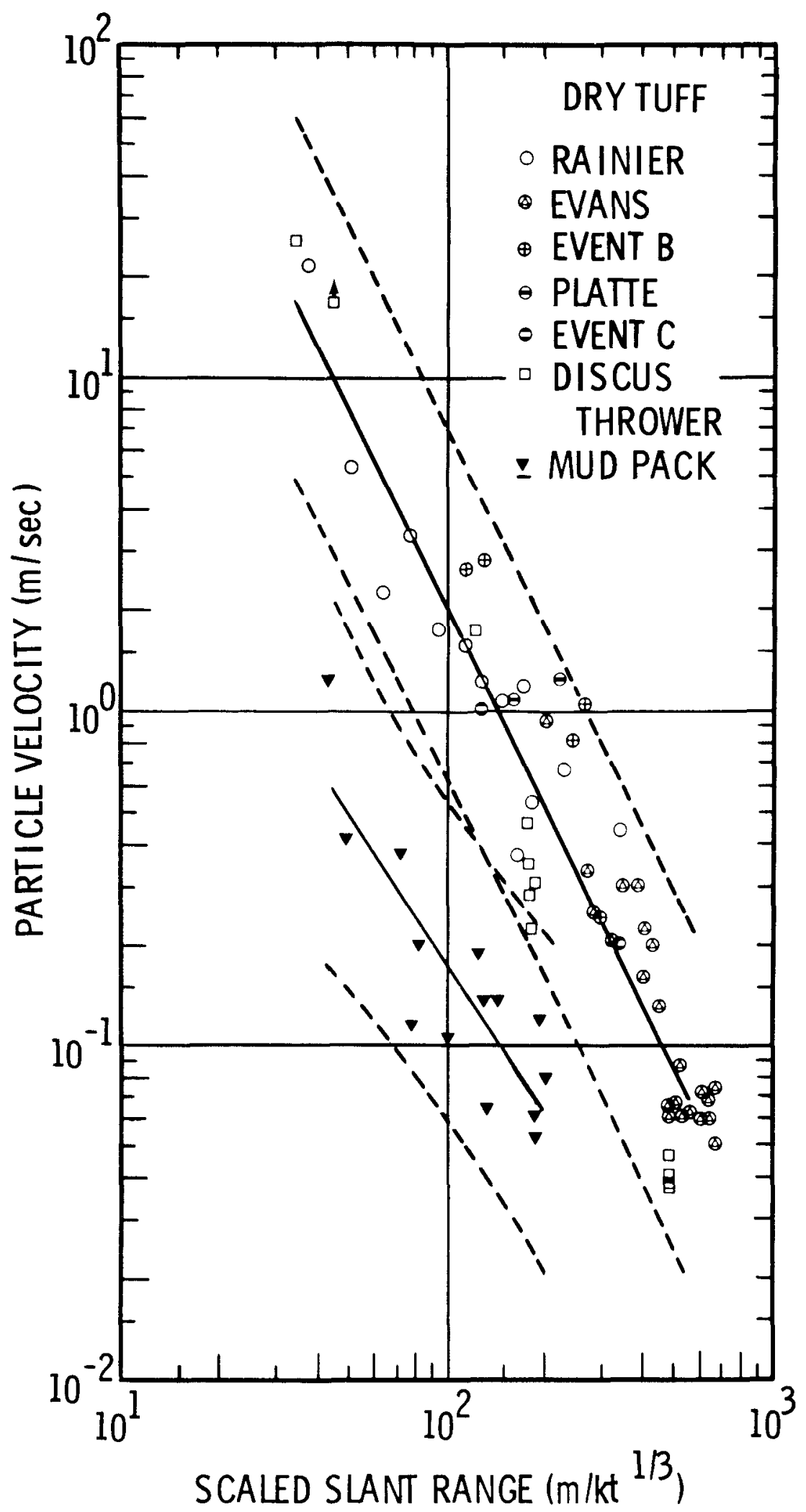

Figure 3.5. Attenuation of particle velocity-dry tuff 


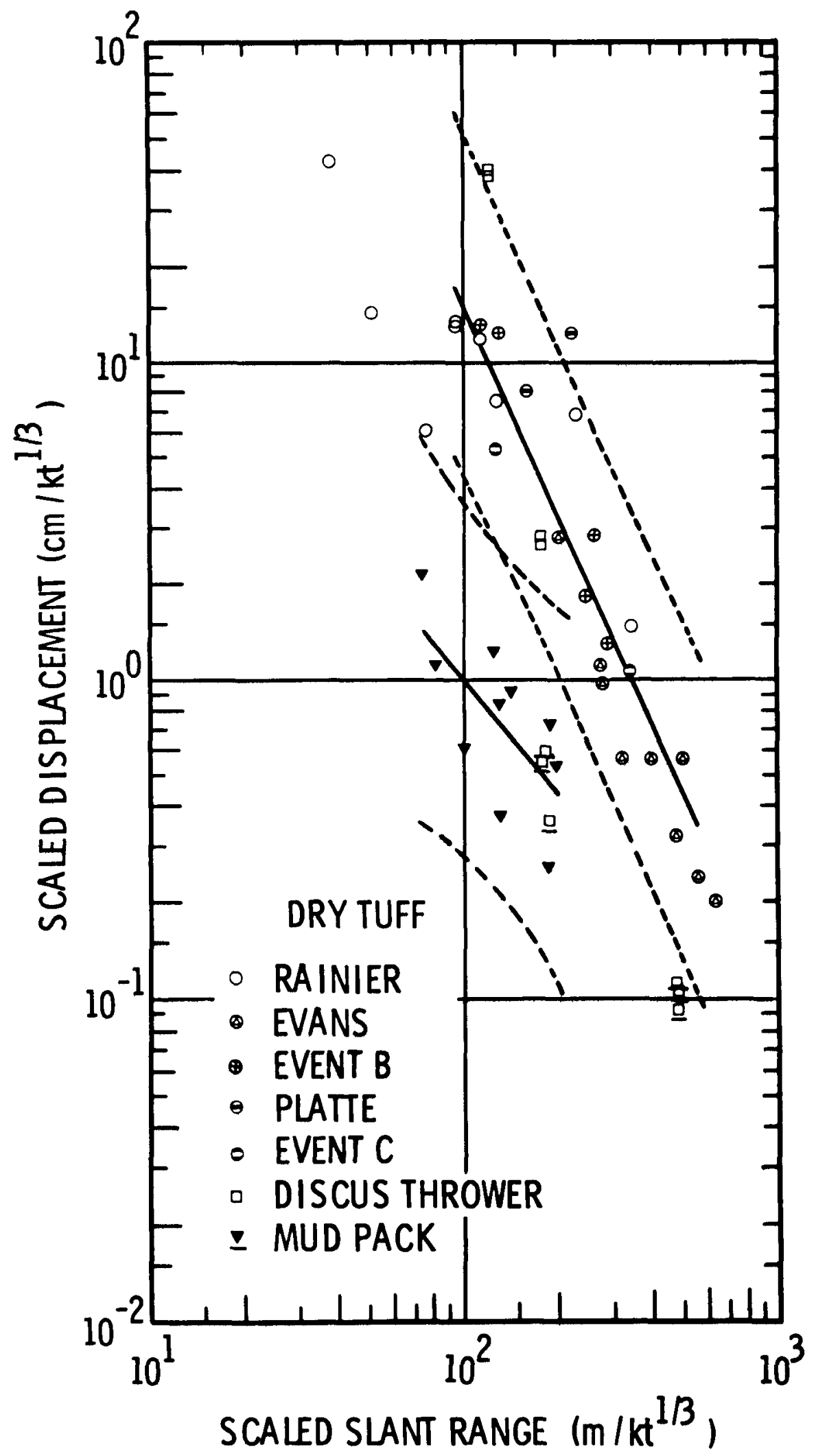

Figure 3.6. Attenuation of scaled displacement-dry tuff 
nearly like dry than wet tuff. Tuff at that site was also unusually porous. However, at the nearby site of Event M saturation of the tuff was almost complete. Event $I$, above the water table, probably should have been included with the dry tuff events.

Data from seven of the events in deep borings were derived from offset vertical instrumentation arrays which included stations above shot level in dry tuff, near shot level in wet tuff, and, in four cases, one station in deeper carbonate rocks. A few events involved one or two shot level stations. Six events included vertical radial arrays in adjacent borings. Many of the stations in these vertical arrays were in dry tuff or dry alluvium.

Data from all events in Rainier Mesa tunnels were derived from shot level stations.

\subsection{Scaled Acceleration Analysis -- Scaled acceleration data are available from only} 10 events detonated in wet tuff. These data, plotted in Figure 3.7 versus scaled slant range, appear to lie in two groups, one approximately an order of magnitude below the other. This separation of data suggested separate regression analyses because it appears that, with two exceptions, Events $\mathrm{H}$ and L, those data which fall in the lower group derive from offset vertical array stations either above the water table or in underlying carbonate rocks. The linear regression fit to wet tuff acceleration data (uppermost group) resulted in the equation for scaled ranges between 30 and $600 \mathrm{~m} / \mathrm{kt}^{1 / 3}$

$$
a \cdot W_{1}^{1 / 3}=4.31 \times 10^{7}\left(R / W^{1 / 3}\right)^{-2.61 \pm 0.17} .
$$

Variance of the coefficient is expressed by the factor 2.21 and fractional standard deviation is 5.8 percent.

A similar regression fit to the lower set of data yielded, for the scaled slant range span of 30 to $200 \mathrm{~m} / \mathrm{kt}^{1 / 3}$, the equation

$$
\mathrm{a} \cdot \mathrm{w}^{1 / 3}=2.05 \times 10^{5}\left(\mathrm{R} / \mathrm{w}^{1 / 3}\right)^{-2.02 \pm 0.29}
$$

where variance of the coefficient is given by the factor 3.66 and fractional standard deviation of the exponent is 14.3 percent.

Data for this second analysis represent stations from dry tuff above the saturated tuff shot environment, from Event L, which was in exceptionally porous wet tuff that may have been near the lower limit of saturation for that classification, and from stations above Event $H$, which were in a region above the water table in tuff and alluvium. Comparison of Eq. 3.12 with Eq. 3.8 for dry tuff at a somewhat more remote spread of scaled ranges indicates that the exponents -2.02 and -1.92 differ by less than either standard deviation and the intercepts (coefficients) differ by a factor of about 2.6, greater than the variance in Eq. 3. 8, but much less than that in Eq. 3.12. 


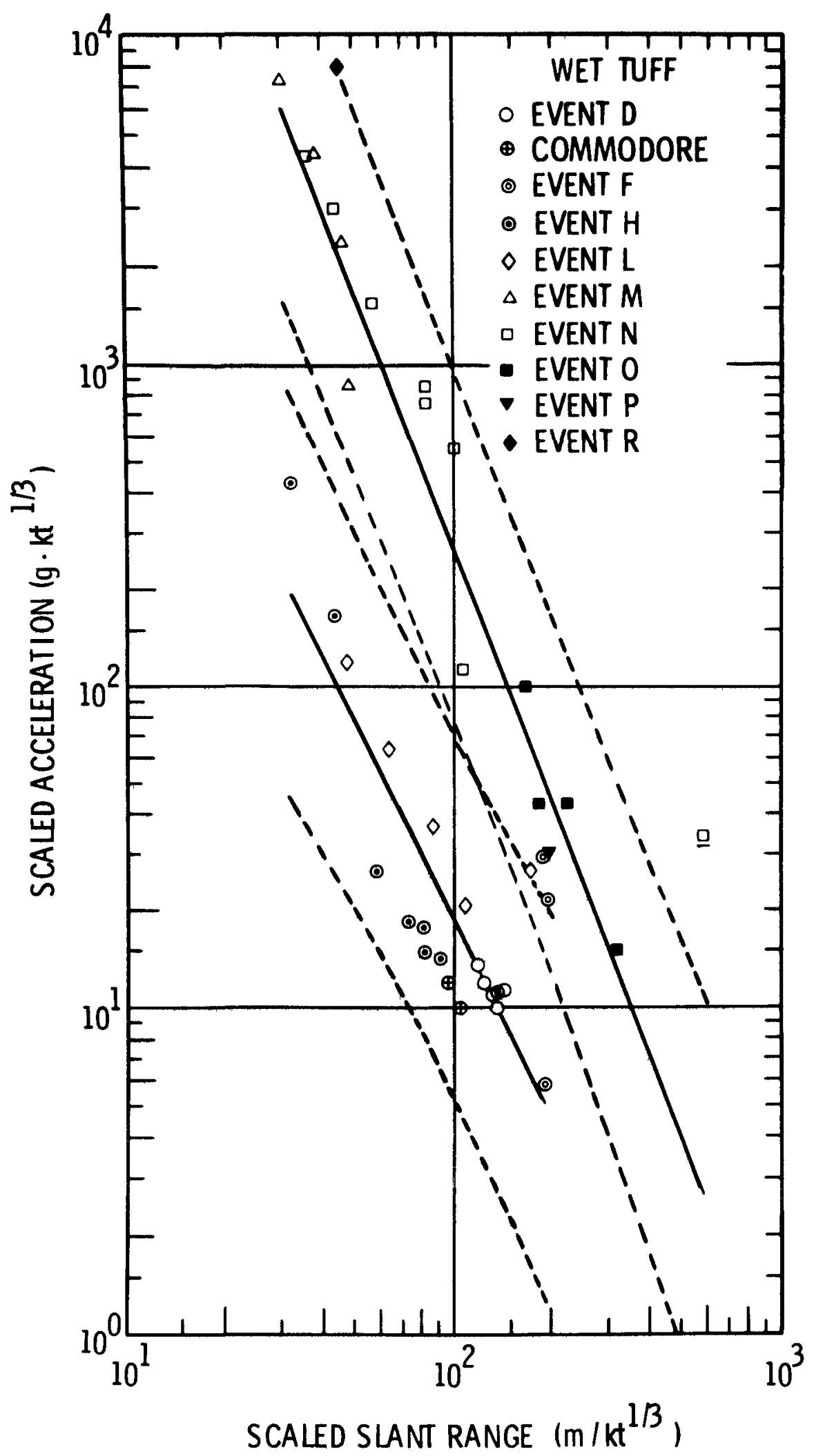

Figure 3.7. Attenuation of scaled acceleration-wet tuff 
High frequency components of motion are attenuated by absorption in dry porous or particulate materials at a considerably higher rate than in similar water saturated materials, and acceleration transients are much more sensitive to the loss of high frequency components of motion than are particle velocities or displacements. Consequently, it seems likely that the data represented by Eq. 3. 15 were derived either from explosions which were within tuff of water content below 90 percent saturation or from stations sufficiently remote in dry tuff or alluvium to receive acceleration transients similar to those from explosions in dry tuff.

3.4.2 Particle Velocity Analysis -- Farticle velocity data from all wet tuff events, as plotted in Figure 3.8, do not suggest the definite segregation indicated by the acceleration data. However, there are a number of individual points, data from Event I and the shorter range velocity data from Event L, which are significantly low. These low points, especially those representative of stations in carbonate rock or dry tuff, have been omitted from the regression fit to velocity data which yielded, for the scaled ranges between 30 and $600 \mathrm{~m} / \mathrm{kt}^{1 / 3}$, the equation

$$
u=6.61 \times 10^{3}\left(\mathrm{R} / \mathrm{W}^{1 / 3}\right)^{-1.56 \pm 0.09} .
$$

In this equation, the coefficient variance is relatively low, the multiplier is 1.56 , and fractional standard deviation of the exponent is only 5.8 percent. However, the span of the 90-percent confidence zone is nearly an order of magnitude, roughly comparable to those for the dry alluvium and dry tuff velocity data.

3.4.3 Scaled Displacement Analysis -- Like the particle velocity data, the scaled displacement data from wet tuff events, Figure 3.9, fail to show a significant differentiation such as that indicated by acceleration data. A few low data points and those from Event $\mathrm{L}$ have been omitted from the regression analysis of scaled displacements which resulted in the equation

$$
\delta / \mathrm{W}^{1 / 3}=4.90 \times 10^{6}\left(\mathrm{R} / \mathrm{W}^{1 / 3}\right)^{-2.63 \pm 0.19}
$$

for which fractional standard deviation of the exponent is 7.2 percent and variance of the coefficient is expressed by the factor 2.63. This fit to the scaled displacement data covers scaled ranges between 50 and $600 \mathrm{~m} / \mathrm{kt}^{1 / 3}$.

\subsection{Free-Field Ground Motion in Hard Rock}

The term "hard rock" as noted earlier is a catchall term for rocks of high seismic impedance, about 1.0 to $1.5 \times 10^{6} \mathrm{gm} / \mathrm{sec} \cdot \mathrm{cm}^{2}$, and generally occurs in massive, though often stratified deposits. Of the eleven hard rock underground nuclear explosions, Tables 6.14 through 6.21 , four, Hard Hat (Perret 1963), Shoal (Weart 1965), Pile Driver (Perret 1968b), and Gnome (Weart 1963), were in deep tunnel complexes reached through access shafts and all were instrumented with both 


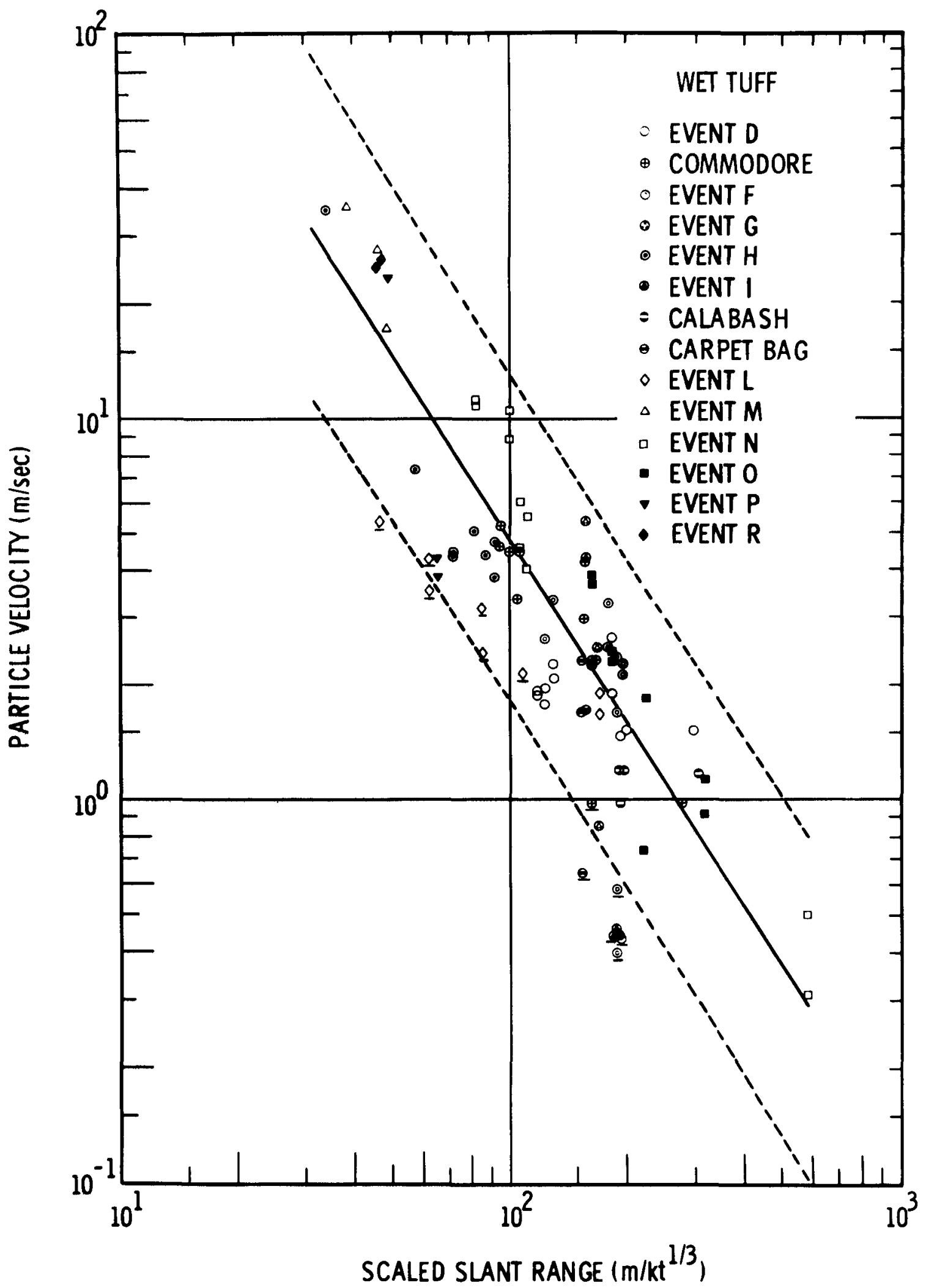

Figure 3.8. Attenuation of particle velocity-wet tuff 


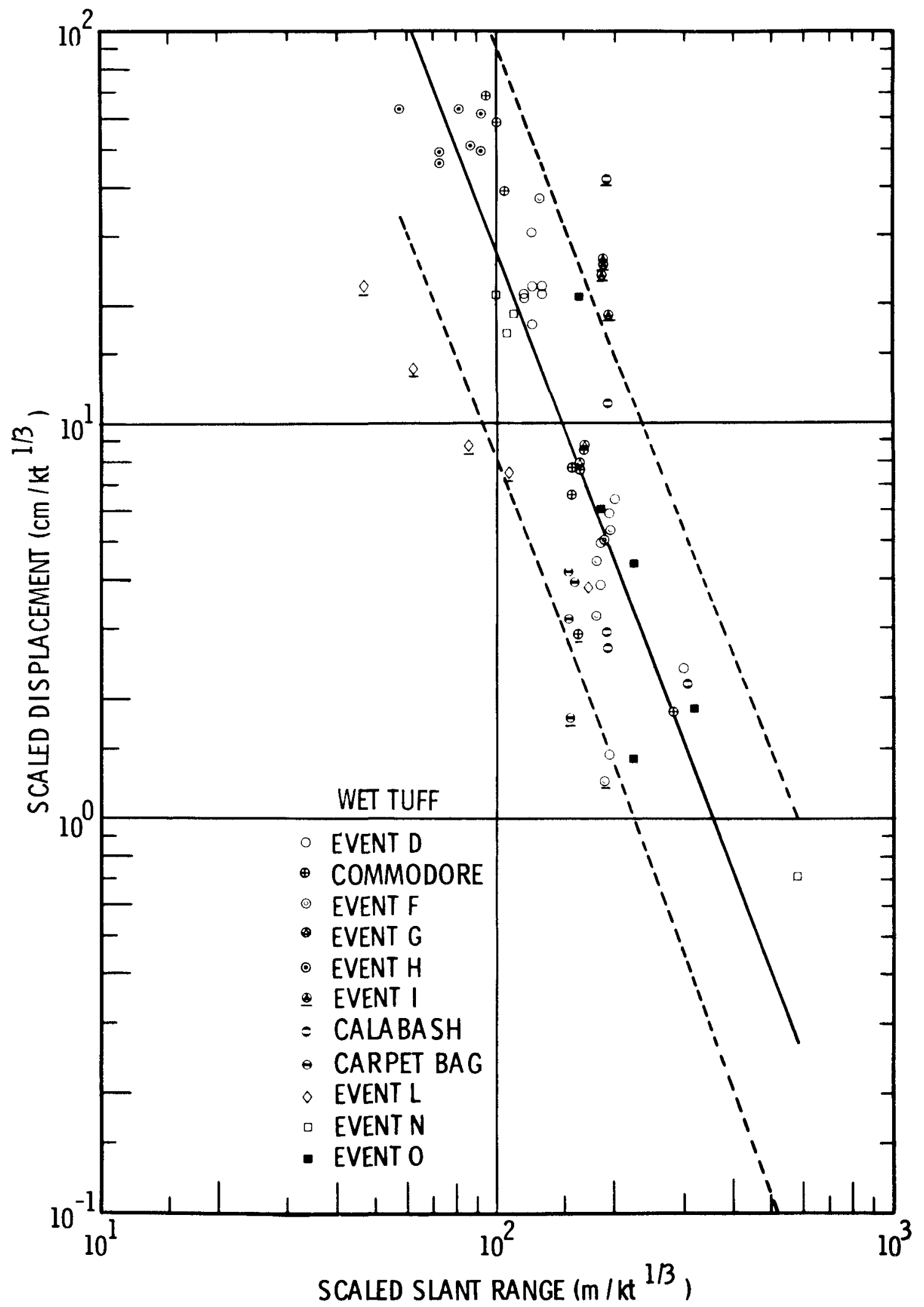

Figure 3.9. Attenuation of scaled displacement-wet tuff 
shot level and vertical radius station arrays. The others, all emplaced in deep borings, were instrumented with vertical radial arrays. Salmon (Perret 1968a) and Handcar (Perret 1970b) instrumentation included of fset vertical arrays which incorporated a shot level gage station array, and that for Boxcar included two remote shot level stations. Because of the wide variety of rock included in this category, because a few events included stations installed in lower impedance rocks than that in which the explosion occurred, or because such things as low impedance strata or thick fault zones filled with clay gouge occurred between the explosion and some stations, there are sets of data or individual points which differ sufficiently from the general trend of more numerous data to suggest their omission from the regression analysis or their separate analysis. In particular, the Salmon and Handcar events indicated both separate analysis of the data set and omission of specific points.

3.5.1 Scaled Acceleration Analysis -- Scaled acceleration data from the hard rock events, Figure 3.10, were divided into two sets, and the Salmon free-field data were analyzed separately. The regression equation for hard rock acceleration in the scaled range from 40 to $200 \mathrm{~m} / \mathrm{kt} / 3$ is

$$
\mathrm{a} \cdot \mathrm{w}_{1}^{1 / 3}=6.20 \times 10^{10}\left(\mathrm{R} / \mathrm{W}^{1 / 3}\right)^{-4.35 \pm 0.32}
$$

with coefficient variance expressed by the factor 4.06 and fractional standard deviation of the exponent given by 7.3 percent. The data in this analysis included many relatively low points from the Handcar and Boxcar events but did not include Salmon data.

Regression analysis of the hard rock scaled acceleration data within the interval from 90 to $2200 \mathrm{~m} / \mathrm{kt}^{1 / 3}$ but exclusive of the Salmon data and the points underscored in Figure 3.10 gave the equation

$$
a \cdot w_{2}^{1 / 3}=9.29 \times 10^{6}\left(R / W^{1 / 3}\right)^{-2.32 \pm 0.08}
$$

where the fractional standard deviation of the exponent is 3.4 percent and the variance factor for the coefficient is 1.56 .

3. 5. 2 Particle Velocity Analysis -- Hard rock free-field particle velocity data appear to be more closely packed than do similar data from explosions in the lower seismic impedance rocks. However, Handcar data are generally lower and Salmon data higher than those from other events and, together with the underscored points in Figure 3.11, have been omitted from regression of the general data set. Handcar particle velocity data were analyzed separately, but Salmon velocity data were not. Regression analysis of the remaining hard rock velocity data yielded the equation

$$
u=1.81 \times 10^{4}\left(\mathrm{R} / \mathrm{W}^{1 / 3}\right)^{-1.72 \pm 0.07}
$$




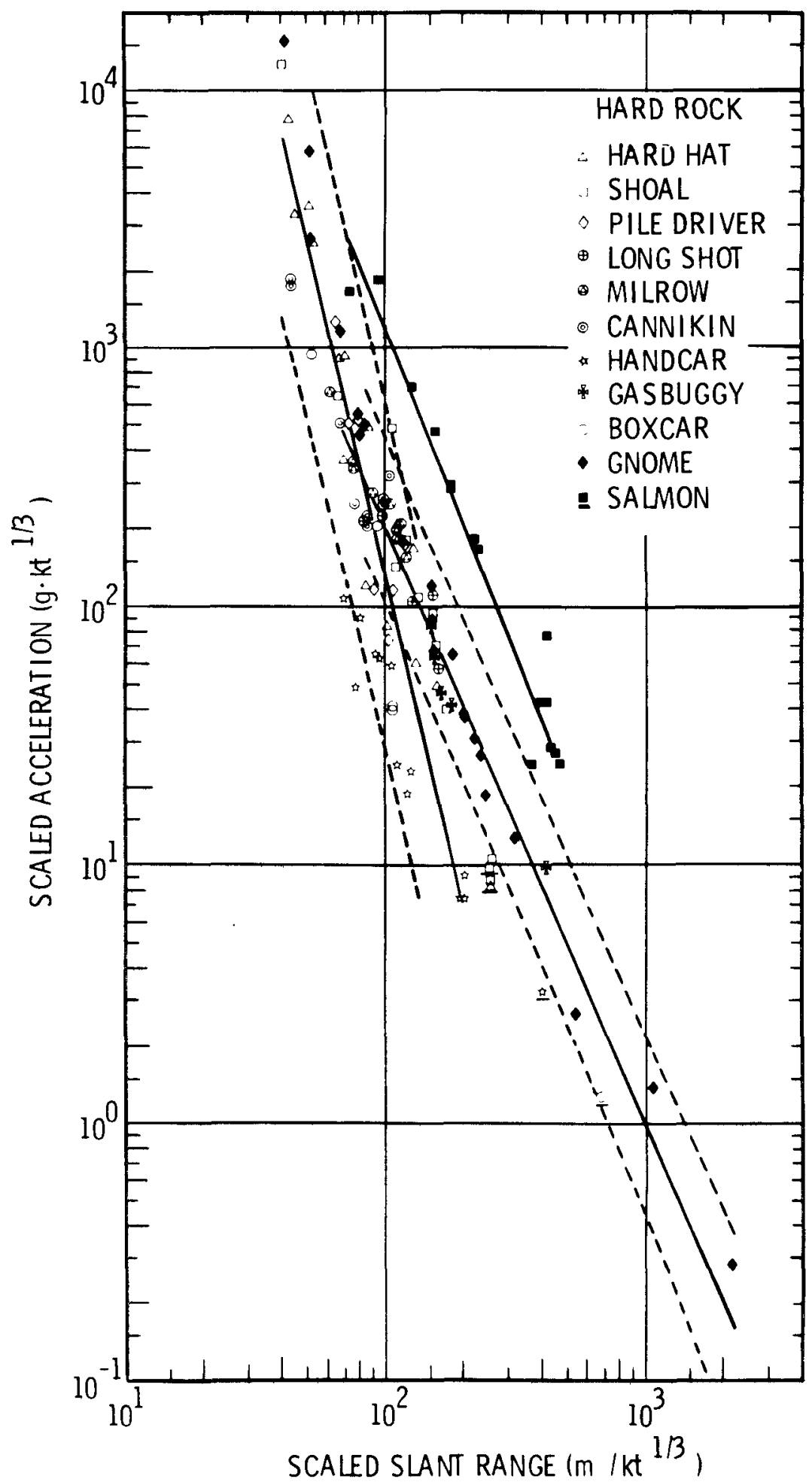

Figure 3.10. Attenuation of scaled acceleration-hard rock 


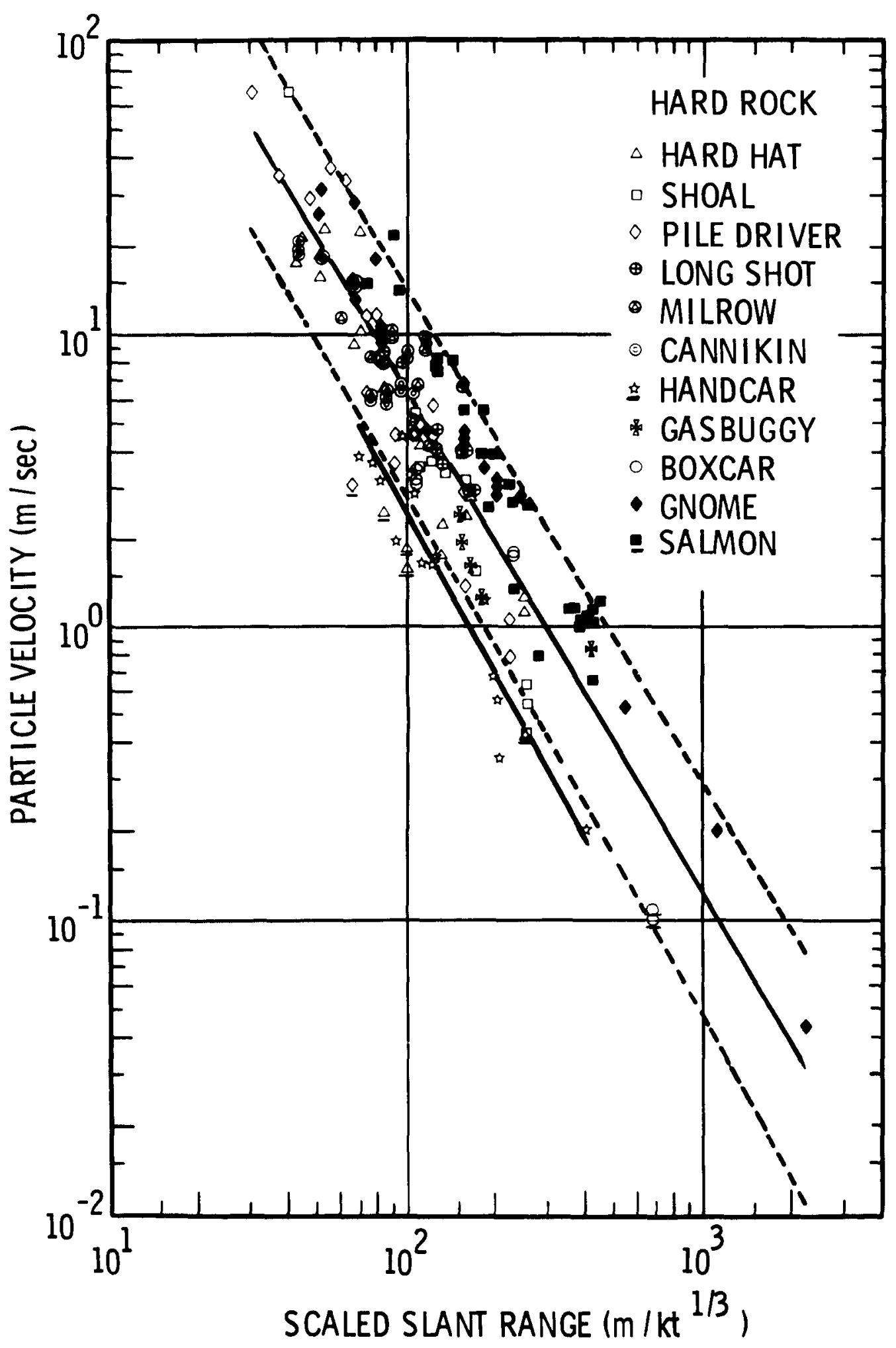

Figure 3.11. Attenuation of particle velocity-hard rock 
where coefficient variance is defined by the multiplier 1. 39; fractional standard deviation of the exponent is 4.1 percent. This equation holds for the scaled slant range span from 40 to 2200 $\mathrm{m} / \mathrm{kt}^{1 / 3}$.

3.5.3 Scaled Displacement Analysis - - Scaled displacement data from all hard rock events are plotted in Figure 3.12. Salmon displacements fall well within the scatter of other data sets, and only a few Hard Hat and Handcar points have been underscored for omission from the regression analysis. The equation for this analysis, which holds for scaled ranges between 70 and 2200 $\mathrm{m} / \mathrm{kt}^{1 / 3}$, is

$$
\delta / \mathrm{W}^{1 / 3}=8.72 \times 10^{4}\left(\mathrm{R} / \mathrm{W}^{1 / 3}\right)^{-1.88 \pm 0.14}
$$

for which the coefficient variance is defined by the factor 2.08 and fractional standard deviation of the exponent is 7.5 percent.

\subsection{General Discussion}

Review of the data plots, Figures 3.1 through 3.12, and of the regression equations pertinent to these data indicates that the most extreme scatter of data and consequently greater variances occur for events in which either some gage stations were emplaced in rock of very different seismic impedance from that in which the explosive was emplaced or the environmental rock at the shot point was probably transitional between two categories, as in the case of the dry friable tuff at the Mud Pack site and the incompletely saturated wet tuff at the Event L location. In many cases, data which derived from such conditions were omitted from analysis, but in others knowledge of the real situation at a gage station or shot point was not sufficient to justify deletion of the data from analysis. In some cases where a complete set of data has been omitted from analysis, a separate regression has been undertaken to those data sets.

The Scooter displacement data, Figure 3.3, were found to fit the equation

$$
\delta / \mathrm{W}^{1 / 3}=8.79 \times 10^{5}\left(\mathrm{R} / \mathrm{W}^{1 / 3}\right)^{-2.30 \pm 0.21}
$$

with a 9.2 percent fractional deviation of the exponent and a coefficient variance multiplier of 2.55 .

Mud Pack data, in addition to being derived from some stations in much higher impedance rock than the shot point material and evidently fitting the dry alluvium category better than the dry tuff one, are characterized by very broad scatter. Regression equations for Mud Pack peak motion data are

$$
\mathrm{a} \cdot \mathrm{W}^{1 / 3}=1.83 \times 10^{5}\left(\mathrm{R} / \mathrm{W}^{1 / 3}\right)^{-2.64 \pm 0.17}
$$




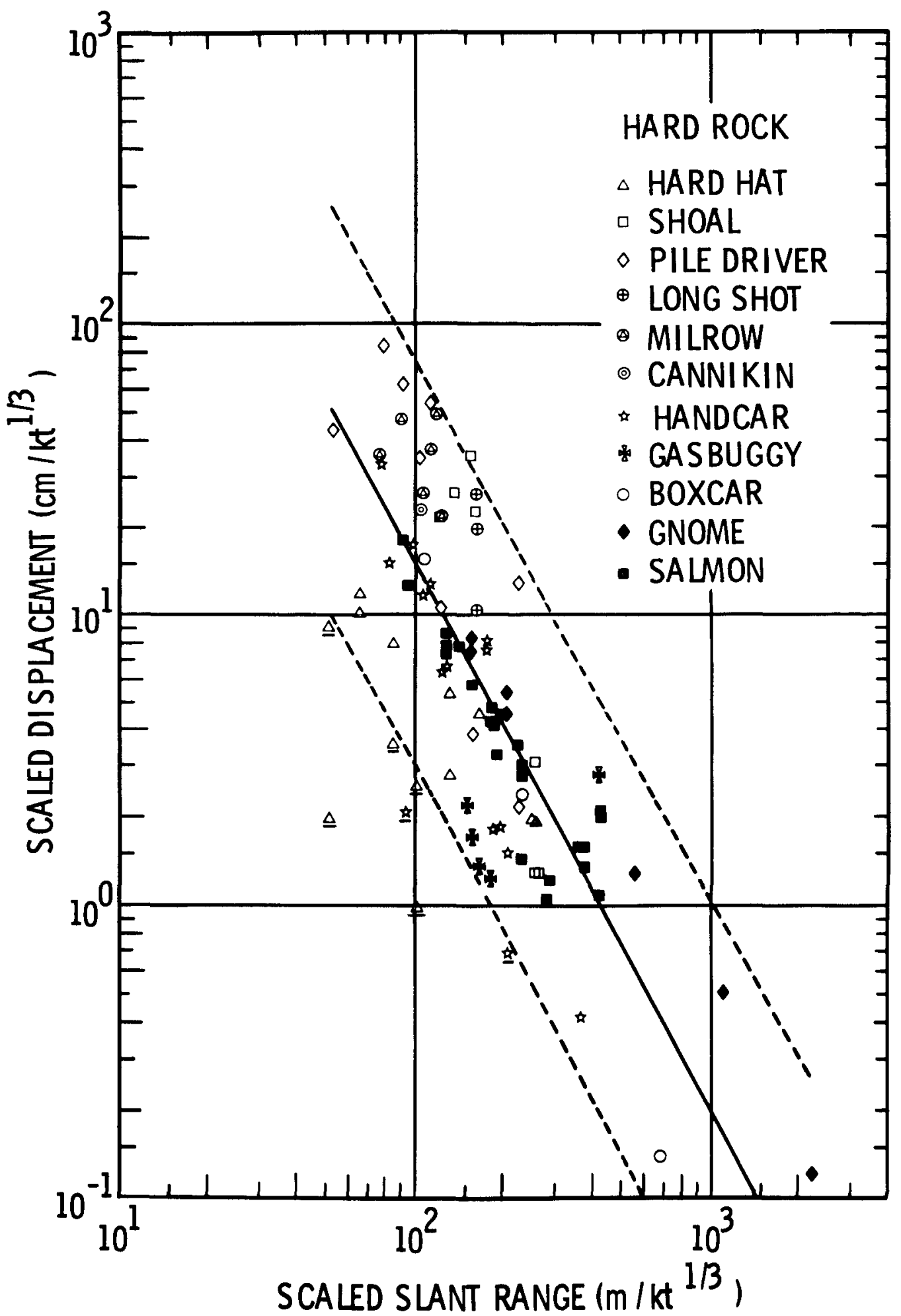

Figure 3.12. Attenuation of scaled displacement-hard rock 
where the variance multiplier for the coefficient is 2.26 and fractional deviation of the exponent is 6.5 percent, Figure 3.4;

$$
\mathrm{u}=1.48 \times 10^{2}\left(\mathrm{R} / \mathrm{W}^{1 / 3}\right)^{-1.47 \pm 0.26}
$$

with a coefficient variance factor of 3.42 and a fractional standard deviation of the exponent of 17.7 percent, Figure 3.5 ; and

$$
\delta / \mathrm{W}^{1 / 3}=2.35 \times 10^{2}\left(\mathrm{R} / \mathrm{W}^{1 / 3}\right)^{-1.19 \pm 0.49}
$$

with a coefficient variance multiplier of 9.34 and a fractional standard deviation of the exponent equal to 38.6 percent, Figure 3.6. It is evident in the figures that scatter is least among Mud Pack scaled accelerations where the variances are not very different from those of the other dry tuff data although magnitudes are significantly below other dry tuff values, but scatter is very broad in both the particle velocity and displacement data from Mud Pack and variances are exceptionally large in both regression fits.

Separate analysis of Salmon scaled acceleration data, Figure 3. 10, yielded the regression equation

$$
a \cdot W^{1 / 3}=1.33 \times 10^{8}\left(R / W^{1 / 3}\right)^{-2.52 \pm 0.11}
$$

where the variance factor for the intercept is 1.79 and fraction standard deviation of the exponent is 4.2 percent.

Finally, separate analysis of Handcar particle velocity data gave the equation

$$
u=1.35 \times 10^{4}\left(R / W^{1 / 3}\right)^{-1.87 \pm 0.18}
$$

with an intercept variance factor of 2.39 and an exponent fractional standard deviation of 9.5 percent.

It must be recognized that, although throughout this analysis and discussion of free-field ground motion data apparently anomalous results have been considered a consequence of environmental anomalies, it is also possible, where complete sets of data such as those just analyzed are above or below the general family of data for a particular environment, that an erroneous value of explosive yield has been used in scaling data. A low yield will shift scaled quantities toward higher values and a high yield toward lower ones. This argument does not serve very well where only one 
motion parameter, such as the Scooter scaled displacement or Salmon scaled acceleration, is anomalous, but it can find support in the Mud Pack analysis where all three data sets are lower than the dry tuff data from other events. The second criterion for comparison of these data is the slope of the linear fit, i. e., the exponents. If these are closest to those of the assumed or prescribed environment, then the assumed yield and consequently the scaling factor may again be in doubt. However, energy yields of most explosions are established by diagnostic measurements well within a factor of 2 and the change in scaling factor for doubling or halving yield is only about 26 percent, so that anomalies in scaled data of the order of 2 or more are most likely caused by differences or uncertainties in environmental characteristics.

It is of interest to tabulate the intercept coefficients and exponents of the regression equations for the various motion parameters and their variance factors, Table 3. 1. In this tabulation, scaled accelerations have been separated into those derived from the shorter scaled ranges and those from the more remote stations. The wet tuff scaled accelerations characterized earlier as being derived from events in rock of transitional water content have been omitted from the table. The equations for shorter range fits to particle velocities and scaled displacements have not been separately listed because such separation was undertaken for the alluvium environment only and even there its justification for particle velocity is questionable.

TABLE 3.1 Regression Parameters for Free-Field Ground Motion

\begin{tabular}{|c|c|c|c|c|c|c|}
\hline Motion & Rock & $\begin{array}{l}\text { Intercept } \\
\text { Coefficient }\end{array}$ & $\begin{array}{c}\text { Variance } \\
\text { Factor } \\
\end{array}$ & Exponent & $\begin{array}{c}\text { Standard } \\
\text { Deviation } \\
(\%) \\
\end{array}$ & $\begin{array}{c}\text { Applicable } \\
\text { Range } \\
\mathrm{m} / \mathrm{kt}^{1 / 3} \\
\end{array}$ \\
\hline$a \cdot w^{1 / 3}$ & Alluvium & $2.24 \times 10^{11}$ & 6.39 & -5.78 & 8.1 & $20-80$ \\
\hline$a \cdot w^{1 / 3}$ & Dry Tuff & 4. $90 \times 10^{10}$ & 4.33 & -4.77 & 6.9 & $40-150$ \\
\hline$a \cdot w^{1 / 3}$ & Hard Rock & $6.20 \times 10^{10}$ & 4.06 & -4.35 & 7.3 & $40-200$ \\
\hline$a \cdot w^{1 / 3}$ & Alluvium & 4. $79 \times 10^{4}$ & 2.34 & -2.13 & 8.4 & $60-350$ \\
\hline $2 \cdot w^{1 / 3}$ & Dry Tuff & $7.71 \times 10^{4}$ & 2.12 & -1.92 & 7.4 & $100-500$ \\
\hline$a \cdot w^{1 / 3}$ & Wet Tuff & 4. $31 \times 10^{7}$ & 2.21 & -2.62 & 5.8 & $30-600$ \\
\hline$a \cdot w^{1 / 3}$ & Hard Rock & $9.28 \times 10^{6}$ & 1.56 & -2.32 & 3.4 & $90-2200$ \\
\hline $\mathbf{u}$ & Alluvium & 1. $52 \times 10^{6}$ & 1.96 & -3.27 & 4.9 & $30-150$ \\
\hline $\mathbf{u}$ & Alluvium & $3.86 \times 10^{1}$ & 2.09 & -1.16 & 12.0 & $100-350$ \\
\hline u & Dry Tulf & $1.85 \times 10^{4}$ & 1.81 & -1.88 & 5.6 & $40-500$ \\
\hline u & Wet Tuff & $6.61 \times 10^{3}$ & 1.56 & -1.56 & 5.8 & $30-600$ \\
\hline u & Hard Rock & $1.81 \times 10^{4}$ & 1.39 & -1.72 & 4.1 & $40-2200$ \\
\hline $8 / w^{1 / 3}$ & Alluvium & $3.44 \times 10^{6}$ & 2.42 & -3.04 & 6.6 & $40-150$ \\
\hline $8 / w^{1 / 3}$ & Alluvium & $2.22 \times 10^{2}$ & 1.72 & -1.11 & 9.9 & $100-350$ \\
\hline $6 / w^{1 / 3}$ & Dry Tuff & $3.80 \times 10^{5}$ & 3.11 & -2.20 & 9.6 & $100-500$ \\
\hline $8 / w^{1 / 3}$ & Wet Tuff & 4. $90 \times 10^{6}$ & 2.63 & -2.63 & 7.2 & $50-600$ \\
\hline $8 / w^{1 / 3}$ & Hard Rock & 8. $72 \times 10^{4}$ & 2.08 & -1.88 & 7.5 & $70-2200$ \\
\hline$a \cdot w^{1 / 3}$ & Mud Pack & $1.85 \times 10^{5}$ & 2.26 & -2.64 & 6.5 & $40-200$ \\
\hline$a \cdot w^{1 / 3}$ & Salmon & 1. $33 \times 10^{6}$ & 1.79 & -2.52 & 4.2 & $70-450$ \\
\hline $\mathbf{u}$ & Mud Pack & $1.48 \times 10^{2}$ & 3.42 & -1.47 & 17.7 & $40-200$ \\
\hline $\mathbf{u}$ & Handcar & $1.35 \times 10^{4}$ & 2.39 & -1.87 & 8.5 & $70-400$ \\
\hline $6 / w^{1 / 3}$ & Mud Pack & 2. $35 \times 10^{2}$ & 9.34 & -1.18 & 38.6 & $70-200$ \\
\hline $6 / w^{1 / 3}$ & Scooter & 8. $79 \times 10^{5}$ & 2.55 & -2.30 & 9.2 & $19-120$ \\
\hline
\end{tabular}


Evidently exponents of scaled accelerations in the shorter ranges are considerably greater than for the more remote data in all but the wet tuff events. This implies that in each of these environments loss of higher frequency components was significantly greater near the beginning of the region of nonlinear response than throughout the remainder. Fractional standard deviation of exponents for close-in scaled acceleration is comparable with those from most of the other data, but since the exponents are larger, the intercept varıances for these acceleration data are greater than for any others.

The more remote scaled accelerations appear to be attenuated as the inverse square of scaled range in alluvium and dry tuff and as the inverse 2.5 power in wet tuff and hard rock. Average variance of the exponents is a little over 6 percent, and the mean intercept variance factor is about 2.1 .

Particle velocity data for most environments are attenuated nearly as the inverse square of the scaled range, but the short and long range portions of the alluvium data are very different from each other and from the other rock categorıes. The exponent variance for long range alluvium data is unusually high, 12 percent. For the tuff and hard rock data, particle velocities fall off as the inverse 1.75 power with an average standard deviation of about 5.2 percent and a mean intercept varıance factor of about 1.6 .

Scaled displacement for all environments is attenuated at an average rate of roughly the inverse 2.2 power of scaled range, with a mean standard deviation of 8.2 percent. Again, omission of the alluvium data results in scaled displacement attenuation for the tuff and hard rock environments equal to the inverse 2.2 power of scaled slant range, with a mean standard deviation of 8.1 percent. Mean intercept variance factor for all four environments 1s 2.4, and for the last three materials it is 2.6.

The apparent anomalous behavior of the alluvium data in both particle velocity and displacement may be a consequence either of the fact that the particulate nature of the alluvium emphasized the difference in reaction at short versus longer scaled ranges or that greater scatter in the other media resulted in masking of real but small differences in attenuation rates in the tuff and hard rock data. However, it is also possible that the evident, more rapid attenuation of particle velocity, and consequently of stress, in alluvium resulted in the onset of linear or quasi-linear response within the scaled range of avallable data. This argument is based on the assumption that within the region of linear elastic response particle velocity and stress will decrease as a consequence of spherical dispersion only and consequently with the inverse first power of distance. 
4. 1 Comparison of Free-Field Motion in Regions of Hydrodynamic and Nonlinear Response

Attenuation of free-field particle velocity in the region of hydrodynamic response for all rocks, Figure 2.1, occurred as the inverse 1.87 power of scaled range. Similar data from the domain of nonlinear response for dry tuff, wet tuff, and hard rock indicated attenuation as the inverse $1.98,1.56$, and 1.72 power, respectively. Intercept coefficients in the corresponding regression equations were roughly similar, $2.43 \times 10^{4}, 1.85 \times 10^{4}, 6.61 \times 10^{3}$, and $1.81 \times 10^{4}$. However, the dry tuff regression equation within the span of pertinent data is significantly below those for wet tuff and hard rock; at a scaled range of $100 \mathrm{~m} / \mathrm{kt} / 3$, the dry tuff fit is $2.11 \mathrm{~m} / \mathrm{sec}$ as compared to 4.96 and $6.51 \mathrm{~m} / \mathrm{sec}$ at the same distance in wet tuff and hard rock. Consequently, a logical comparison of particle velocities in the hydrodynamic and nonlinear regions should be limited to data from wet tuff and hard rock in the latter region. All particle velocity data from the three data sets corresponding to Figures 2.1,3.8, and 3.11 are plotted in Figure 4.1 as a function of scaled range, and a linear regression was performed on these data, omitting the underscored points as in the previous analyses.

The data in Figure 4.1 evidently follow a single trend; there is no obvious change in slope or transitional offset, and data from the three sets overlap through one decade of velocity values. In general, the principal difference between the data sets is the greater scatter in the nonlinear region where differences in physical characteristics of the rock can influence data significantly.

The linear fit to these data is shown in Figure 4.1 and is described by the equation

$$
u=1.85 \times 10^{4}\left(R / W^{1 / 3}\right)^{-1.76 \pm 0.02}
$$

where the intercept variance factor is 1.12 and fractional standard deviation of the exponent is 1. 4 percent. The extent of data represented by this equation is suggested by the fact that the nearly 350 particle velocity data range between $4.4 \times 10^{3}$ and $4.3 \times 10^{-2} \mathrm{~m} / \mathrm{sec}$ and the corresponding range of stress, from nearly one megabar to about one bar, is over five orders of magnitude.

Therefore, throughout both the hydrodynamic and nonlinear response domains surrounding contained underground nuclear explosions in competent rock, particle velocity decreases as the inverse 1.76 power of scaled distance, and can be very roughly approximated by inverse square attenuation. It has been noted previously that in the domain of hydrodynamic response, although stress is attenuated roughly as the inverse cube of distance, variability of density and shock 


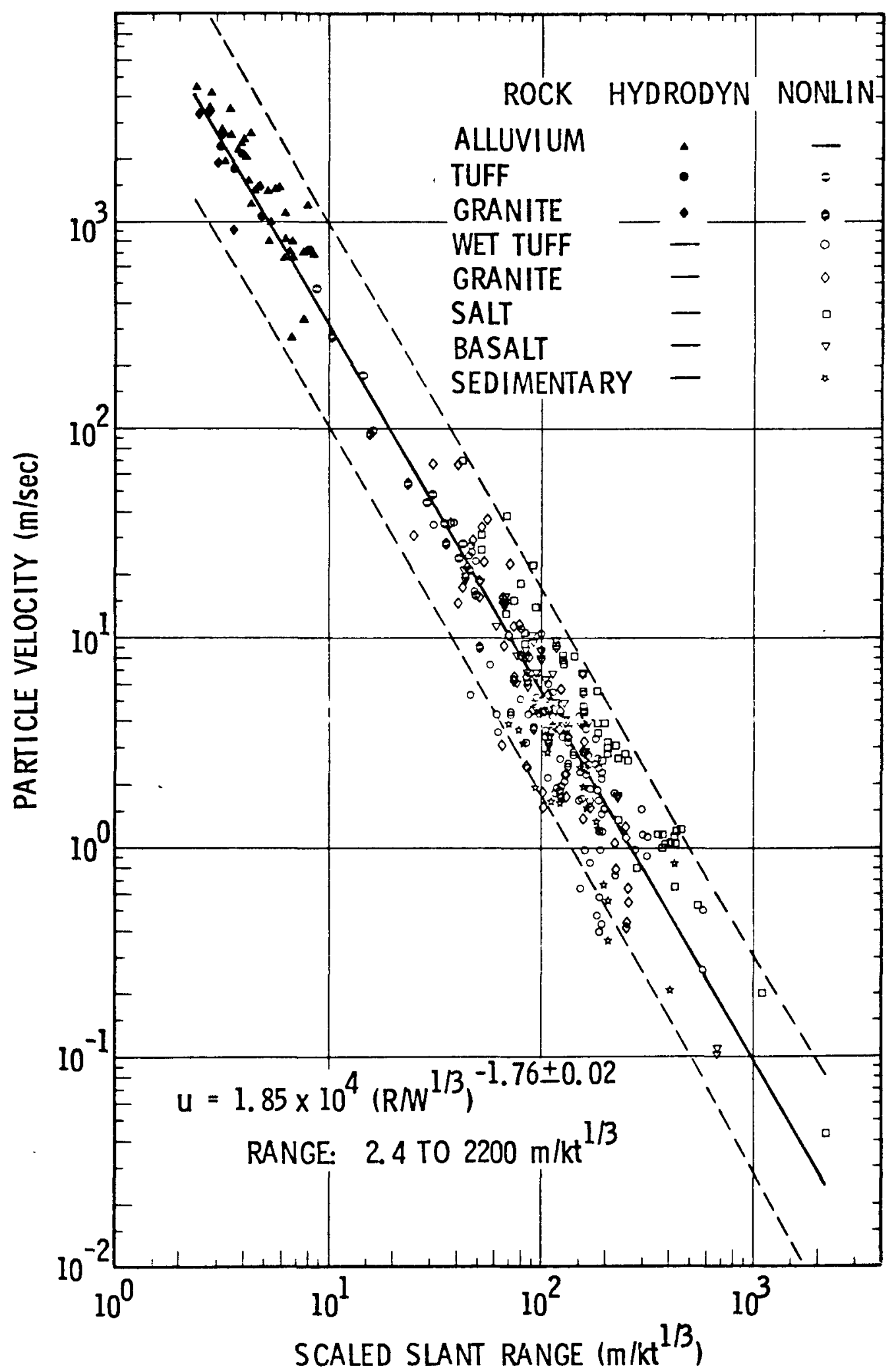

Figure 4.1. Attenuation of particle velocity in the regions of hydrodynamic and nonlinear response 
velocity with stress in the equation of state results in inverse square attenuation of particle velocity. At lower stress levels within the domain of nonlinear response, both stress and particle velocity are attenuated at similar rates since the seismic impedance, 1. e., the product of density by propagation velocity, remains essentially constant beyond the hydrodynamic regime. In this region, particle velocities in competent rocks (high impedance) were found to be attenuated roughly as the inverse square of scaled distance. The significant result derived from this analysis is the strong evidence that a single continuous rate describes attenuation of particle velocity over a peak stress range from a megabar to a bar in a number of competent rock environments.

\section{2 Comparison of Motion in Different Rocks}

More meaningful interpretation of differences in attenuation between a particular motion parameter in different rock environments should be avallable from comparison of the regression curves and equations. For this purpose, plots which include each regression fit for a single parameter, as scaled acceleration, for the four rock environments were assembled. Corresponding regression equations are grouped in tables. These plots ald in identıfying the influence of general rock characteristics on response to the explosion induced motion.

4.2.1 Scaled Acceleration -- Figure 4.2 includes the regression curves for scaled acceleration data from alluvium, Figure 3.1, from dry tuff, Figure 3.4, from wet tuff, Figure 3. 7, and from hard rock, Figure 3.10. Equations for these curves are listed in Table 4.1. In each rock type there are two linear regression phases; however, those for wet tuff data differ from the others, and the lower one is probably anomalous, as discussed in Chapter 3.

Both phases of the alluvium and dry tuff lines are roughly parallel, but the tuff lines and their intersection represent higher acceleration levels than the alluvium ones for identical scaled ranges. This situation is very likely a consequence of greater energy absorption, particularly of the high frequency components at high stress levels in the unbonded porous alluvium.

The wet tuff curve and both phases of the hard rock curve are roughly similar and at much higher acceleration levels than the dry tuff and alluvium ones. This fact confirms the anticipated lower energy losses in the competent, higher impedance rocks.

4.2.2 Particle Velocity -- The curves plotted in Figure 4.3 are those fitted to particle velocity data from alluvium in Figure 3.2, from dry tuff in Figure 3.5, from wet tuff in Figure 3.8, and from hard rock in Figure 3.11. The equations for these curves are presented in Table 4.2. Included in Figure 4.3 is the general linear fit to particle velocity data from Figure 4.1. 
TABLE 4.1 Scaled Acceleration in Nonlinear and Linear Regions

\section{ALLUVIUM}

$\mathrm{a} \cdot \mathrm{W}_{1}^{1 / 3}=2.24 \times 10^{11}\left(\mathrm{R} / \mathrm{W}^{1 / 3}\right)^{-5.78} \pm 0.47 \quad$ RANGE: $20 \mathrm{TO} 80 \mathrm{~m} / \mathrm{kt}^{1 / 3}$ $\mathrm{a} \cdot \mathrm{w}_{2}^{1 / 3}=4.79 \times 10^{4}\left(\mathrm{R} / \mathrm{w}^{1 / 3}\right)^{-2.13} \pm 0.18 \quad$ RANGE: $60 \mathrm{TO} 350 \mathrm{~m} / \mathrm{kt}^{1 / 3}$

DRY TUFF

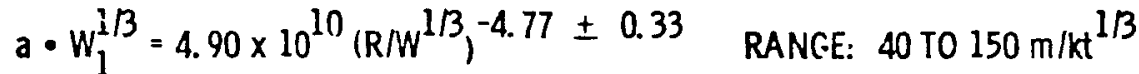

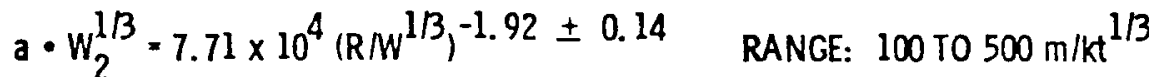

WET TUFF

$\left.\mathrm{a} \cdot w_{1}^{\mathrm{i} / 3}=4.31 \times 10^{7}: \mathrm{R}^{1 / 3}\right)^{1 / 2.61 \pm 0.17}$

$a \cdot W_{2}^{1 / 3}=2.06 \times 10^{5}\left(R_{i}^{\prime} W^{1 / B}\right)^{-2.02} \pm 0.29$

RANGE: 30 TO $600 \mathrm{~m} / \mathrm{kt}^{13}$

RANGE: $30 \mathrm{TO} 200 \mathrm{~m} / \mathrm{kt}^{1 / 3}$

HARD ROCK

$\mathrm{a} \cdot \mathrm{W}_{1}^{1 / 3}=6.20 \times 10^{10}\left(\mathrm{R} / \mathrm{W}^{1 / 3}\right)^{-4.35} \pm 0.32$

RANGE: $40 \mathrm{TO} 200 \mathrm{~m} / \mathrm{kt}^{13}$

a. $W_{2}^{1 / B}=9.29 \times 10^{6}\left(R / w^{1 / 3}\right)^{-2.32} \pm 0.08$

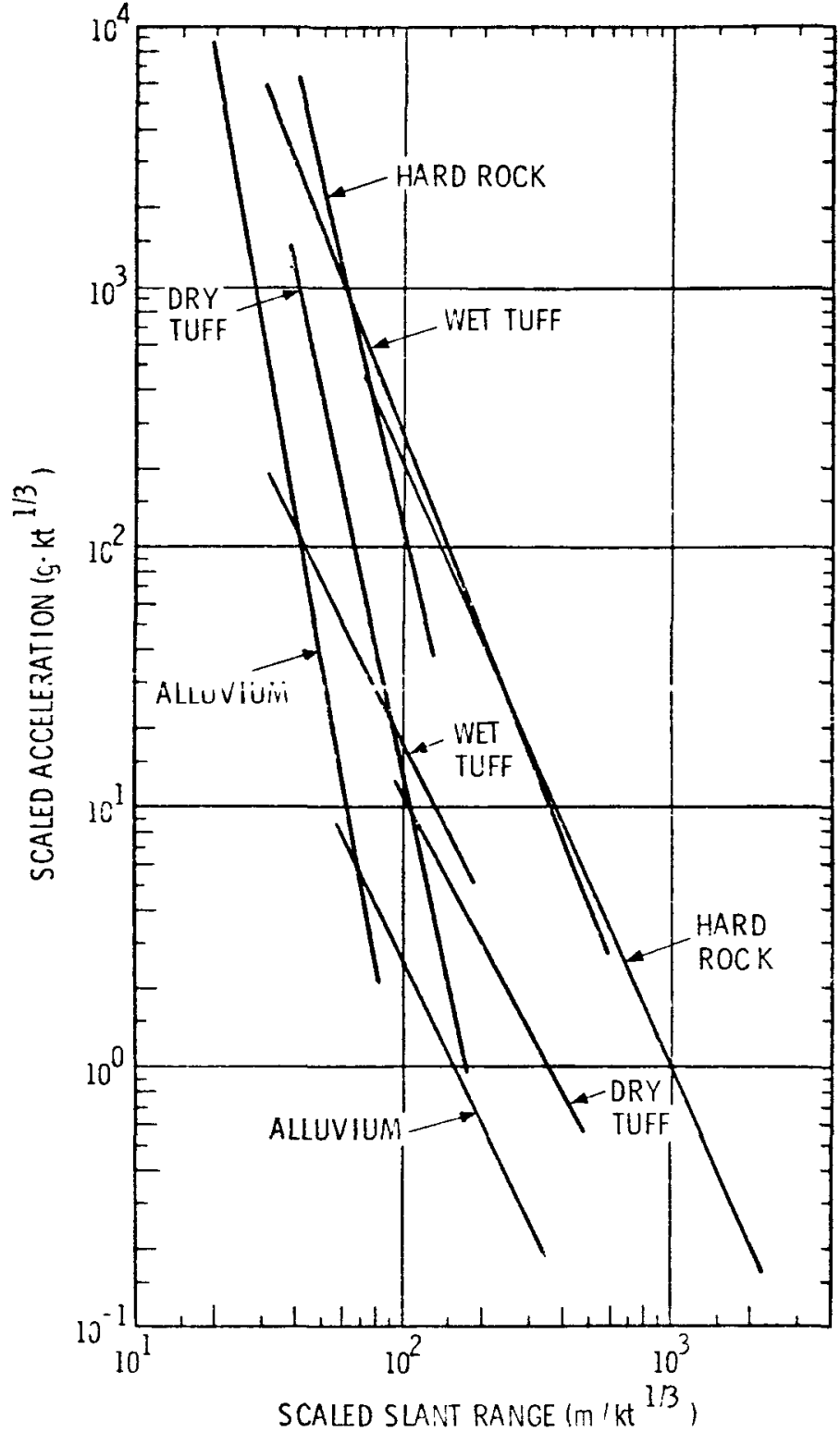

Figure 4.2. Attenuation comparıson-scaled acceleration 
TABLE 4.2 Particle Velocity in Nonlinear and Linear Regions

\section{ALLUVIUM}

$$
\begin{array}{ll}
u_{1}=1.52 \times 10^{6}\left(R / N^{1 / 3}\right)^{-3.27} \pm 0.16 & \text { RANGE: } 30 \mathrm{TO} 150 \mathrm{~m} / \mathrm{kt}^{1 / 3} \\
u_{2}=3.86 \times 10^{1}\left(R / w^{1 / 3}\right)-1.16 \pm 0.14 & \text { RANGE: } 100 \mathrm{T0} 350 \mathrm{~m} / \mathrm{kt}^{1 / 3}
\end{array}
$$

\section{DRY TUFF}

$$
u=1.85 \times 10^{4}\left(R / W^{1 / 3}\right)^{-1.98} \pm 0.11
$$

RANGE: 40 TO $500 \mathrm{~m} / \mathrm{kt}^{1 / 3}$

\section{WET TUFF}

$$
u=6.6 ! \times 10^{3}\left(R / w^{1 B}\right)-1.56 \pm 0.09
$$

RANGE: 30 TO $60 \mathrm{~m} / \mathrm{kt}^{1 / 3}$

\section{HARD ROCK}

$u=1.81 \times 10^{4}\left(R W^{1 / 3}\right)^{-1.72} \pm 0.07$

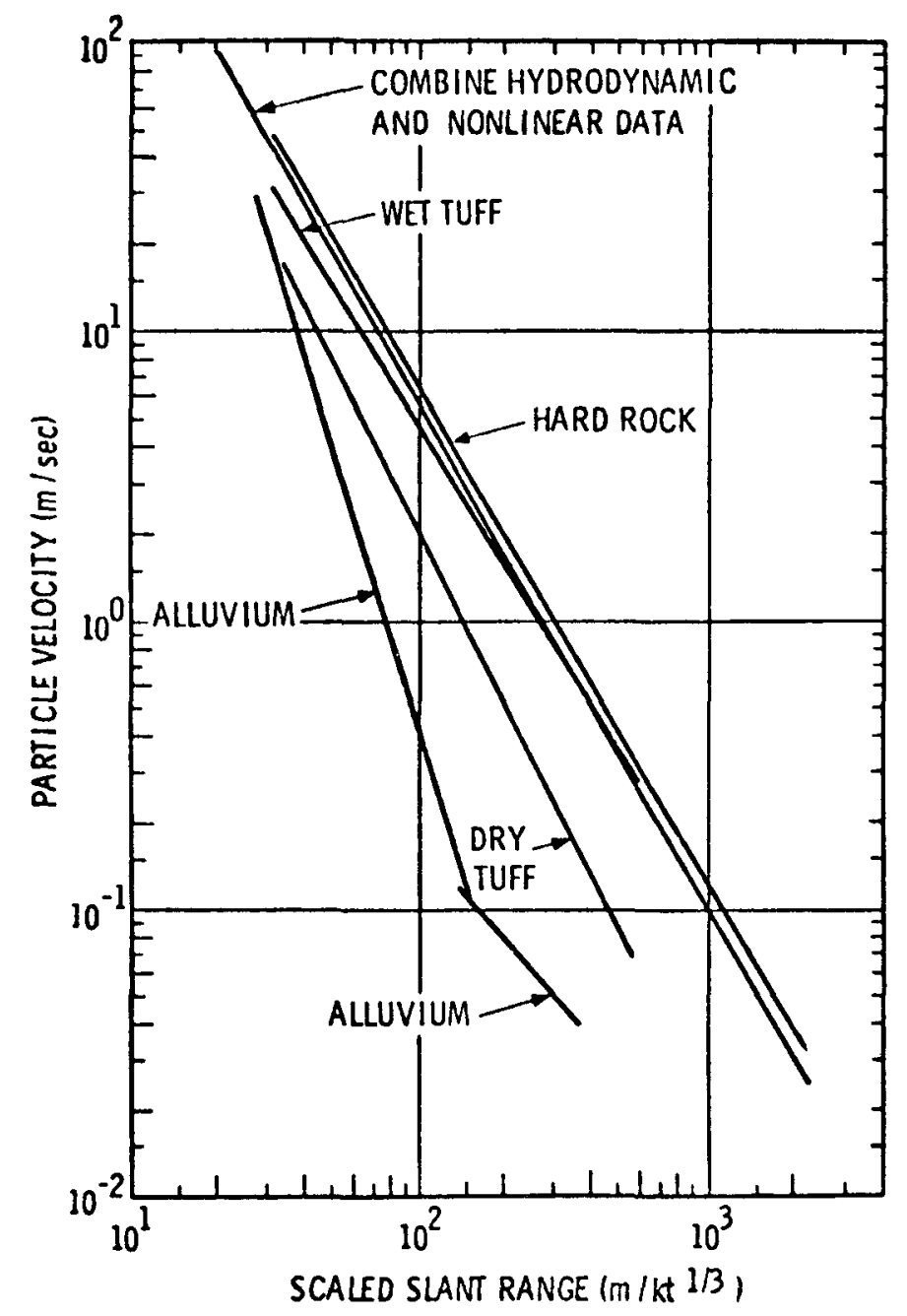

Figure 4.3. Attenuation comparison-particle velncity 
Only the alluvium curve includes two phases, of which the second with an attenuation rate near the inverse furst power suggests linear or elastic propagation beyond a scaled range of about 150 $\mathrm{m} / \mathrm{kt}^{1 / 3}$. Again, the alluvium curves are considerably lower than the others, a fact which, in conjunction with the lower seismic impedance in alluvium, implies much lower stress levels at similar scaled ranges.

Of the remaining four regression curves, that for dry tuff falls below the more competent rock although its slope is comparable, as noted in the preceding section. The significant factor in this difference is probably the much larger proportion of gas-filled pore volume as compared with the wet tuff and the much stronger interparticle bonding as compared with alluvium which may have porosity comparable to tuff. Propagation of motion through the dry tuff is inhibited by its porosity, but the stronger bonding in the tuff also inhibits some of the losses which occur in the unbonded porous alluvium.

The wet tuff and hard rock curves lie near each other and obviously near the curve for composite data. As previously noted, in these higher impedance rocks attenuation seems to occur, in general, at a constant rate over a very wide range of pressures.

4.2.3 Scaled Displacement -- Regression curves for scaled displacement data presented in Figure 4. 4 are those derived from alluvium data, Figure 3. 3; dry tuff data, Figure 3.6; wet tuff data, Figure 3.9; and hard rock data, Figure 3. 12. The equations for these curves are assembled in Table 4. 3. Of the three motion transients generated by underground explosions, displacement is not only an appreciably longer duration phenomenon than particle velocity or acceleration but it is the only one which may have residual nonzero values as a result of irreversible processes.

Curves for both types of tuff and for hard rock are closely grouped and, although slopes of these lines differ, within the range of data scaled displacements are not very different in the three rock types. However, scaled displacements in alluvium not only appear to include two phases within the range of data, but are lower than those in higher impedance rock by factors of 5 to 10 . The corresponding particle velocity factors coupled with a factor of 3 difference in seismic impedance between alluvium and hard rock indicate that in the region of nonlinear response stresses in hard rock are between 9 and 30 times those in alluvium at the same scaled range. Further, because the alluvium is a much more dispersive material than is hard rock, the lower stress transients are broadened and a relatively larger portion of this transient is too small to exceed intergranular friction and thus contribute to significant displacement. 
TABLE 4.3 Scaled Displacement in Nonlinear and Linear Regions

\section{ALUUVIUM}

$8 N N_{1}^{1 / 3}=3.44 \times 10^{6}\left(\mathrm{R} / \mathrm{W}^{1 / 3}\right)^{-3.04} \pm 0.20$

RANGE: 40 TO $150 \mathrm{~m} / \mathrm{kt}^{1 / 3}$

$\delta W_{2}^{1 B}=2.22 \times 10^{2}\left(R N^{1 B}\right)^{-1.11} \pm 0.11$

RANGE: 100 TO $350 \mathrm{~m} / \mathrm{kt}^{1 / 3}$

DRY TUFF

$8 N^{1 / 3}=3.80 \times 10^{5}\left(R / W^{1 / 3}\right)^{-2.20} \pm 0.21 \quad$ RANGE: 100 TO $500 \mathrm{~m} / \mathrm{kt}^{1 / 3}$

WET TUFF

$\delta / W^{1 B}=4.90 \times 10^{6}\left(R W^{1 B}\right)^{-2.63 \pm 0.10}$

RANGE: 50 TO $600 \mathrm{~m} / \mathrm{kt}^{1 / 3}$

HARD ROCK

$\delta / W^{1 B}=8.72 \times 10^{4}\left(R / W^{1 B}\right)^{-1.88 \pm 0.14}$
RANGE: 70 TO $2200 \mathrm{~m} / \mathrm{kt}^{1 / 3}$

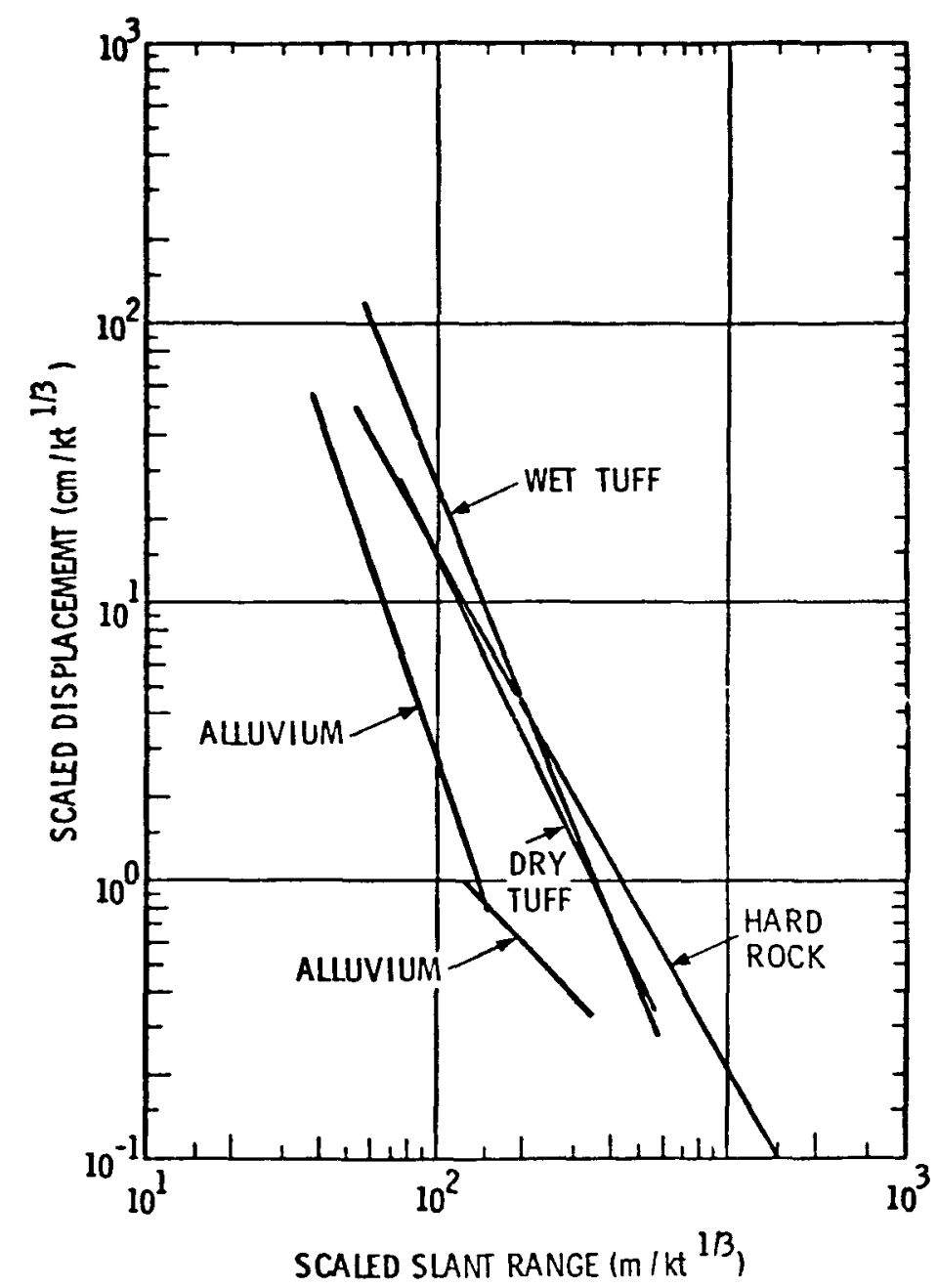

Figure 4.4. Attenuation comparison-scaled displacement 
Studies of seismic source energies of contained nuclear underground explosions (Perret 1972) in various geologic materials indicate that near the onset of linear or elastic response the ratio of available seismic energy to released explosive energy is less than 0.1 percent in alluvium and between 2 and 3 percent in hard rock and wet tuff. Energy from an explosion in alluvium is less effectively coupled to the environment than is that for one in higher impedance rock. This energy has been more rapidly dissipated in transit through the alluvium to the seismic region. The consequence must be reduced motion throughout the same region in alluvium compared to motion in higher impedance rocks. 


\section{PART II}

The second part of this report concerns those records and data which were the basis for the analysis of free-field peak stress and motion data derived from numerous underground nuclear explosions in several geologic environments in Part I. In Chapter 5, time-motion records obtained from explosions in some typical geological environments are presented together with discussion of pertinent features of both the instrumentation and records. Chapter 6 includes tabulations of scaled motion maxima, rise times and slant or radial ranges representing all data used in Part I. For convenience, these records and tables are included at the end of each chapter.

\section{Chapter 5}

\section{RECORDS}

\section{1 General Comments}

Records of motion versus time are avallable for all data used in the analysis. The data used were in all cases derived from the radial component of motion either as recorded directly from gages oriented with response-axis radial to the source or as derived by vectorial combination of two or more recorded nonradial components of motion. The records have been included in referenced reports identıfied in each table in Chapter 6, except for those cases where currently unreported programs have been noted. Of the nearly 1100 data which are the basis for this free-field motion study, nearly 1000 derive from motion-time records and it is obviously impracticable and would serve no useful purpose to include all of them in this chapter. However, pertinent sequences of motion records from events detonated in four different geological environments have been chosen to illustrate typical characteristics of motion records and to indicate some typical problems. In addition to the motion records, two stress-time records from the region of plastic response in grante and tuff are presented.

\section{2 Stress Records}

It was noted in Chapter 2 that in the region surrounding an underground explosion where stress has decreased sufficiently for the rock to respond plastically to the transient load, several types of gage have been devised for recording stress as a function of time. Two stress records from this region are included in Figure 5. 1; the first, Figure 5.1a, was derived from an X-cut quartz crystal gage installed in grante at Station B-SL below the Pile Driver tunnel at a range of about $204 \mathrm{~m}$ from the explosion; the other, Figure 5. 1b, was obtained from an ytterbium-grid gage installed in the wall of a tunnel in wet tuff. A description of the quartz gage used in the Pile Driver program is included in a separate report (Bass 1965). 
The quartz stress gage record shown here has been smoothed in tracing, but it is representative of the actual recorded stress-time relationship. The peak stress level indicated for granite is considered to be low by a factor of nearly 3 because of serious impedance mismatch between the gage, grout, and rock, a situation noted later in connection with records of ground motion from Pile Driver.

The stress history for tuff represented by the ytterbium gage record is considered not only an accurate time-history of stress in the rock at this gage, but installation of the gage provided a sufficiently good impedance match with the rock to yield a peak stress level accurate within 20 to 30 percent.

\section{3 Records from the Salmon Event}

The Salmon event was a 5.3-kt nuclear explosion detonated in a boring at a depth of $828 \mathrm{~m}$ within the Tatum salt dome near Hattiesburg, Mississippi. Two programs of free-field ground motion measurements within the salt dome were included in this event. In each program, instrument stations including both accelerometers and velocity gages were emplaced in deep borings at several depths including shot level. Five instrument borings were included in the Sandia Laboratories effort (Perret 1968a), and seven comprised that undertaken by Stanford Research Institute (SRI), (Eisler, Hoffman 1969). Records presented here are those obtained by Sandia, primarily because they are part of a more complete set and were more readily available to the authors.

The plan and elevation drawing of the gage arrays used by Sandia, Figure 5.2, shows the relative position of instrument holes and the shot hole as well as location of both the instrument stations and explosive and the slant range to each station. Gage stations are identified by boring number and depth in hundreds of feet; thus, Sta E $14 \mathrm{C}-27$ was in Boring E14C at a depth of about $2700 \mathrm{ft}$ or $828 \mathrm{~m}$, approximately at shot level. Each station included accelerometers and particle velocity gages oriented to respond to motion along 3 orthogonal axes--vertical, horizontal radial, and tangential. Some stations included a fourth accelerometer oriented to respond along the true radius from the explosion. Gage designations included, in addition to the station number, a gage type index, A for accelerometers and $\mathrm{U}$ for velocity gage, and a direction index, $\mathrm{V}$ for vertical, $\mathrm{RH}$ for horizontal radial, $\mathrm{TH}$ for horizontal tangential, and $\mathrm{R}$ for slant radial. Velocity gages must be oriented to respond to either vertical or horizontal components of motion. Consequently, in the absence of a true radial accelerometer or to obtain radial particle velocity, the vertical and horizontal radial records were combined vectorially. Such records of radial vector motion are identified by a superscript bar as in $14 \mathrm{C}-39 \overline{\mathrm{UR}}$. Both acceleration and velocity gage records were integrated to velocity and displacement records either by processing the digital data derived from record tapes or by electronic integrating of a portion of the gage output prior to recording. The digitally integrated records are indicated by single or double integral symbols and electronically integrated ones by a capital letter I. 
Salmon records included here are limited to radial components of acceleration, particle velocity and displacement. Figure 5.3 includes data from those stations in Borings E14 and E14C which included radially oriented accelerometers. In the other borings, only the shot level stations included radially oriented gages. Radial particle velocity records from Borıngs E14 and E14C, Figure 5. 4, include both integrated radial acceleration data and vectorially combined velocity gage records; where both are plotted in the same frame, the smoother trace is the integral. Corresponding records from Borings E6 and E11, Figure 5. 5, include only velocity gage records. Radial displacement records from all stations, including E5-27 are shown in Figure 5.6. At the latter station, only the integrated radial velocity gage signal was recorded because of failure in the tape channel which received the direct output from the gage. Differentiation of the E5-27 IURH record was not completed prior to assembly of these figures. In some displacement-record figures, dual integrated records on a single frame are distinguished by circled numbers keyed to the record identıfication.

The salt dome environment within which both the Salmon explosion and all free-field gage stations were located provided a good approximation to an infinite homogeneous medium for these measurements. As a consequence, the records from this portion of the Salmon program comprise the cleanest suite of free-field ground motion data available.

\section{4 Records from the Plle Driver Event}

The 56-kt nuclear explosion designated Pile Driver was detonated at a depth of $460 \mathrm{~m}$ in a tunnel complex within the granitic Climax Stock in Area 15 at NTS. The explosive was placed in a vertical shaft about $30 \mathrm{~m}$ below the tunnel floor level, and a radial line of free-field gage stations was emplaced in borings beneath the tunnel at shot level, Figure 5.8, (Hoffman, Sauer 1969) and (Perret 1968b). As a consequence of cable damage by falling rock shortly after shock arrival, many of the motion records from this program were truncated during the decay phase of particle velocity, and only two stations, B-SL and 16-SL, produced full duration records. These records are included in Figures 5.9, 5. 10, and 5.11. No acceleration records were obtained at Sta B-SL, but the radial velocity, stress, and strain gages performed satisfactorily. The stress and strain records compare well with the velocity record except in amplitude, since the maxima are both lower than those derived from the velocity record by a factor of nearly three. These low peak values are considered to represent underregistration of the stress and strain gages as a result of serious impedance mismatch between rock, grout and gage and resulting partial isolation of the gages from the transient load. Motion gages are much less sensitive to such mismatch than are stress or strain gages.

Records from Sta $16-\mathrm{SL}$, Figures 5.10 and 5.11, represent vertical and radial motion at shot level where the driving stress is roughly 20 percent of that at Sta B-SL. Records from both stations are typical of truly free-field motion and include only negligible perturbations from such discontinuities as the tunnel openings. 


\section{5 Records from the Merlin Event}

The Merlin event was a 10-kt nuclear explosion detonated at a depth of $296 \mathrm{~m}$ in dry desert alluvium in Area 3 at NTS. At a depth of about $60 \mathrm{~m}$ below shot level, the alluvium is underlain by tuff which has a seismic impedance roughly 40 percent greater than that of the alluvium. This event was instrumented for a study of subsurface spallation and cavity collapse with three gage arrays, Figure 5.12; one on the ground surface, one included two vertical lines of gages in borings offset about 15 and $45 \mathrm{~m}$ from the shot hole, and the third a radial line of shot-level gage stations in borıngs at distances ranging from about 15 to $760 \mathrm{~m}$ from the explosion (Perret 1971 ). Data from the shot level array and from the deeper stations in the vertical array were considered representative of free-field motion because perturbation from reflection at the free surface should be either negligible or sufficiently late to have no effect on recorded maxima; this was particularly true of the shot level stations where radial motion was recorded in the horizontal plane normal to the strongest surface reflection signals.

Acceleration, particle velocity, and displacement records derived from five shot level stations, U3 at $107 \mathrm{~m}, \mathrm{U} 4$ at $213 \mathrm{~m}, \mathrm{U} 5$ at $335 \mathrm{~m}, \mathrm{U} 6$ at $488 \mathrm{~m}$, and U7 at $763 \mathrm{~m}$, are included in Figures 5.13 through 5.17. Instrumentation at the two closest stations, U 1 at $15 \mathrm{~m}$ and U2 at $46 \mathrm{~m}$, did not survive long enough to provide useful signals.

The initial acceleration and particle velocity peaks in these records are typical of free-field

data. However, the second impulse, represented by the second peaks in particle velocity records, suggest serious perturbation. These secondary peaks, which occur in Sta U4 records and from all more remote stations, lag the initial peaks at a nearly constant interval and increase relatively with distance, becoming dominant in records from Stas U6 and U7. These characteristics together with only very little evidence of these secondary signals in the vertical array records suggest that the source is a horizontally polarized reflection signal from the underlying alluvium-tuff intertace. It is noted however that these perturbations do not occur early enough to affect tree-field velocity peaks although they do, obviously, increase displacement maxima.

\section{6 Records from the Handcar Fvent}

The Handcar event was a 12-kt nuclear explosion detonated at a depth of $402 \mathrm{~m}$ in a boring in Area 8 at NTS. The explosive was placed in dolomite about $170 \mathrm{~m}$ below its interface with an overlying $28 \mathrm{~m}$ thick shale layer (Perret 1970b). Above the shale is stratified tutf about $78 \mathrm{~m}$ thick beneath a $126 \mathrm{~m}$ surface layer of desert alluvium. Ground motion induced by an explosion in such a layered earth cannot be expected to fit the definition of free-field motion, but in some respects it may approach those characteristics.

Ground motion instrumentation for this event included gage stations in five borings at various distances from the shot hole, Figure 5. 18. This figure also indicates the geological and geophysical interpretation of the Handcar environment including the effect of normal and reverse faulting in the 
intersected by Boring U10b-4 which caused repetition of the shale-dolomite interface four times in that boring. In general, however, the explosion was sufficiently far below the shale and the dolomite was sufficiently massive to produce ground motions at the shot level, dolomite, and shale stations that were reasonably free of serious perturbations and consequently were good approximations to free-field motion for an explosion in dolomite.

Vertical components of particle velocity recorded at stations in three borings are presented in Figure 5.19 superimposed on the geologic section at respective gage station positions. Horizontal radial component records of particle velocity are similarly shown in Figure 5. 20. Radial vector records of particle velocity from the stations included in the two foregoing figures are presented in Figures 5. 21, 5.22, and 5.23, and corresponding radial vector displacement records are shown in Figures 5.24, 5.25, and 5.26. These radial motion records indicate only minor perturbation of velocity records except in the stations in tuff and shale at the more remote boring, and again serious perturbation in displacement records appears as a dominant second peak only at the station in tuff in the remote boring. Consequently, these radial vector records appear to be representative of actual free-field motion. 


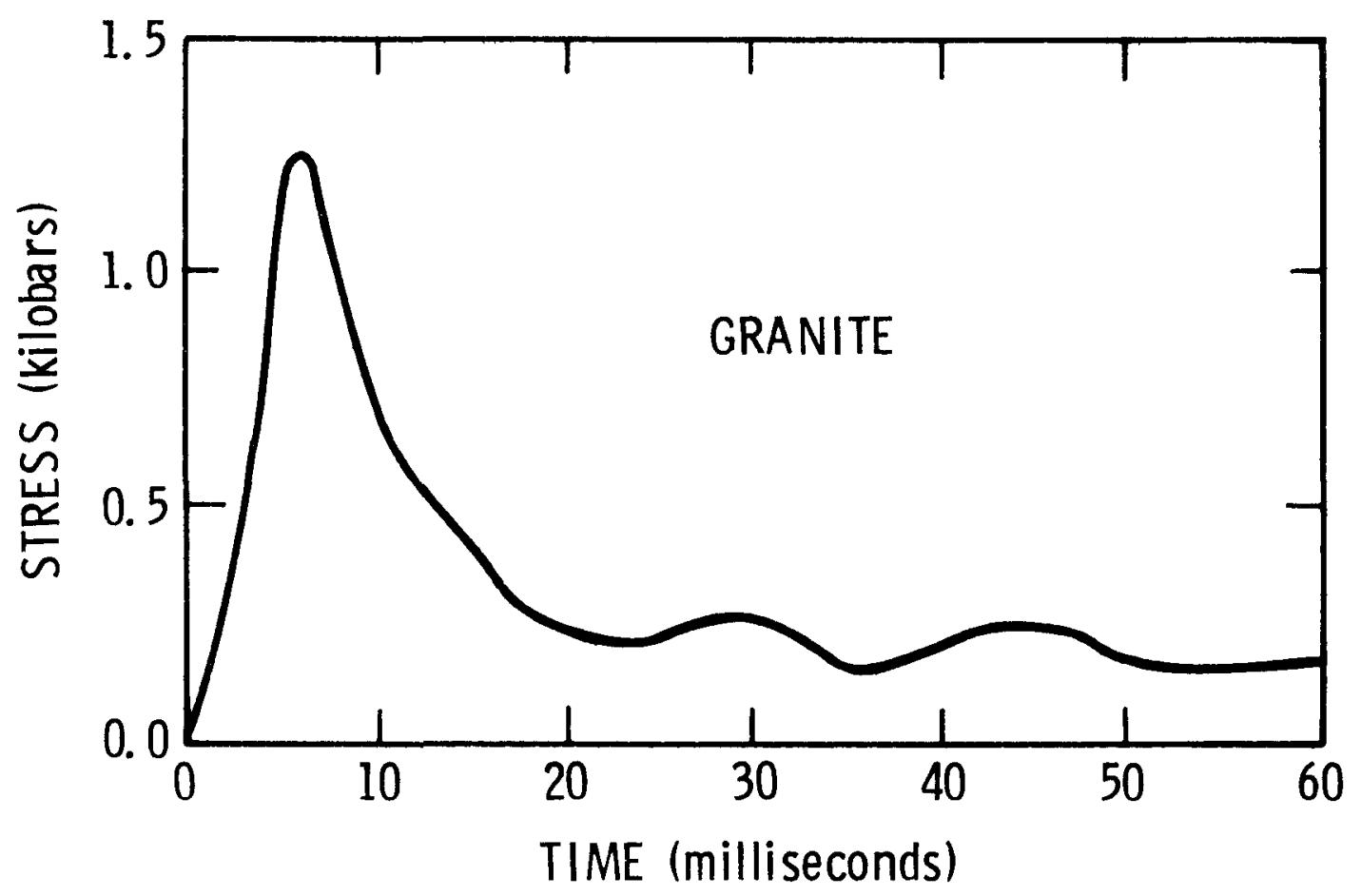

5. $1 \mathrm{a}$

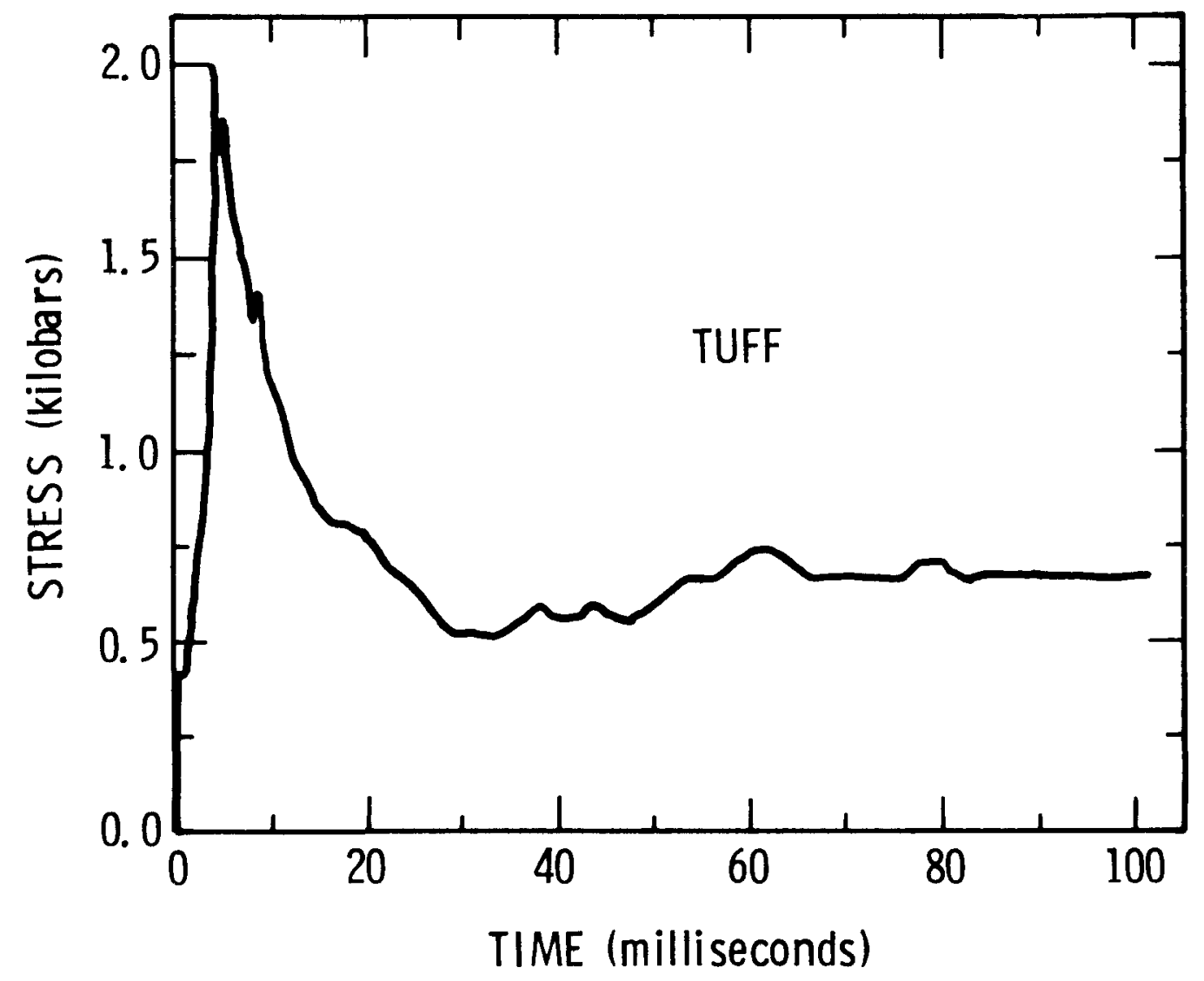

$5.1 \mathrm{~b}$

Figure 5.1. Stress records 
PLAN
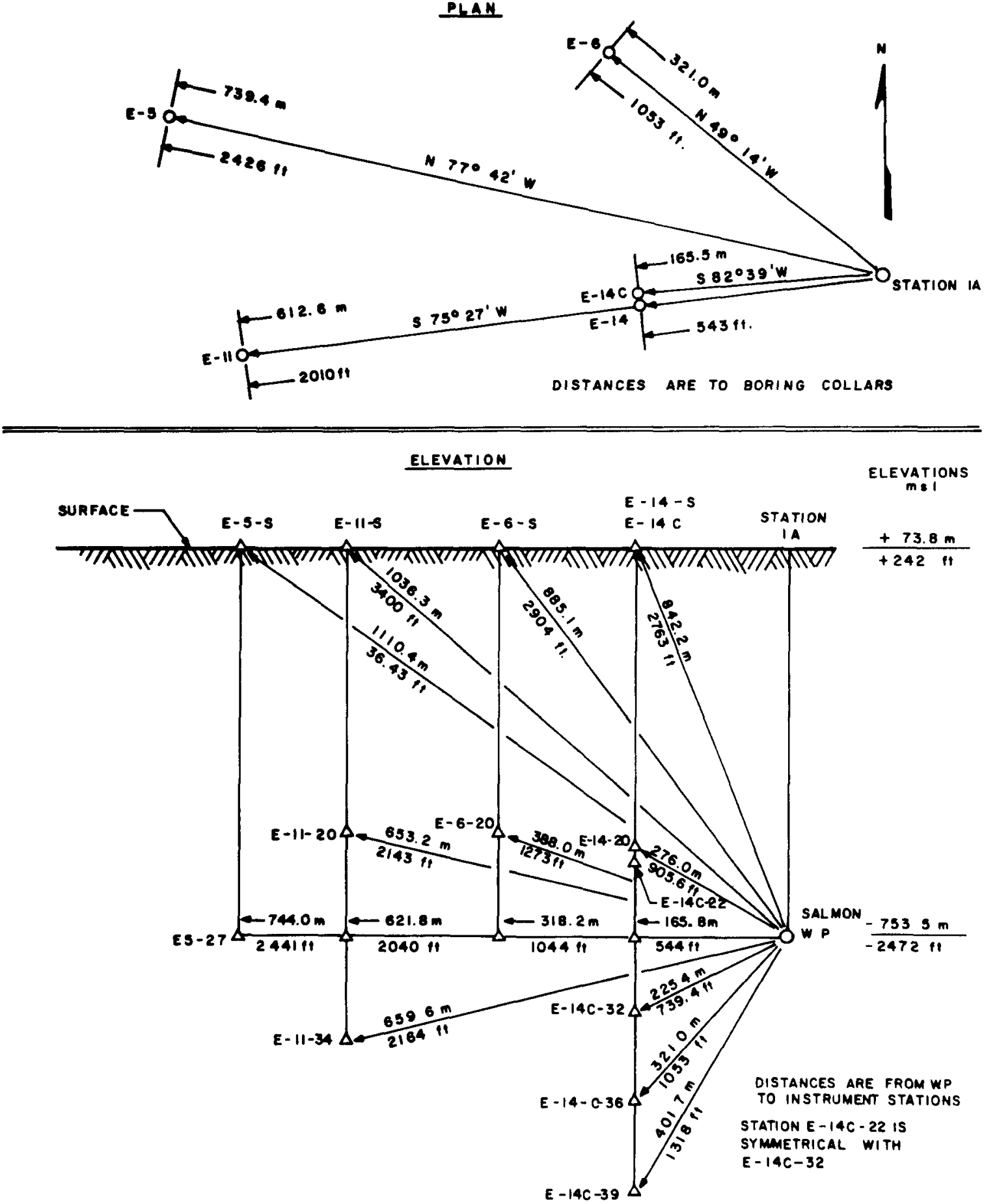

Figure 5.2. Salmon instrumentation scheme-Sandia 


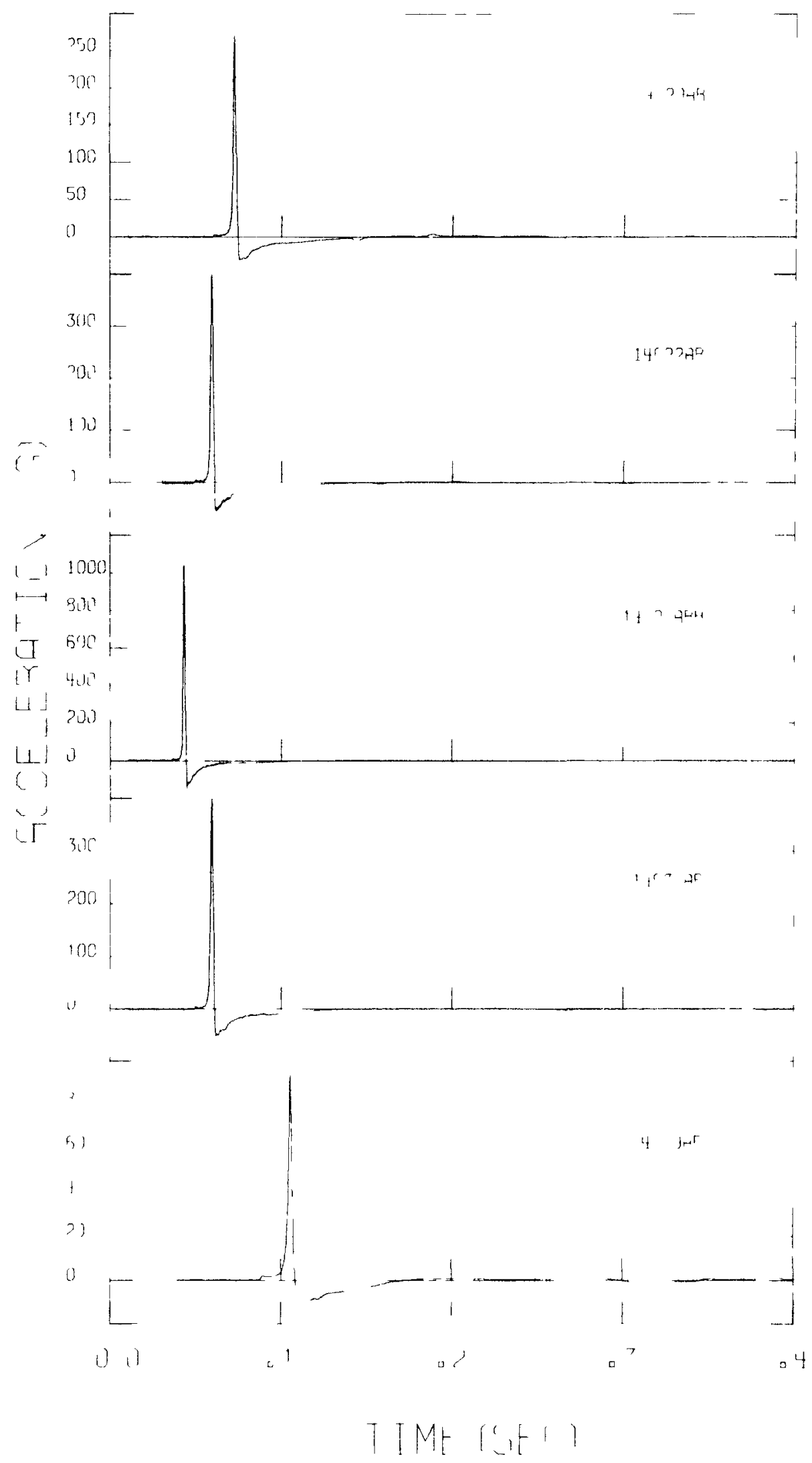

Figure 5.3. Radial acceleratıon records-Borings 14 and $14 \mathrm{C}$ 


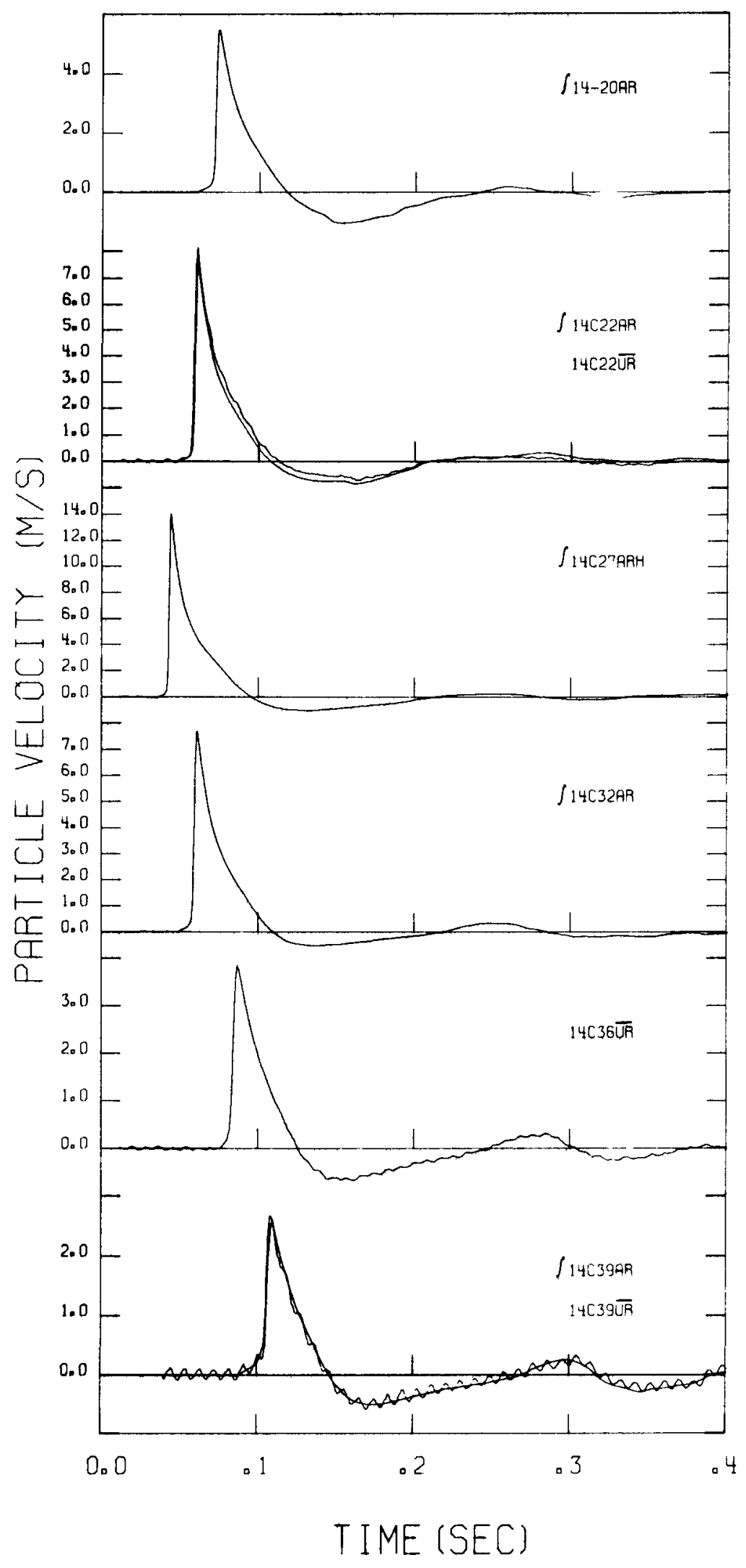

Figure 5.4. Radial particle velocity records-Borings 14 and $14 \mathrm{C}$ 


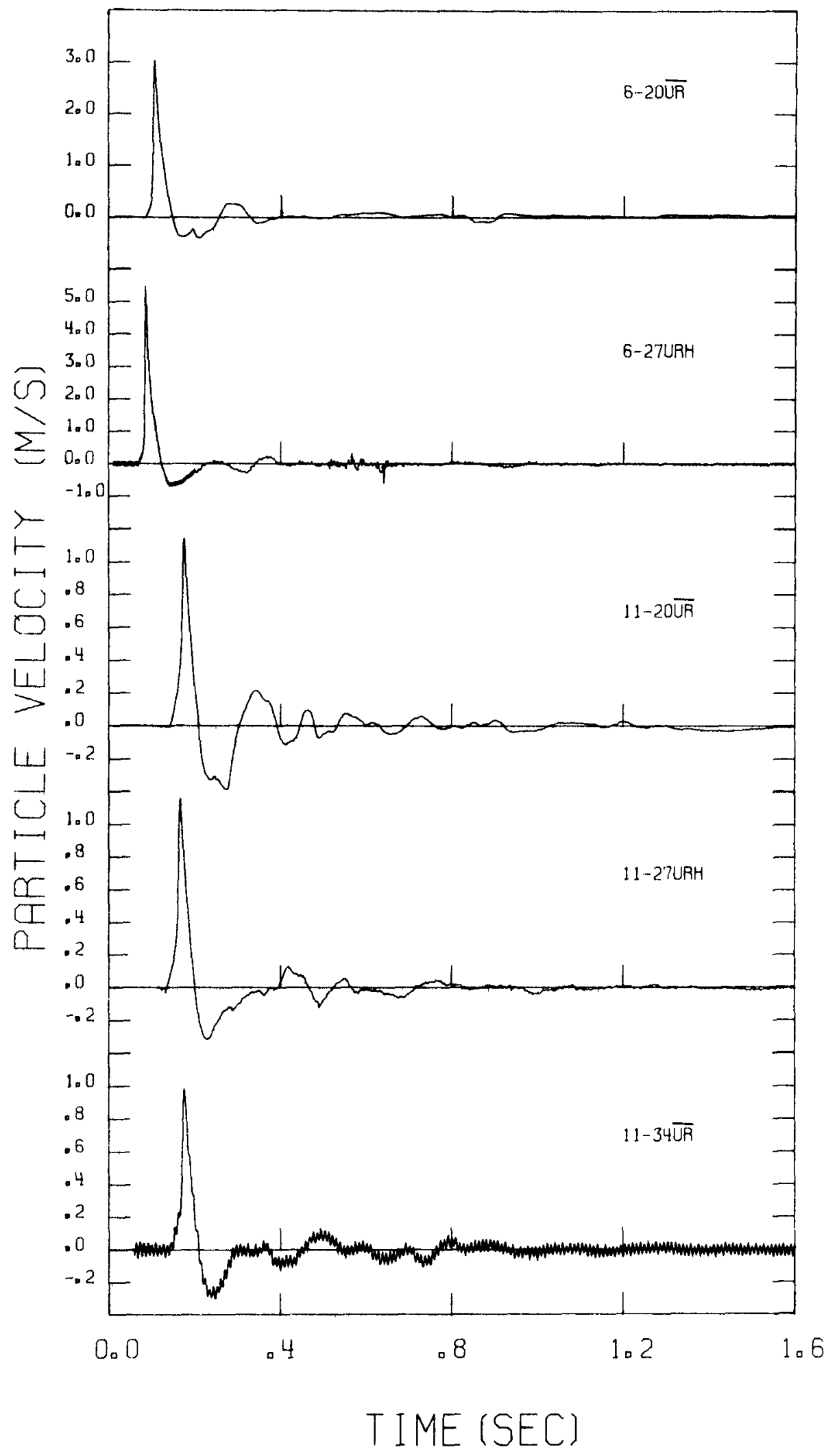

Figure 5.5. Radial particle velocity records-Borings 6 and 11 


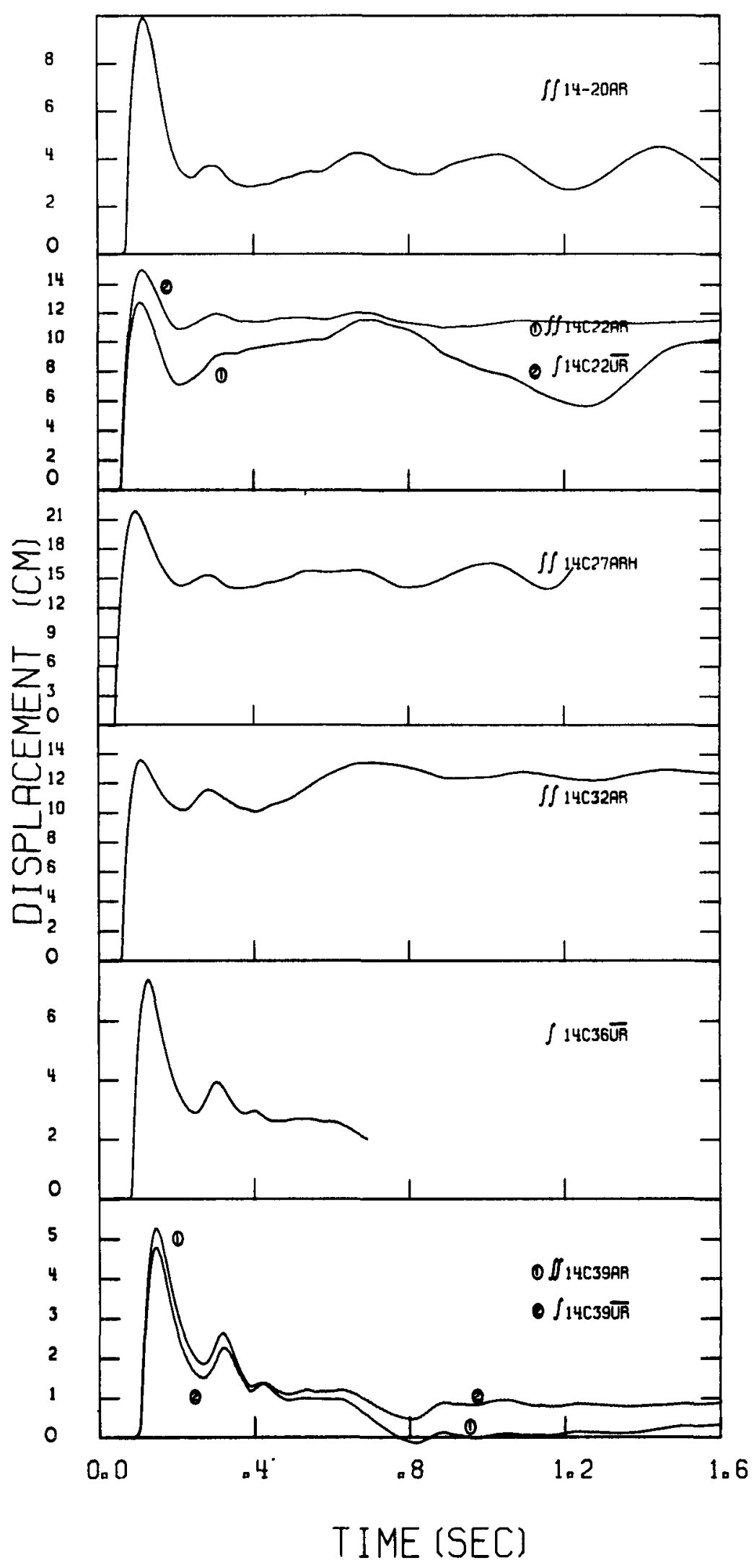

Figure 5.6. Radial displacement records-Borings 14 and $14 \mathrm{C}$ 


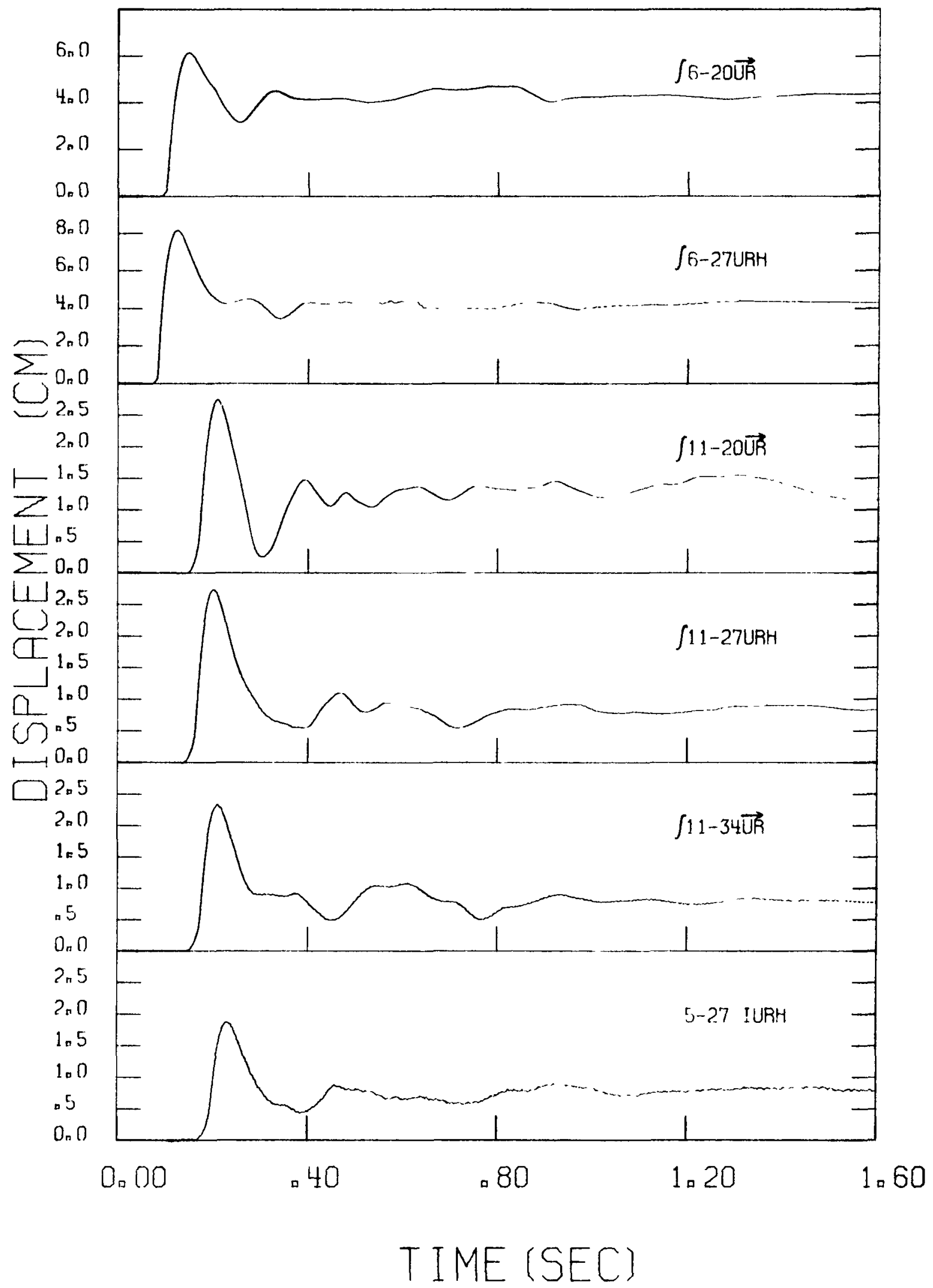

Figure 5.7. Radial displacement records-Borings 6,11 , and 5 


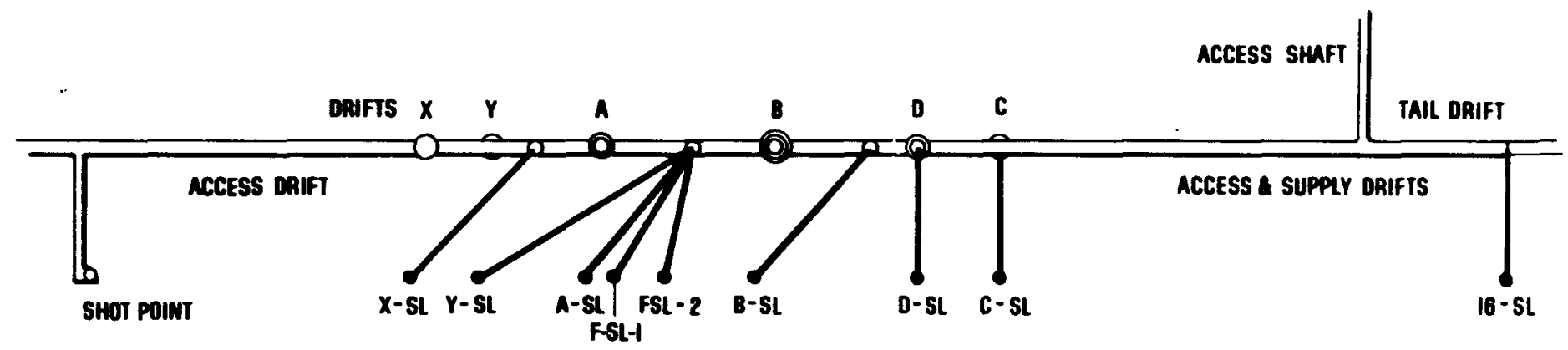

Figure 5. 8. Pile Driver free-field instrument stations 

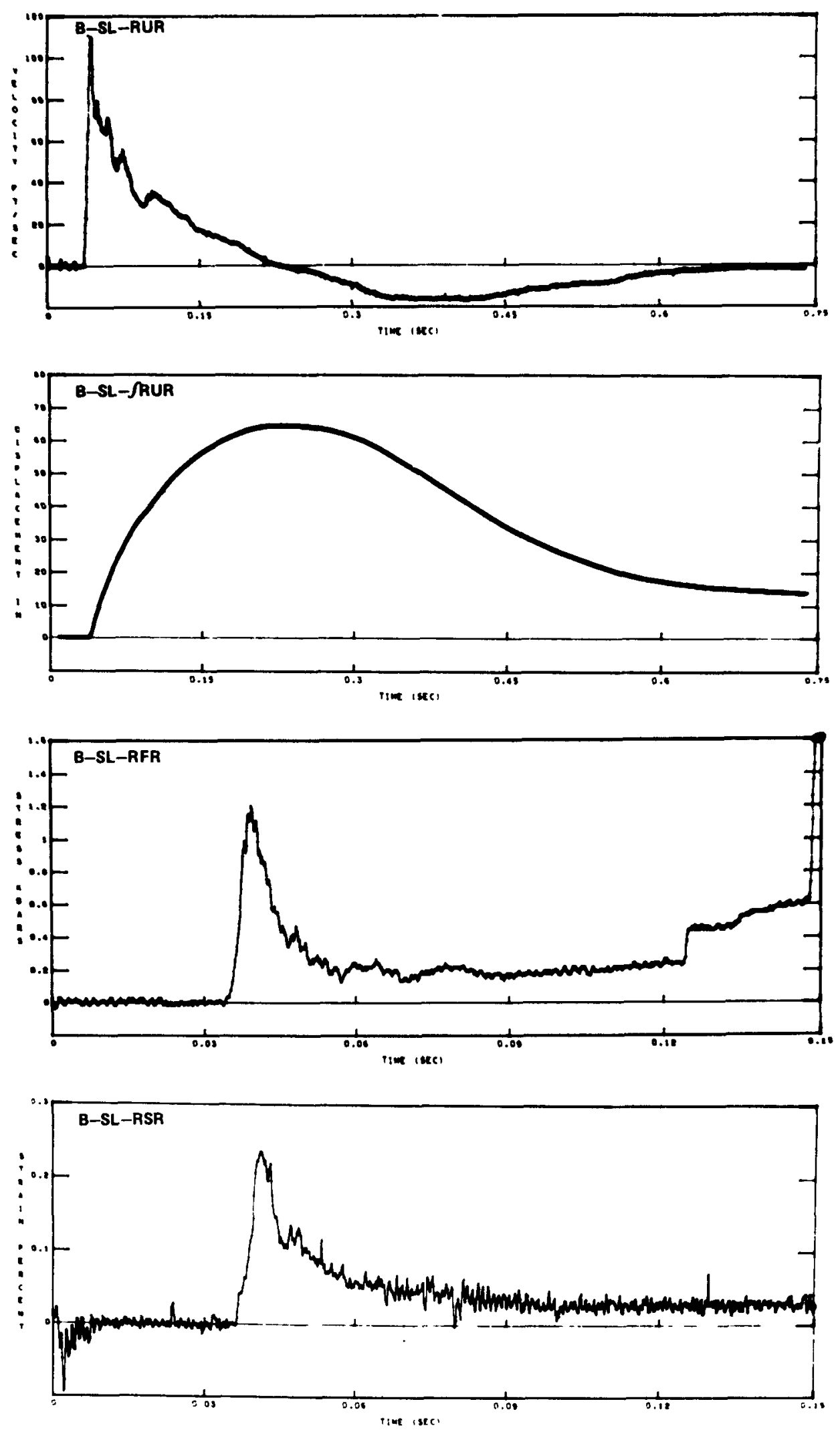

Figure 5.9. Pile Driver radial motion and stress records-Station B-SL 

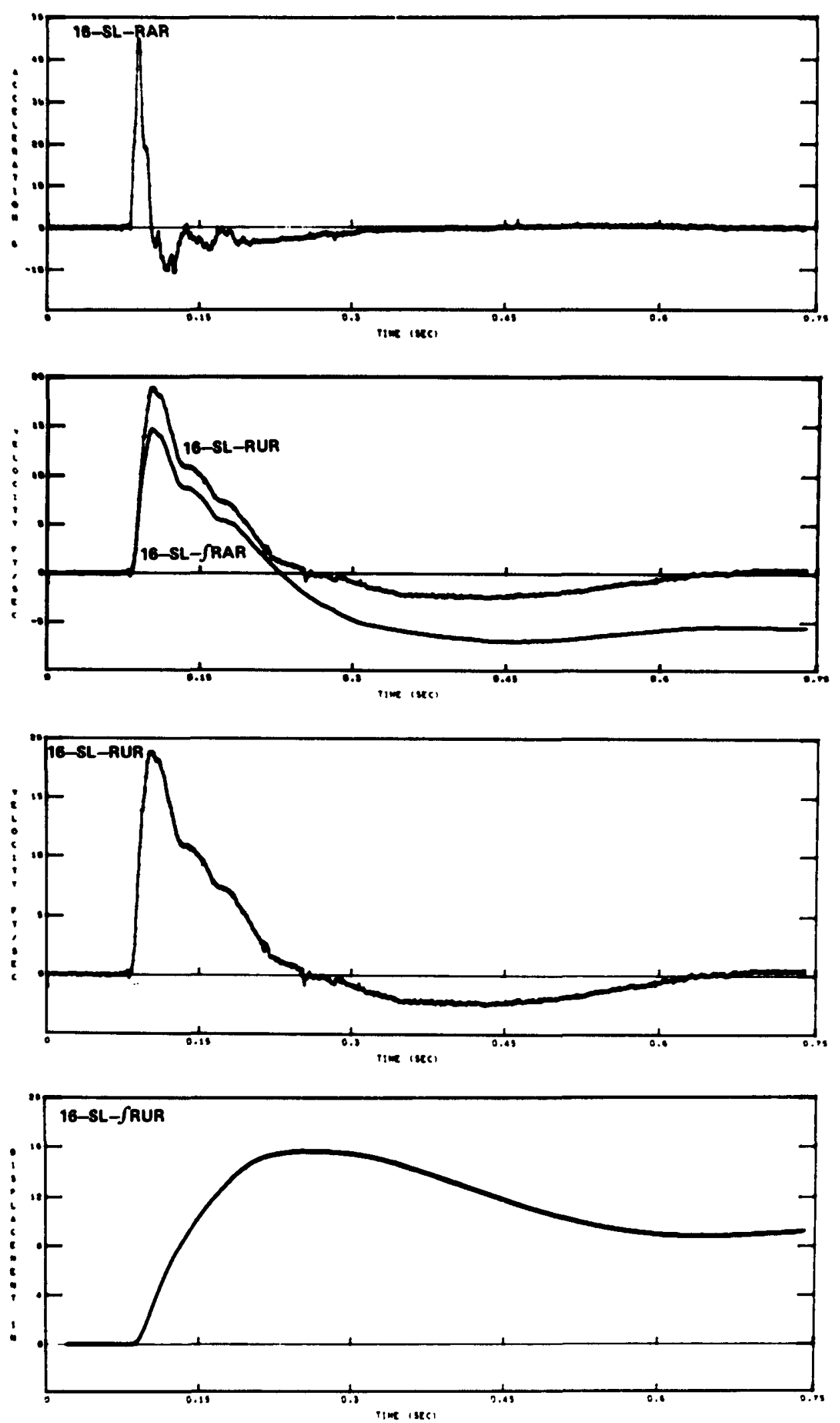

Figure 5.10. Pile Driver radial motion records-Station 16-SL 

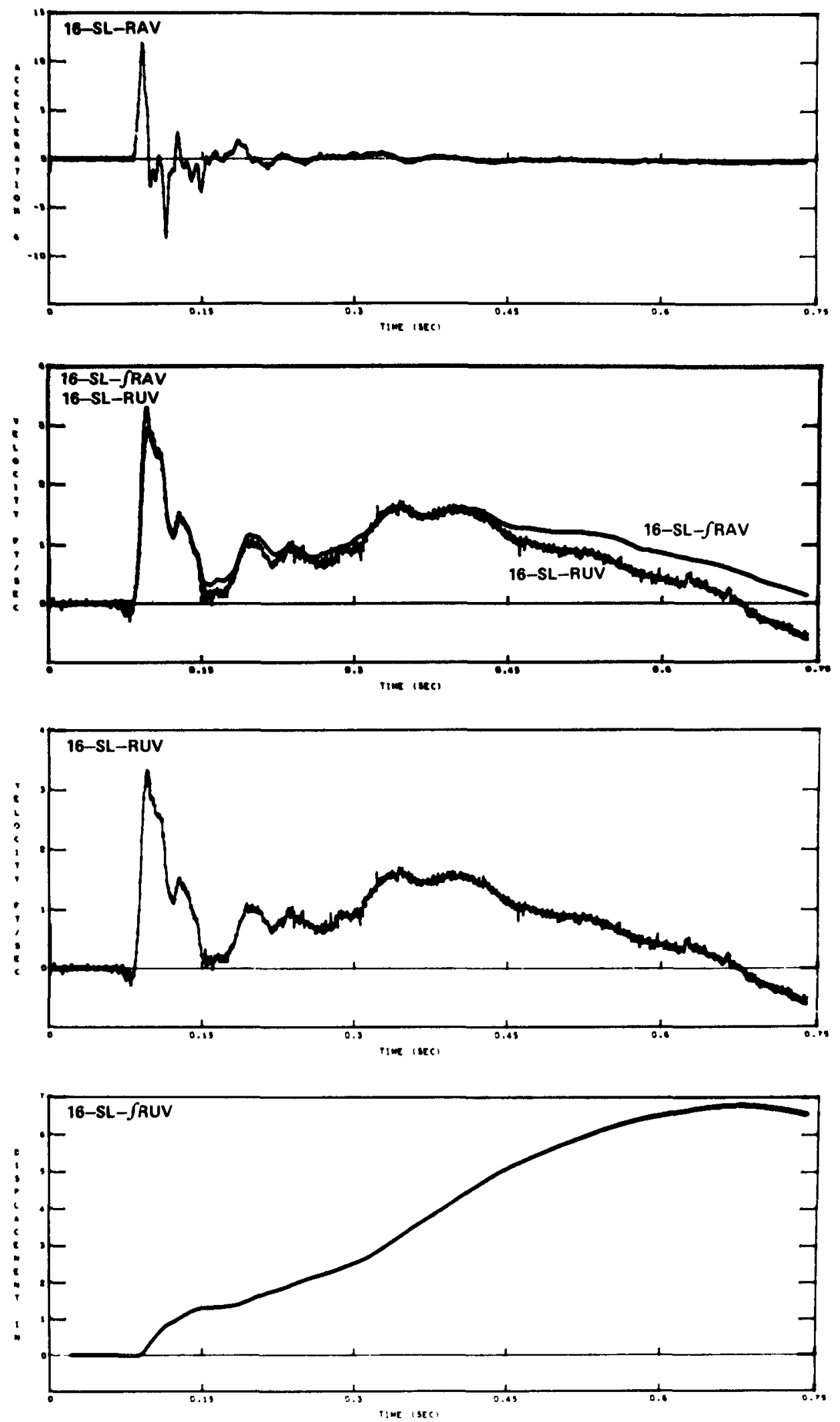

Figure 5.11. Pile Driver vertical motion records-Station 16-SL 


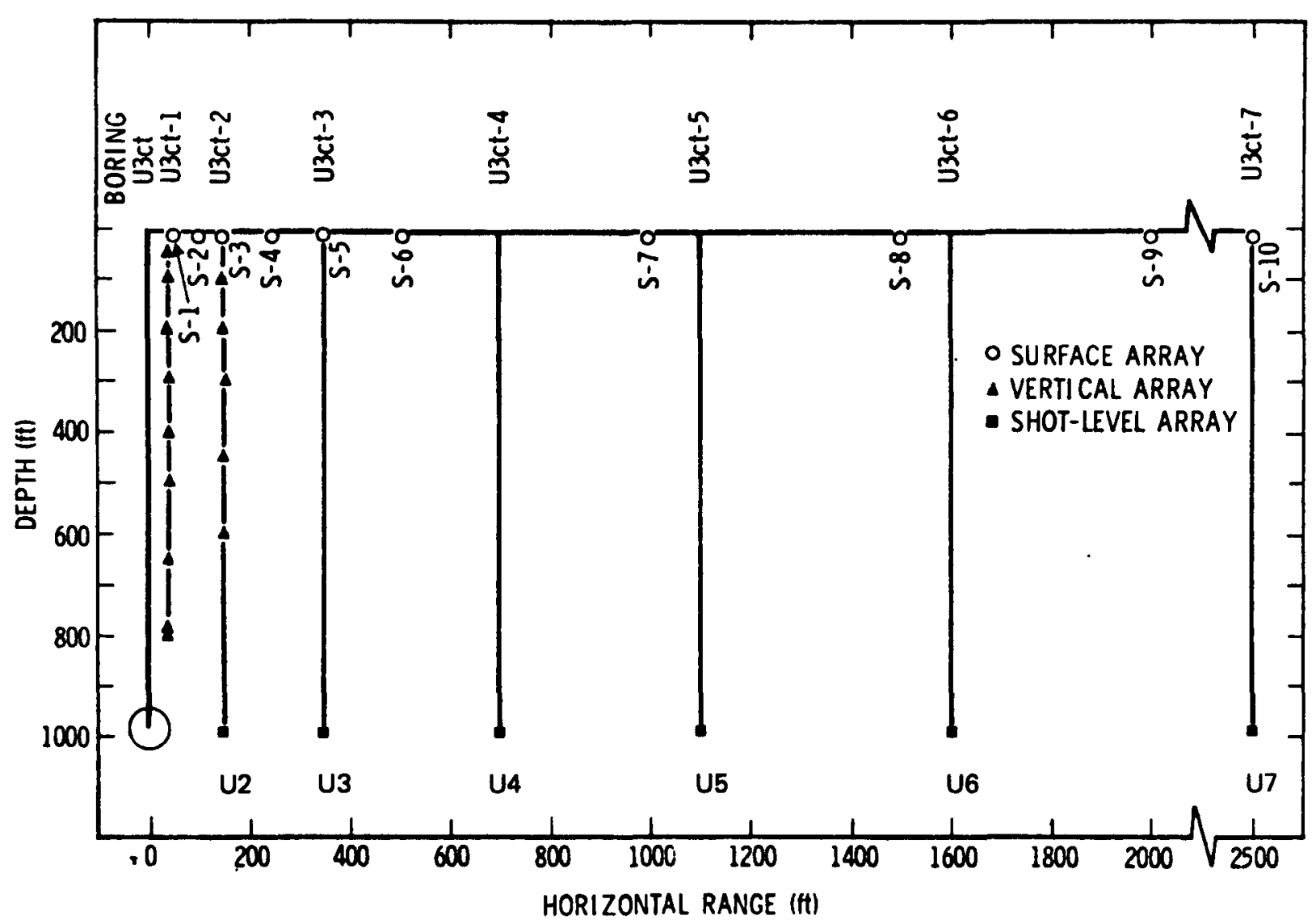

Figure 5.12. Merlin instrumentation 


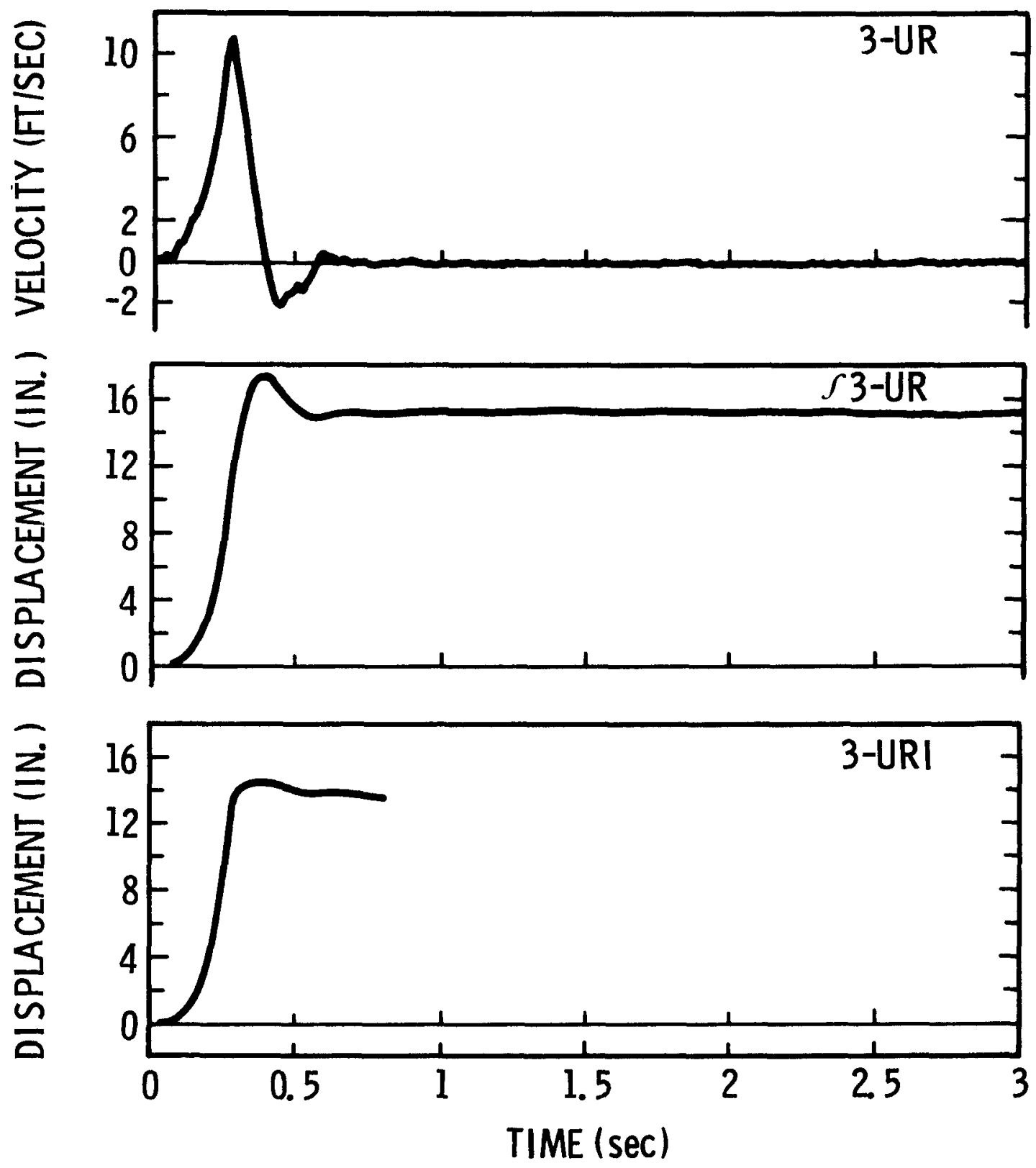

Figure 5.13. Merlin free-field ground motion, Station U3; slant range: 350 feet 

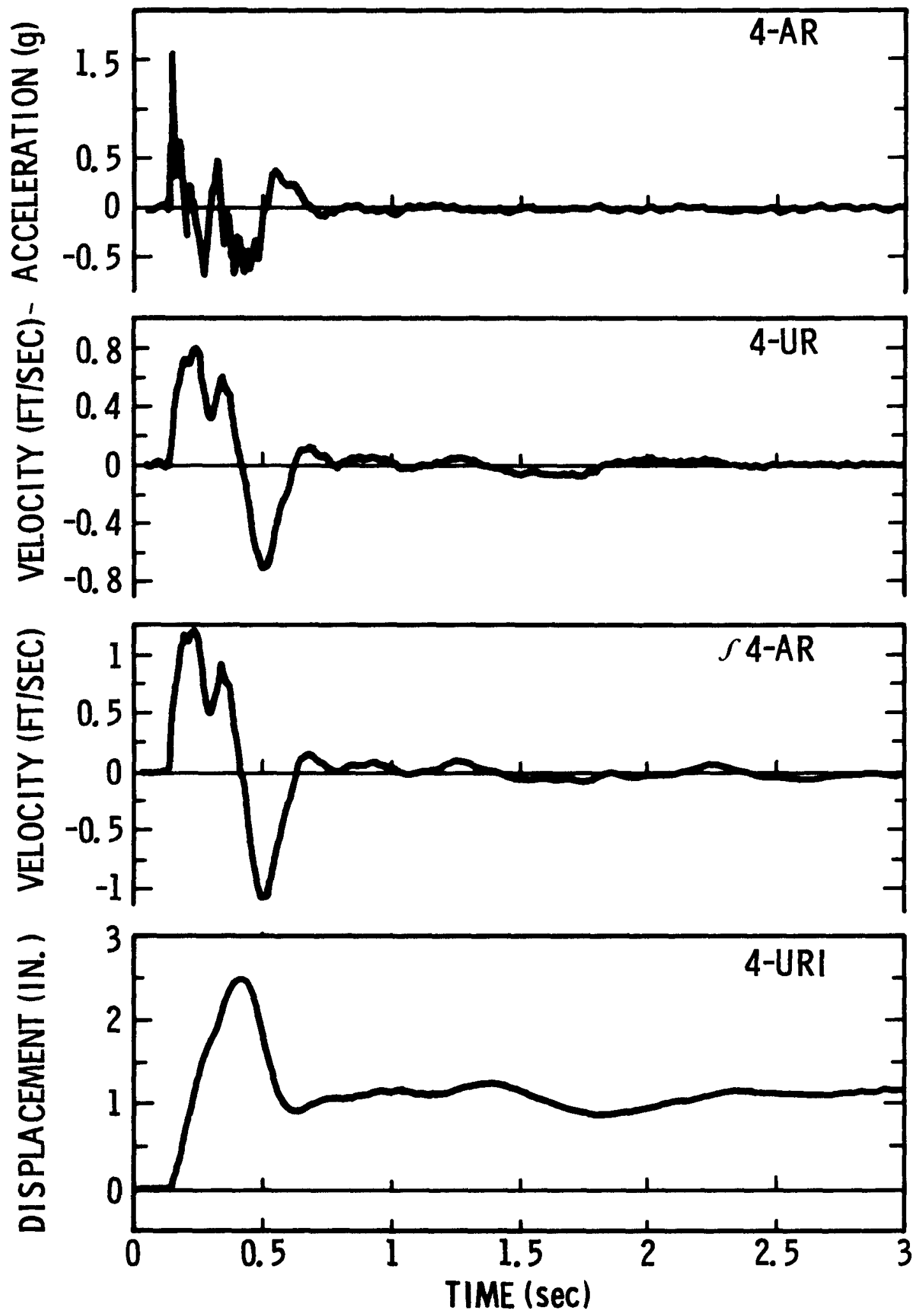

Figure 5. 14. Merlin free-field ground motion, Station U4; slant range: 700 feet 

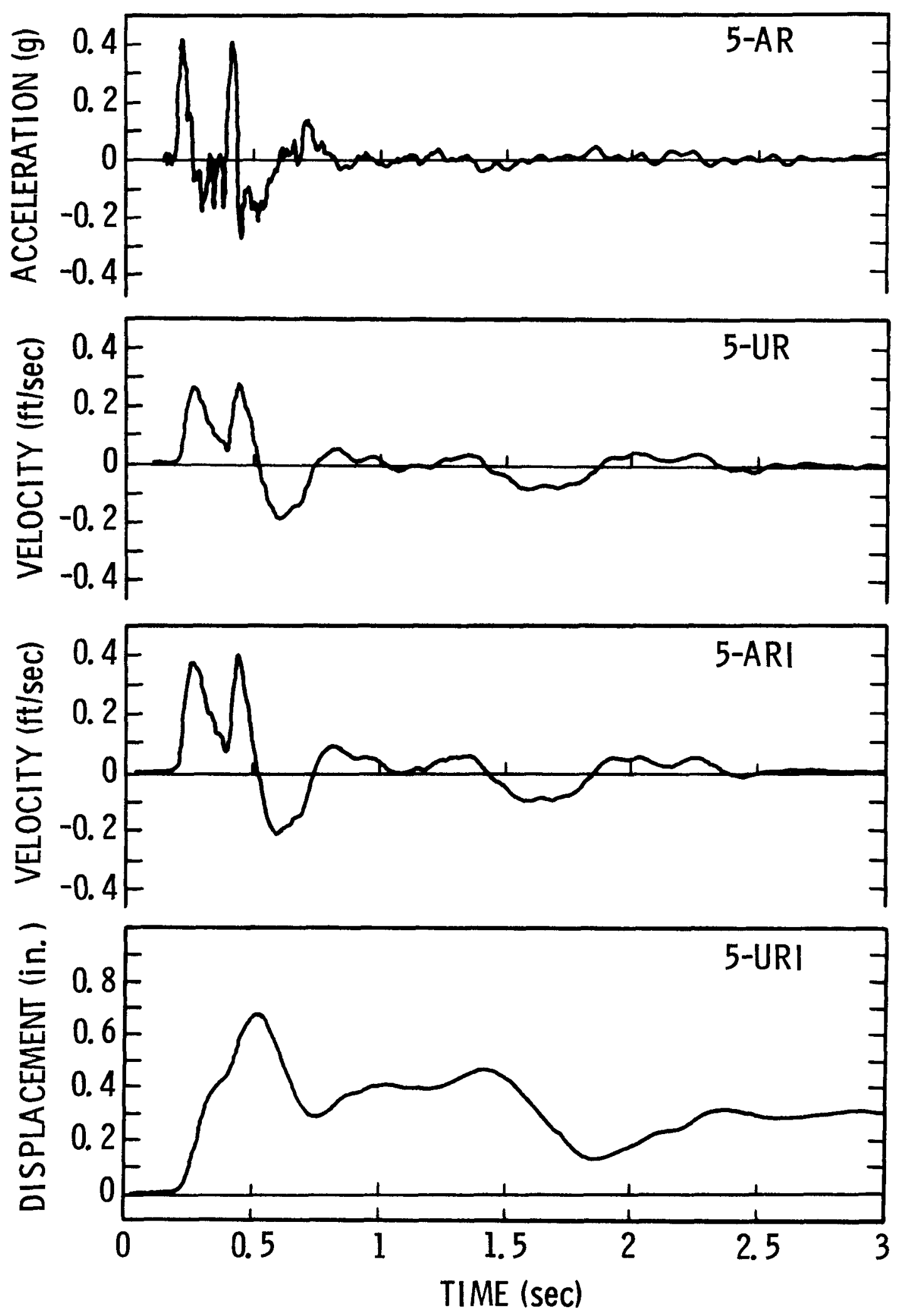

Figure 5. 15. Merlin free-field ground motion, Station U5; slant range: 1100 feet 

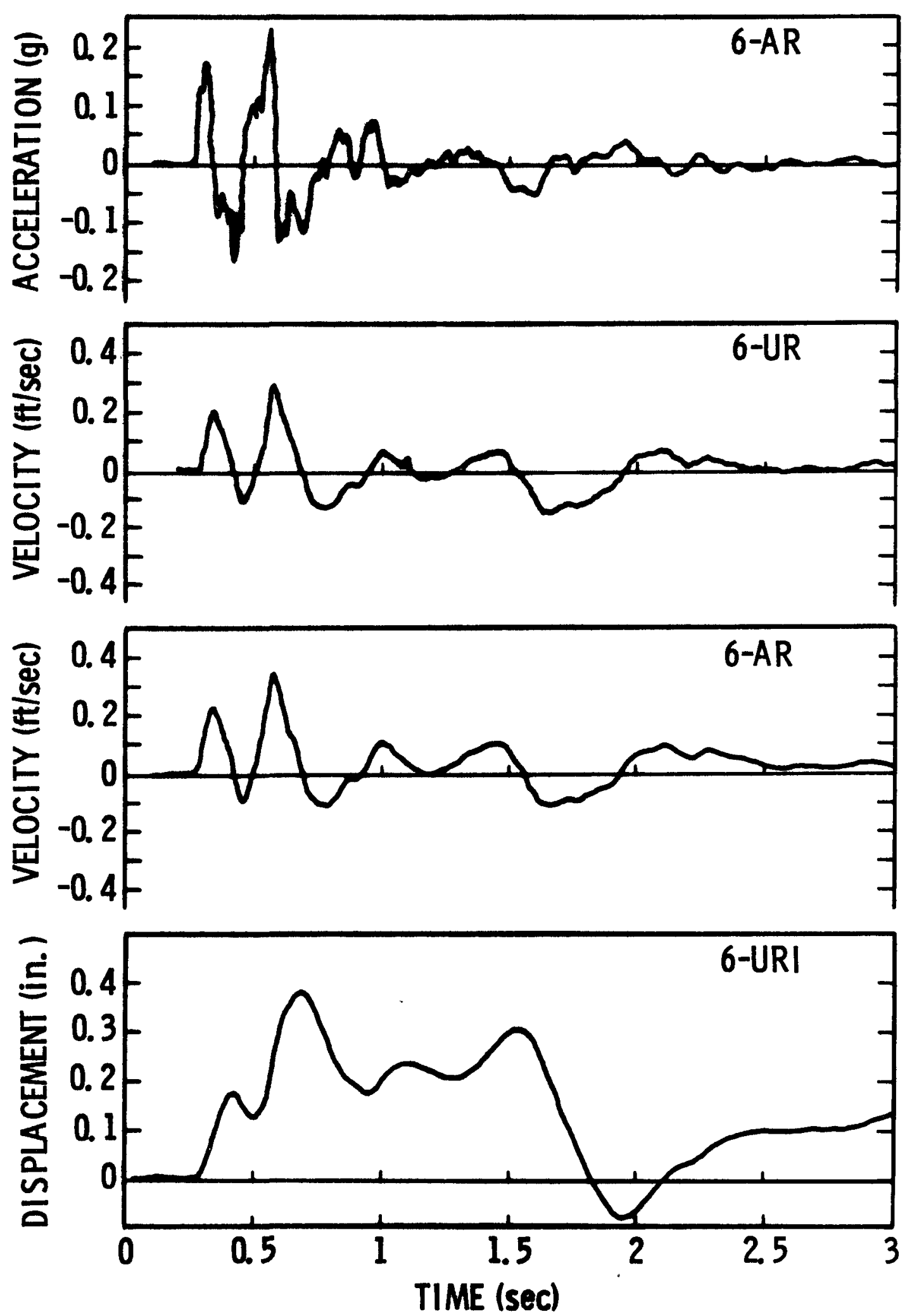

Figure 5. 16. Merlin free-field ground motion, Station U6; slant range: 1602 feet 

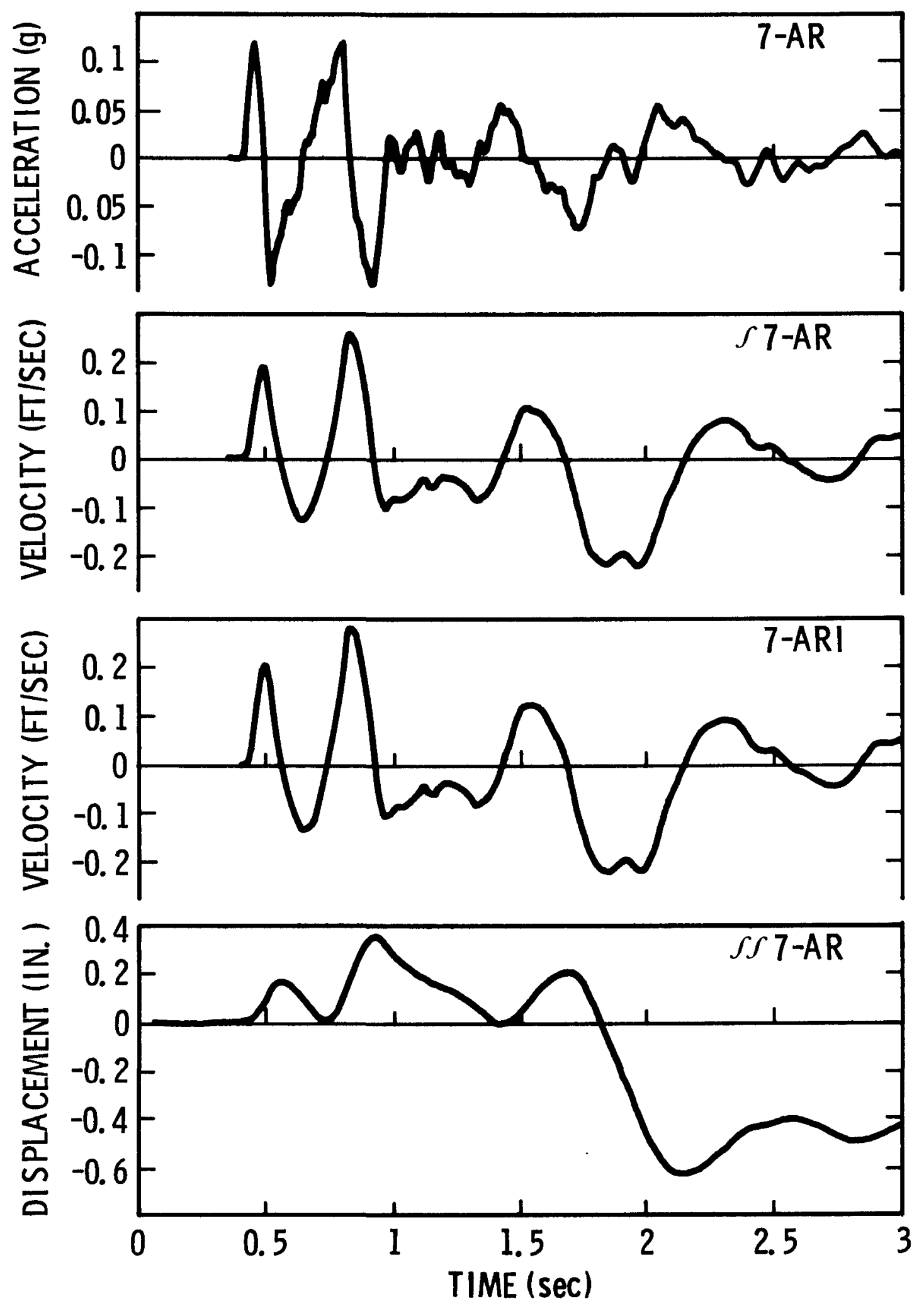

Figure 5. 17. Merlin free-field ground motion, Station U7; slant range: 2503 feet 

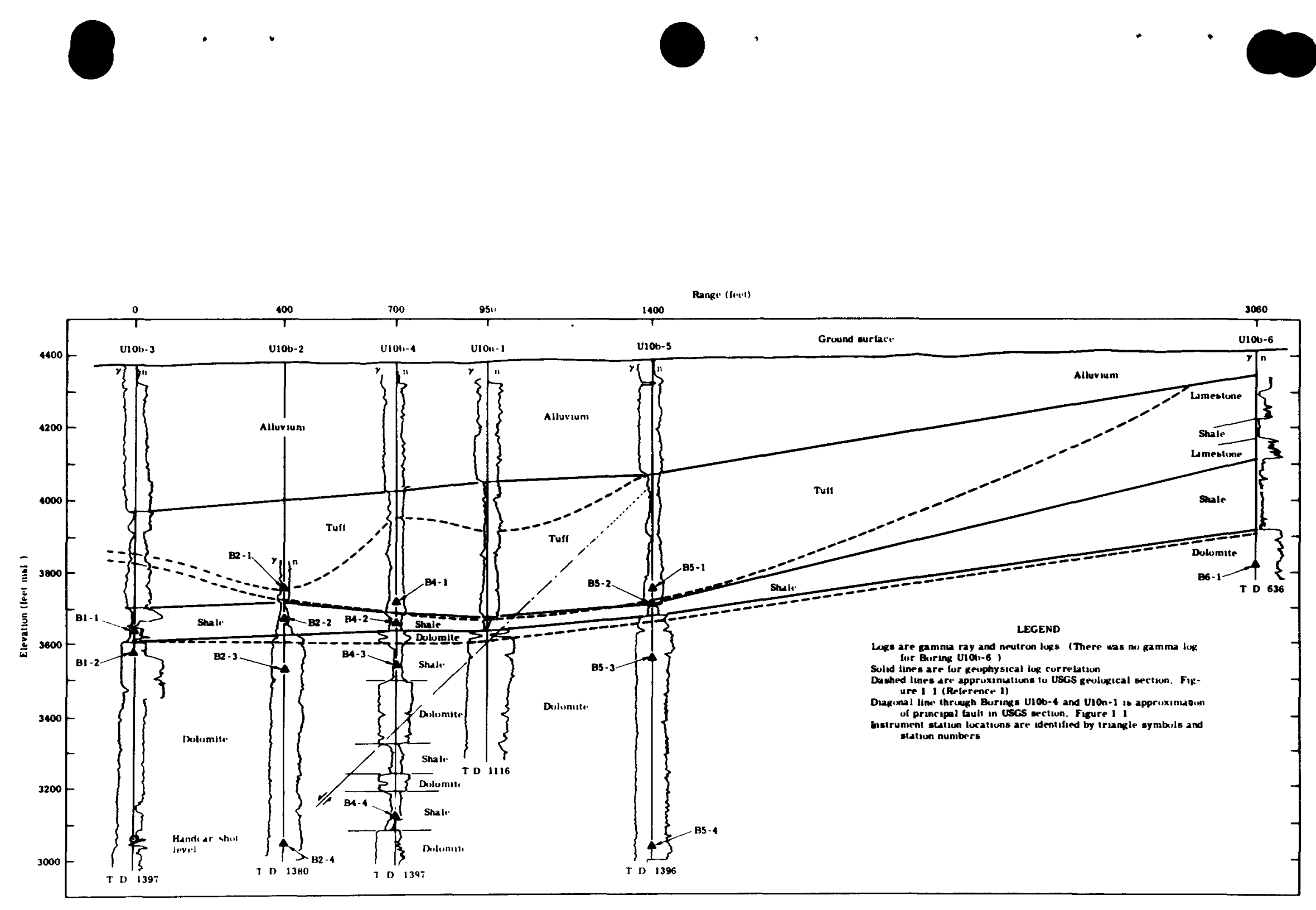

Figure 5. 18. Handcar instrumentation plan and geophysical cross section 


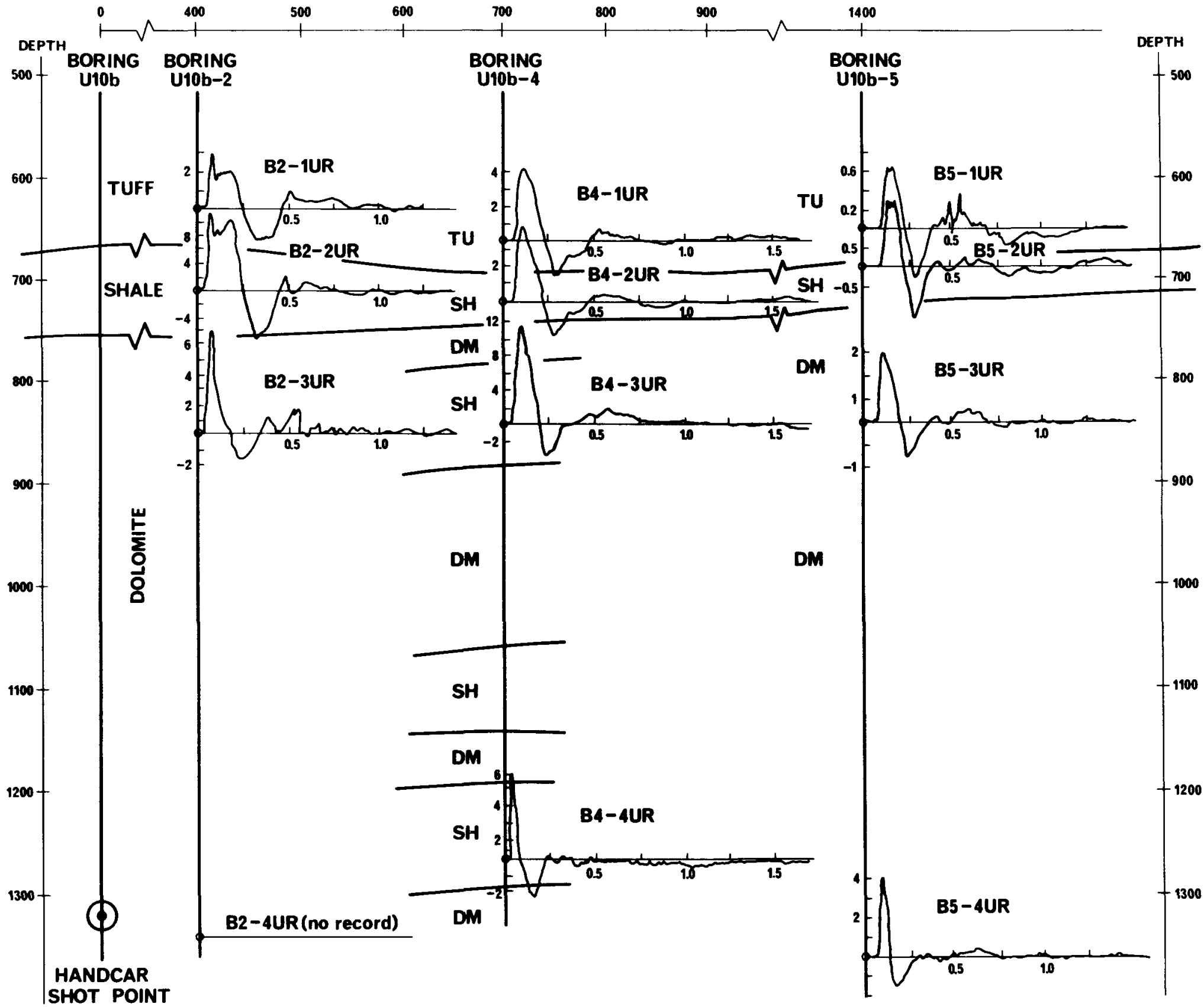

Figure 5.19. Handcar horizontal radial particle velocity records on geologic section 


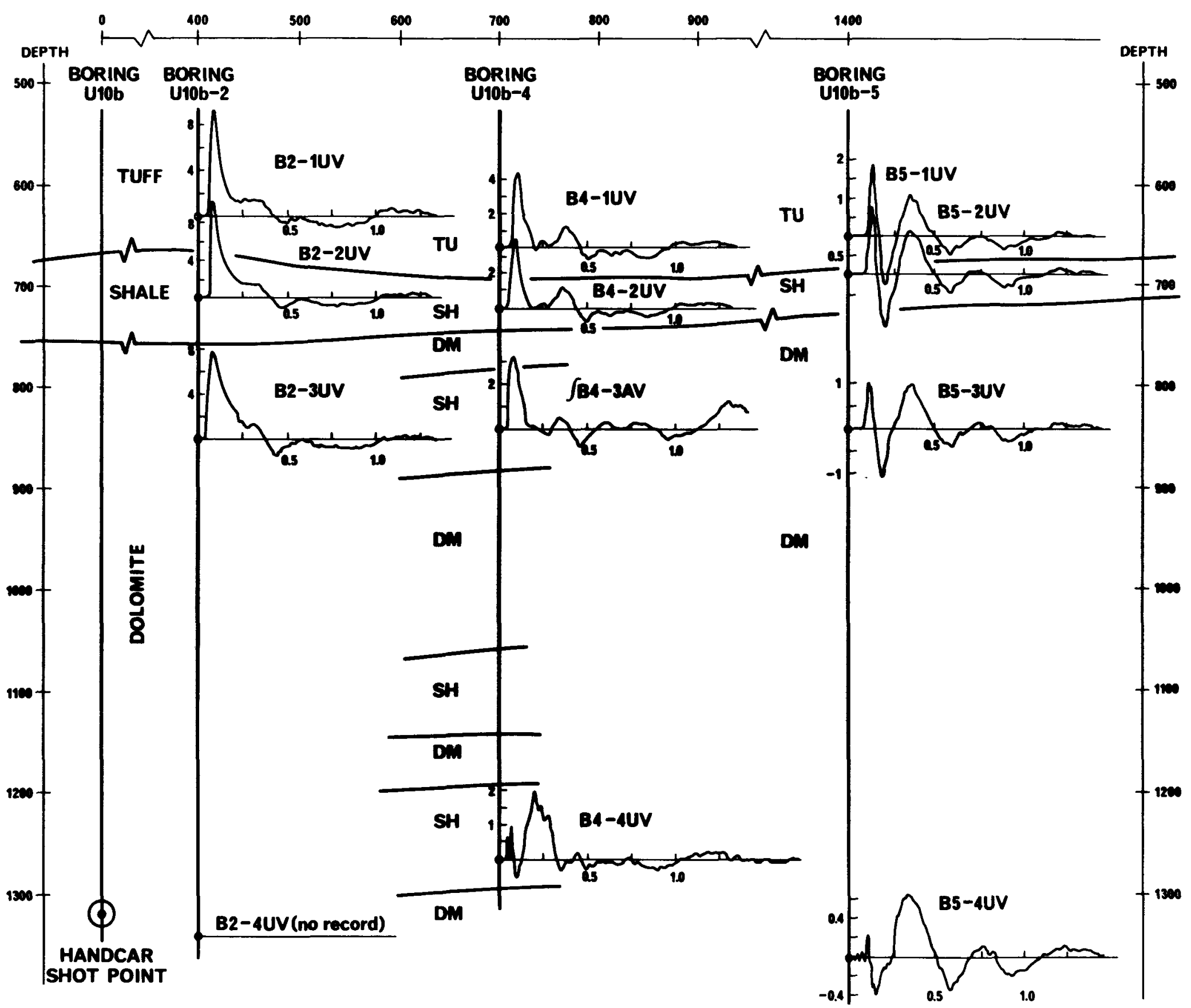

Figure 5. 20. Handcar vertical particle velocity records on geologic section 

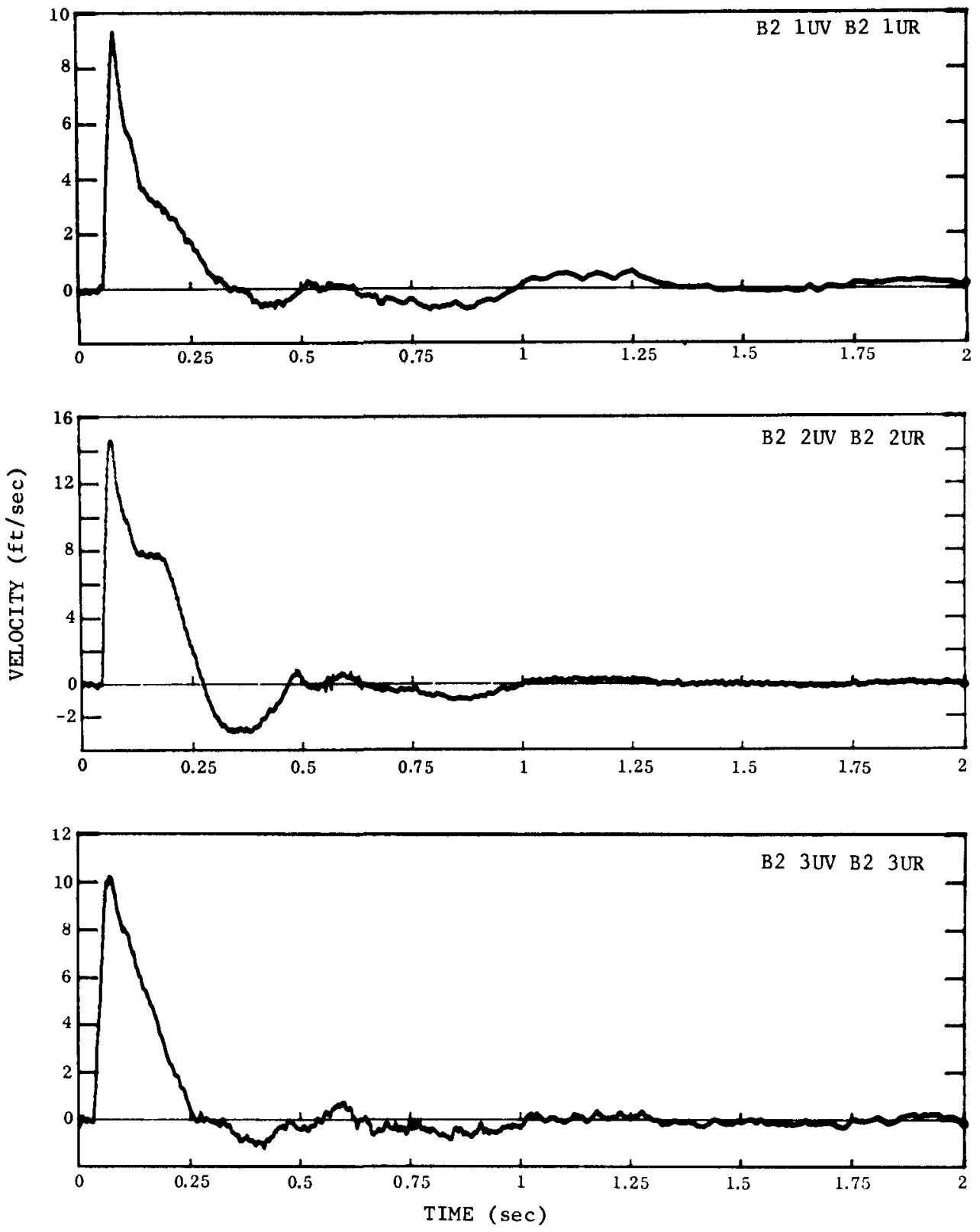

Figure 5.21. Handcar radial vector particle velocity records-Boring U10b-2 

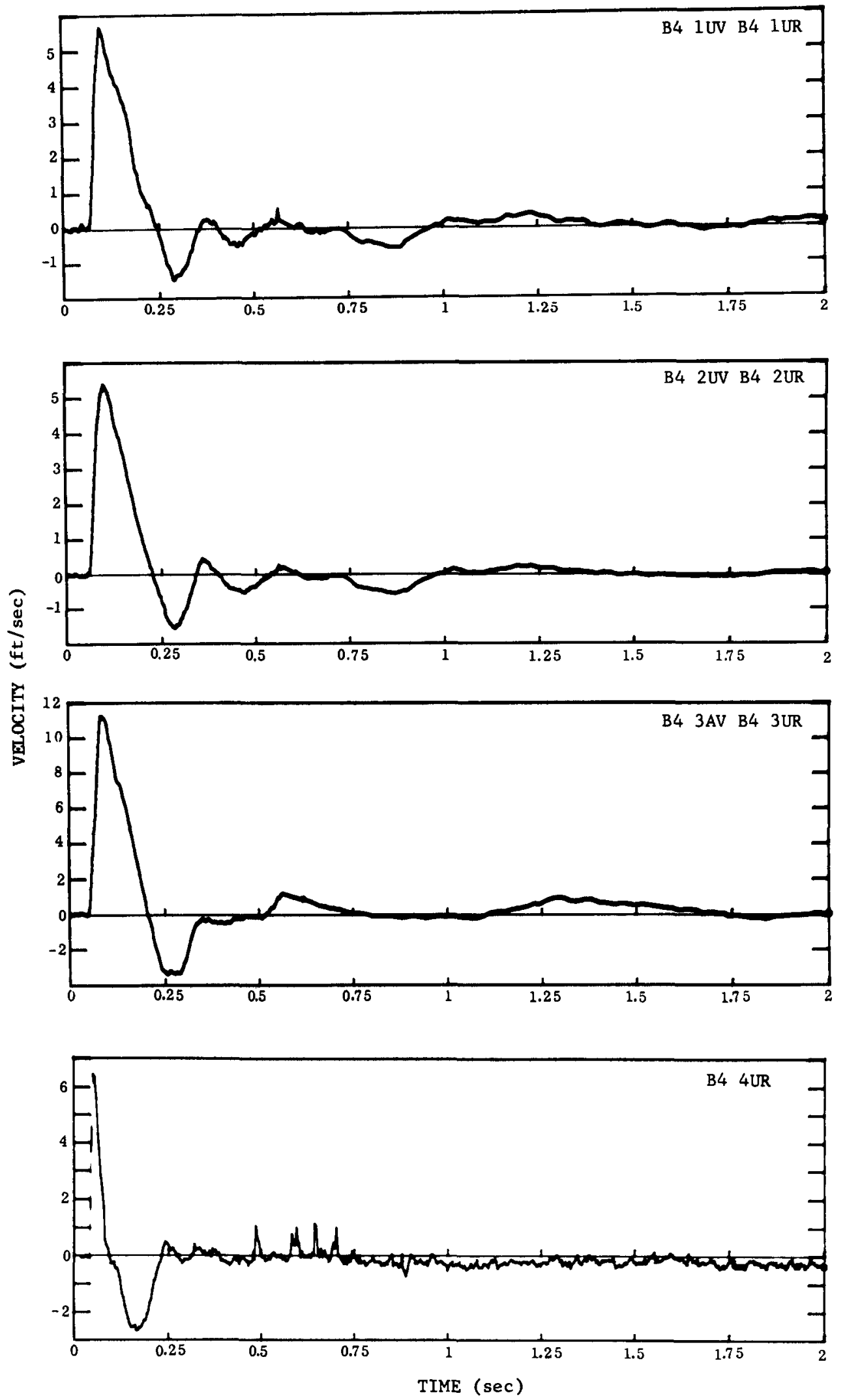

Figure 5.22. Handcar radial vector particle velocity records-Boring U10b-4 

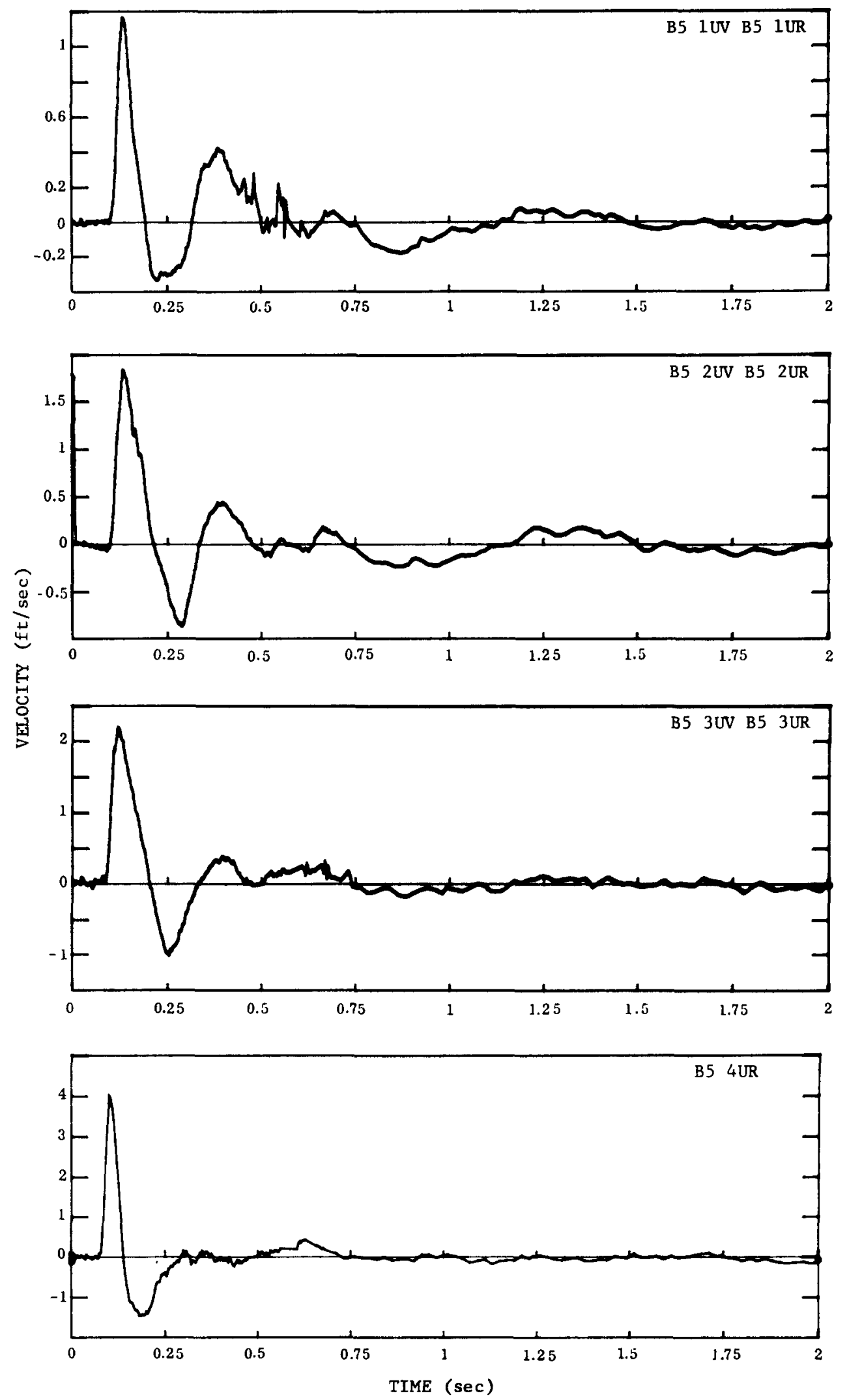

Figure 5.23. Handcar radial vector particle velocity records-Boring U10b-5 

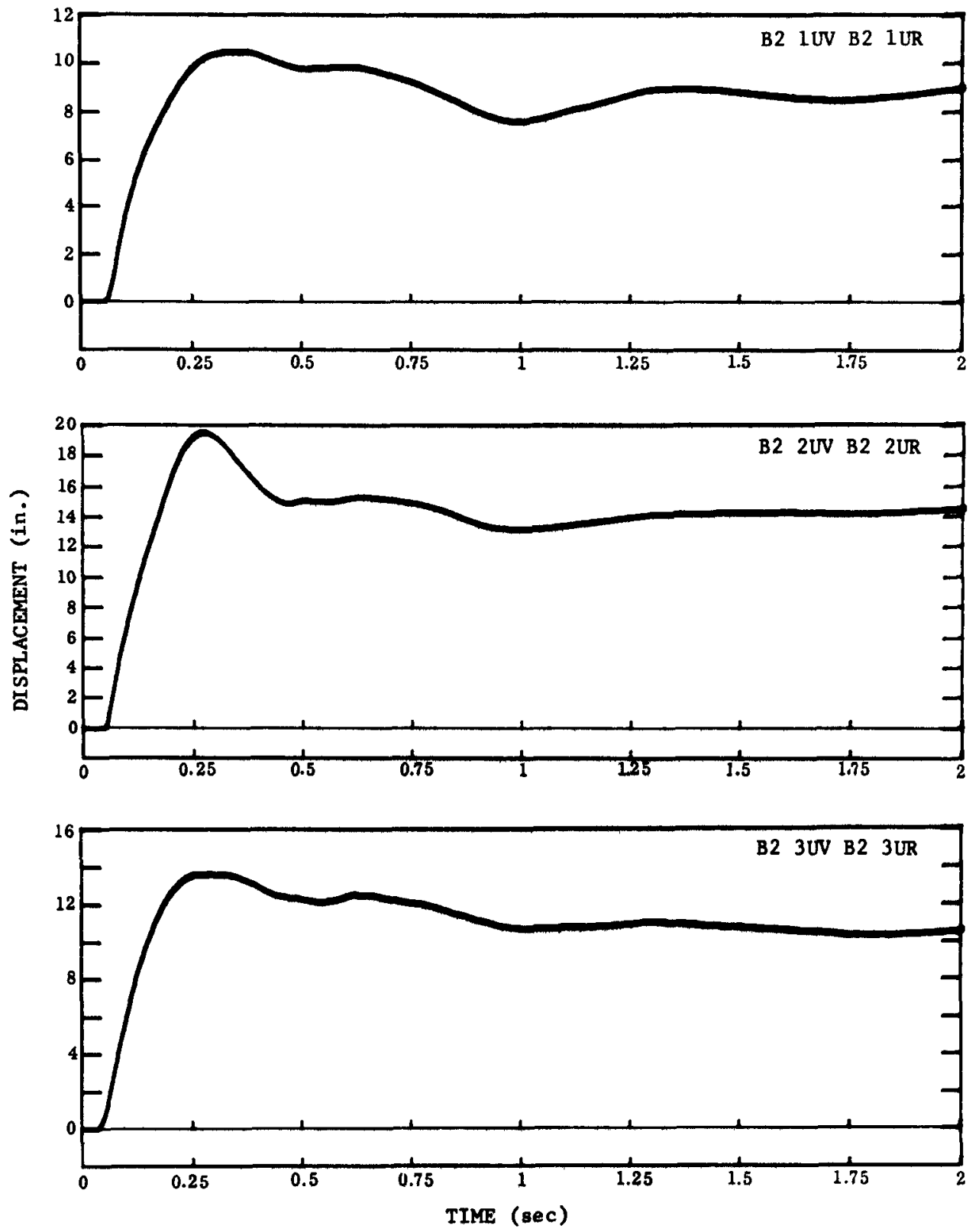

Figure 5.24. Handcar radial vector displacement-Boring U10b-2 

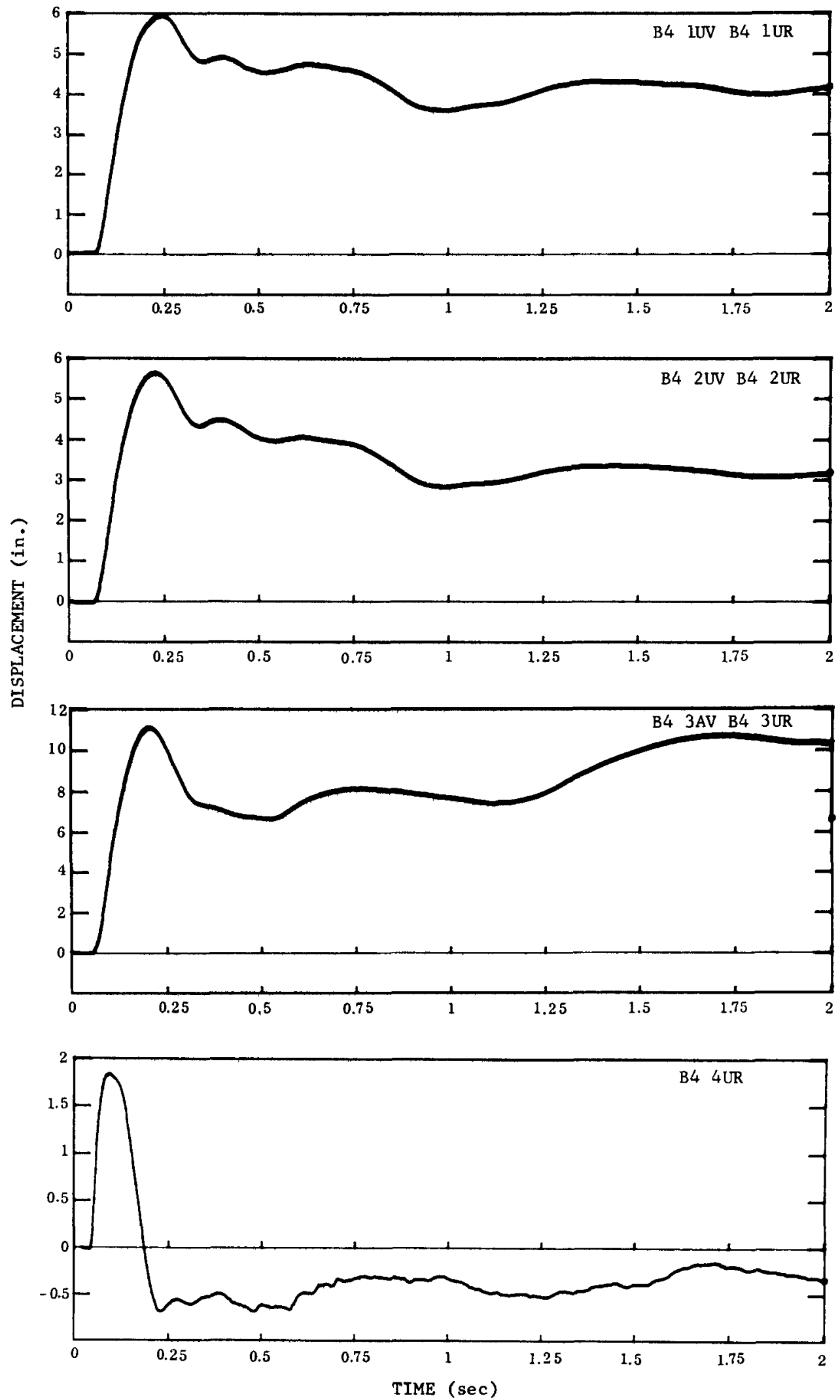

Figure 5.25. Handcar radial vector displacement-Boring U10b-4 

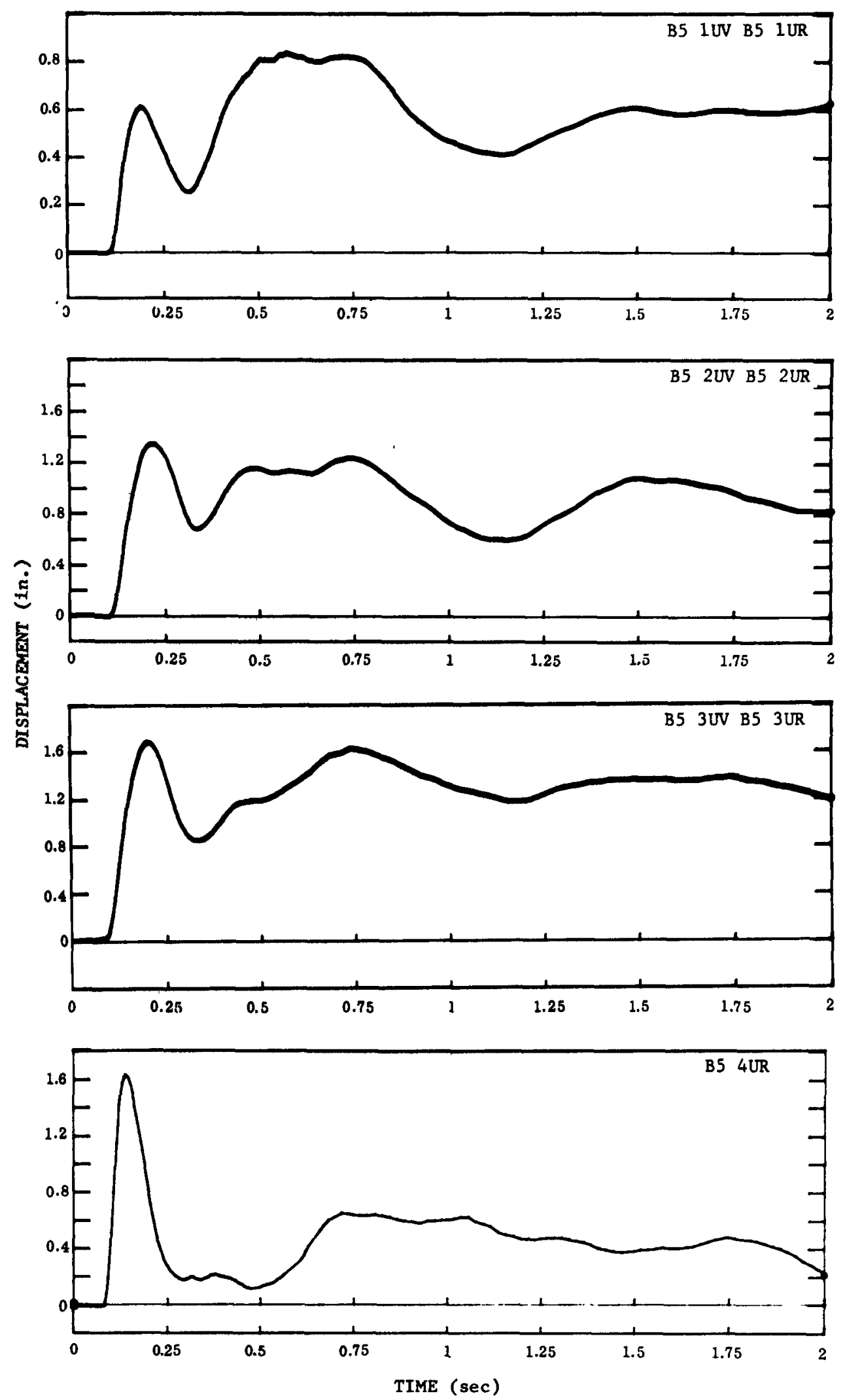

Figure 5.26. Handcar radial vector displacement-Boring U10b-5 


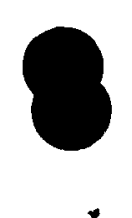


Chapter 6

SCALED DATA

The problem of direct comparison of ground motion data induced by underground explosions of widely differing energy yield requires that some form of normalization to a common explosive energy base be applied to all data. It was noted in Chapter 1 that dimensional analysis indicates that necessary and sufficient conditions for such normalization or scaling are met by use of the cube-root of actual energy yield as the scaling factor for both free-field motion parameters and distances or ranges between the measuring station and explosion. The result of such scaling, using the explosive energy, $\mathrm{W}$, in terms of equivalence to energy released by a kiloton of TNT, is that normalized acceleration is the actual acceleration multiplied by $\mathrm{W}^{1 / 3}$; stress, strain, and particle velocity are unaltered; distances, displacements, and times are divided by $\mathrm{W}^{1 / 3}$; and the results of these operations are equivalent to motion or stress produced by one kiloton equivalent energy. It is noted here that free-field conditions satisfy such scaling, but phenomena which depend upon such factors as gravity or density require considerably more sophisticated procedures for analytical comparison.

All free-field stress and motion data used in this study have been assembled in Tables 6.1 through 6.21. All tables include dimensions in both metric and american measurement systems; meters and feet are used in all cases except diaplacements where centimeters and inches apply. In general, the tables are self-explanatory. The gage numbers quoted in Tables 6.3 through 6.21 are significant only in identifying data with record traces or gage stations in referenced reports or in Chapter 5. In a few cases, apecial commenta will be referenced to a table where it seems pertinent.

The energy yields of some of the events included in these tables are classified information and might be compromised if the scaled data were associated with the event name; however, all of these events have unclassified coded yields; i.e., "L" indicates a low yield, less than $20 \mathrm{kt}$; "L-I" refers to a low-intermediate yield of between 20 and $200 \mathrm{kt}$; and " $\mathrm{I}$ " indicates an intermediate yield of between 200 and $1000 \mathrm{kt}$ ( 1 megaton). Those events for which only coded yields have been released are designated alphabetically, but not in chronological sequence, to provide a means for easier reference in discussion.

The first two tables present data from the regions of hydrodynamic and plastic response. None of these data has been identified here with a specific event. Table 6. 1 includes only data obtained from underground nuclear explosions in desert alluvium at NTS; Table 6.2 includes data from similar explosions in tuff and granite. Gage types refer to gages discussed in Chapter 2. Data from quartz, manganin, ytterbium, and ferroelectric gages represent measurements from the region of plastic response. 
Data in all remaining tables are from ground motion gages. When a report is pertinent to an event, it is referenced in the tables, and the agencies responsible for the data are indicated for each event. These agencies include Sandia Laboratories; Stanford Research Institute (SRI); Lawrence Radiation Laboratory (LRL) or, more recently, Lawrence Livermore Laboratory (LLL); Edgerton, Germeshausen, and Grier (EG\&G); Defense Nuclear Agency (DNA); Physics Interational Company (PI); and U.S. Army Engineers Waterways Experiment Station (WES). In addition to scaled ranges, accelerations, particle velocities, and displacements, scaled risetimes are noted where available. Rise time is defined here as the time interval between onset of motion and the first peak in a record. Residual displacements refer to apparent stable displacement levels in those records where such a term is definable for a period several times the transient displacement duration. Those record numbers which include the letter " $S$ " in the various tables represent data from stations on the ground surface directly above the explosion. These data obviously do not represent free-field motion; however, essentially total reflection of the stress at the free surface doubles the motion amplitude. Such"surface zero" data have been included at half-value in some of the analyses, and in general the corrected values fall within normal scatter of the actual free-field data from the same event.

The sign convention in these measurements is as follows: for vertical gages upward motion is positive, for radial gages outward motion is positive, and for tangential gages clockwise motion is positive. The standard coordinate system is cylindrical, with the vertical axis through the shot point. The exceptions to this are the radial vector measurements or vectorially derived records which correspond to a spherical corrdinate system.

For all events which have unclassified numerical yields, that yield, the shot depth, environmental rock, and type of installation is given. For those events designated alphabetically, only the location, rock type, and type of installation are given.

Table 6. 3 includes data from Scooter (Perret et al 1963), the only nonnuclear explosion included in this study. This was a cratering shot, as previously noted, and was included for comparison of both cratering versus contained and chemical versus nuclear explosion effects. Tables $6.3,6.4$, and 6.5 include all events detonated in alluvium which have been included in this study.

Tables 6.6, 6.7, and 6.8 include data from all events detonated in dry tuff. Note that for Event $N$ several values of peak acceleration carry the prefix for "greater than" as an indication that the record peak indicated system saturation and in general that no true peak appears on the record, as indicated by the uncertainty in the scaled risetime and absence of velocity data from those gages.

In Tables 6.11 and 6.12, certain of the measurements from Commodore and Events D, F, and $G$ were obtained from the same gage stations in one particular boring, U2Z-1; these stations at depths of $1100 \mathrm{ft}(335 \mathrm{~m}), 1400 \mathrm{ft}(427 \mathrm{~m}), 2200 \mathrm{ft}(670 \mathrm{~m}), 2600 \mathrm{ft}(792 \mathrm{~m})$, and $3400 \mathrm{ft}(1036 \mathrm{~m})$ 
were in various types of rock, as indicated by the foot notes to these tables. It is also noteworthy that the deepest station, Z34, was probably not securely bonded to the carbonate rock although direct evidence of this fact is lacking.

A similar situation holds for Calabash, Carpetbag, and Event I in Table 6. 12 where similarly positioned stations in Borings U2Z-2 and U2Z-3 were used for several events. Depths to these stations were $1400 \mathrm{ft}(427 \mathrm{~m}), 1800 \mathrm{ft}(549 \mathrm{~m}), 2000 \mathrm{ft}(610 \mathrm{~m})$, and $2400 \mathrm{ft}(732 \mathrm{~m})$, with similar identification of the rock surrounding each station.

Data presented in Tables 6.14,6.15, and 6.16 were derived from nuclear explosions in granite and in dolomite. All three events in granite occurred in tunnel complexes. The explosive for the dolomite event (Handcar) was, as noted in Chapter 5, emplaced in a deep boring and the ground motion stations were positioned at various depths in instrument borings in different types of rock, as indicated by superscripts and the footnote to Table 6.15.

The Aleutian Island of Amchitka was the locale of the three events included in Tables 6.17 and 6.18. These events were all detonated in volcanic rocks, and all free-field motion gage stations were along approximately vertical radii, i. e., in vertical arrays offset a short distance from the shot hole. For the Milrow (Perret, Breding 1972) and Cannikin (Perret 1973) events, station numbers include the approximate distance above the explosion in hundreds of feet, except that the uppermost stations for Cannikin were somewhat deeper as a consequence of a change in shot depth. For both events, the uppermost 2 or 3 stations produced records seriously perturbed by the surface reflection and were omitted from the analysis.

Data in Table 6.19 represent two events in very different hardrock environments. The Gasbuggy (Perret 1970a) stations were in a single boring offset about $460 \mathrm{~m}$ from the shot hole. These stations were at nominal depths of $3200 \mathrm{ft}(975 \mathrm{~m}), 3600 \mathrm{ft}(1097 \mathrm{~m}), 4100 \mathrm{ft}(1250 \mathrm{~m})$, and $4600 \mathrm{ft}(1402 \mathrm{~m})$ in the several rocks noted in the foot note. The two free-field stations associated with the Boxcar event in Pahute Mesa at NTS were in deep borings approximately at shot level and offset laterally, about $8000 \mathrm{ft}(2438 \mathrm{~m})$ and $24,000 \mathrm{ft}(7315 \mathrm{~m})$, from the Boxcar shot hole.

Finally, the data in Tables 6.20 and 6.21 were obtained from the two nuclear detonations in salt: Gnome in a tunnel complex in horizontally bedded salt and Salmon in a salt dome. 
TABLE 6. 1 Scaled Free-Field Ground Motion and Pressure

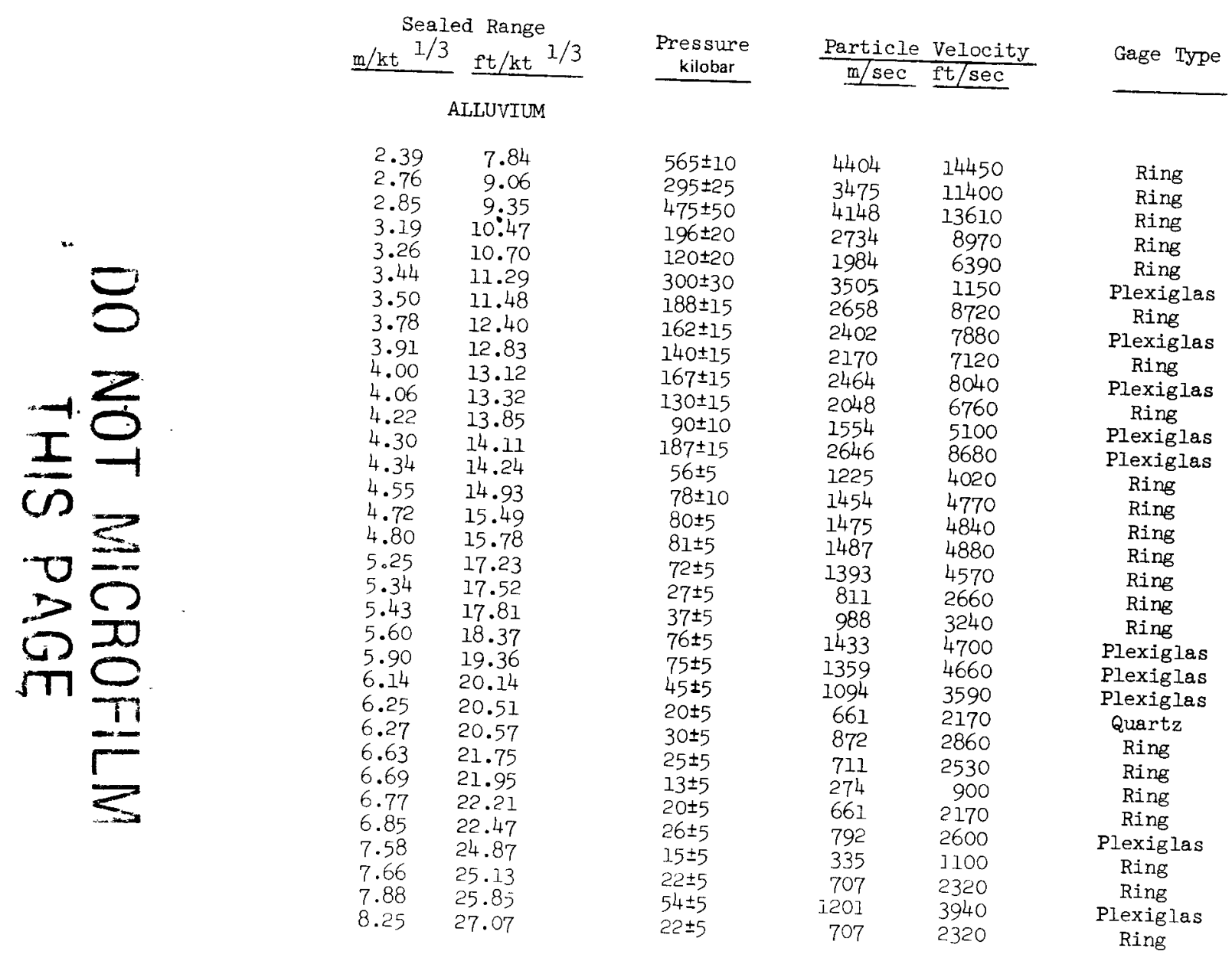


TABLE 6.1 Scaled Free-Field Ground Motion and Pressure

\begin{tabular}{|c|c|c|c|c|c|}
\hline $\begin{array}{r}\text { Sea } \\
\mathrm{m} / \mathrm{kt} \quad \mathrm{I} / \\
\end{array}$ & $\begin{array}{l}\text { Range } \\
\mathrm{ft} / \mathrm{kt} 1 / 3\end{array}$ & $\begin{array}{c}\text { Pressure } \\
\quad \text { kilobar } \\
\end{array}$ & $\frac{\text { Particle }}{\underline{m} / \mathrm{sec}}$ & $\frac{\text { Velocity }}{\text { ft/sec }}$ & Gage Type \\
\hline & LLUVIUM & & & & \\
\hline 2.39 & 7.84 & $565 \pm 10$ & 4404 & 14450 & Ring \\
\hline 2.76 & 9.06 & $295 \pm 25$ & 3475 & 11400 & Ring \\
\hline 2.85 & 9.35 & $475 \pm 50$ & 4148 & 13610 & Ring \\
\hline 3.19 & 10.47 & $196 \pm 20$ & 2734 & 8970 & Ring \\
\hline 3.26 & 10.70 & $120 \pm 20$ & 1948 & 6390 & Ring \\
\hline 3.44 & 11.29 & $300 \pm 30$ & 3505 & 11500 & Plexiglas \\
\hline 3.50 & 21.48 & $188 \pm 15$ & 2658 & 8720 & Ring \\
\hline 3.78 & 12.40 & $162 \pm 15$ & 2402 & 7880 & Plexiglas \\
\hline 3.91 & 12.83 & $140 \pm 15$ & 2170 & 7120 & Ring \\
\hline 4.00 & 13.12 & $167 \pm 15$ & 2451 & 8040 & Plexiglas \\
\hline 4.06 & 13.32 & $130 \pm 15$ & 2060 & 6760 & Ring \\
\hline 4.22 & 13.85 & $90 \pm 10$ & 1554 & 5100 & Plexiglas \\
\hline 4.30 & 14.11 & $187 \pm 15$ & 2646 & 8680 & Plexiglas \\
\hline 4.34 & 14.24 & $56 \pm 5$ & 1225 & 4020 & Ring \\
\hline 4.55 & 14.93 & $78 \pm 10$ & 1454 & 4770 & Ring \\
\hline 4.72 & 15.49 & $80 \pm 5$ & 1475 & 4840 & Ring \\
\hline 4.80 & 15.78 & $81 \pm 5$ & 1487 & 4880 & Ring \\
\hline 5.25 & 17.23 & $72 \pm 5$ & 1393 & 4570 & Ring \\
\hline 5.34 & 17.52 & $27 \pm 5$ & 811 & 2660 & Ring \\
\hline 5.43 & 17.81 & $37 \pm 5$ & 988 & 3240 & Ring \\
\hline 5.60 & 18.37 & $76 \pm 5$ & 1433 & 4700 & Plexiglas \\
\hline 5.90 & 19.36 & $75 \pm 5$ & 1420 & 4660 & Plexiglas \\
\hline 6.14 & 20.14 & $45 \pm 5$ & 1094 & 3590 & Plexiglas \\
\hline 6.25 & 20.51 & $20 \pm 5$ & 661 & 2170 & Quartz \\
\hline 6.27 & 20.57 & $30 \pm 5$ & 872 & 2860 & Ring \\
\hline 6.63 & 21.75 & $25 \pm 5$ & 771 & 2530 & Ring \\
\hline 6.69 & 21.95 & $13 \pm 5$ & 274 & 900 & Ring \\
\hline 6.77 & 22.21 & $20 \pm 5$ & 661 & 2170 & Ring \\
\hline 6.85 & 22.47 & $26 \pm 5$ & 792 & 2600 & Plexiglas \\
\hline 7.58 & 24.87 & $15 \pm 5$ & 335 & 1100 & Ring \\
\hline 7.66 & 25.13 & $22 \pm 5$ & 707 & 2320 & Ring \\
\hline 7.88 & 25.85 & $54 \pm 5$ & 1201. & 3940 & Plexiglas \\
\hline 8.25 & 27.07 & $22 \pm 5$ & 707 & 2320 & Ring \\
\hline
\end{tabular}


$=8$

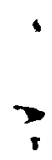


TABLE 6.2 Scaled Free-Field Ground Motion and Pressure

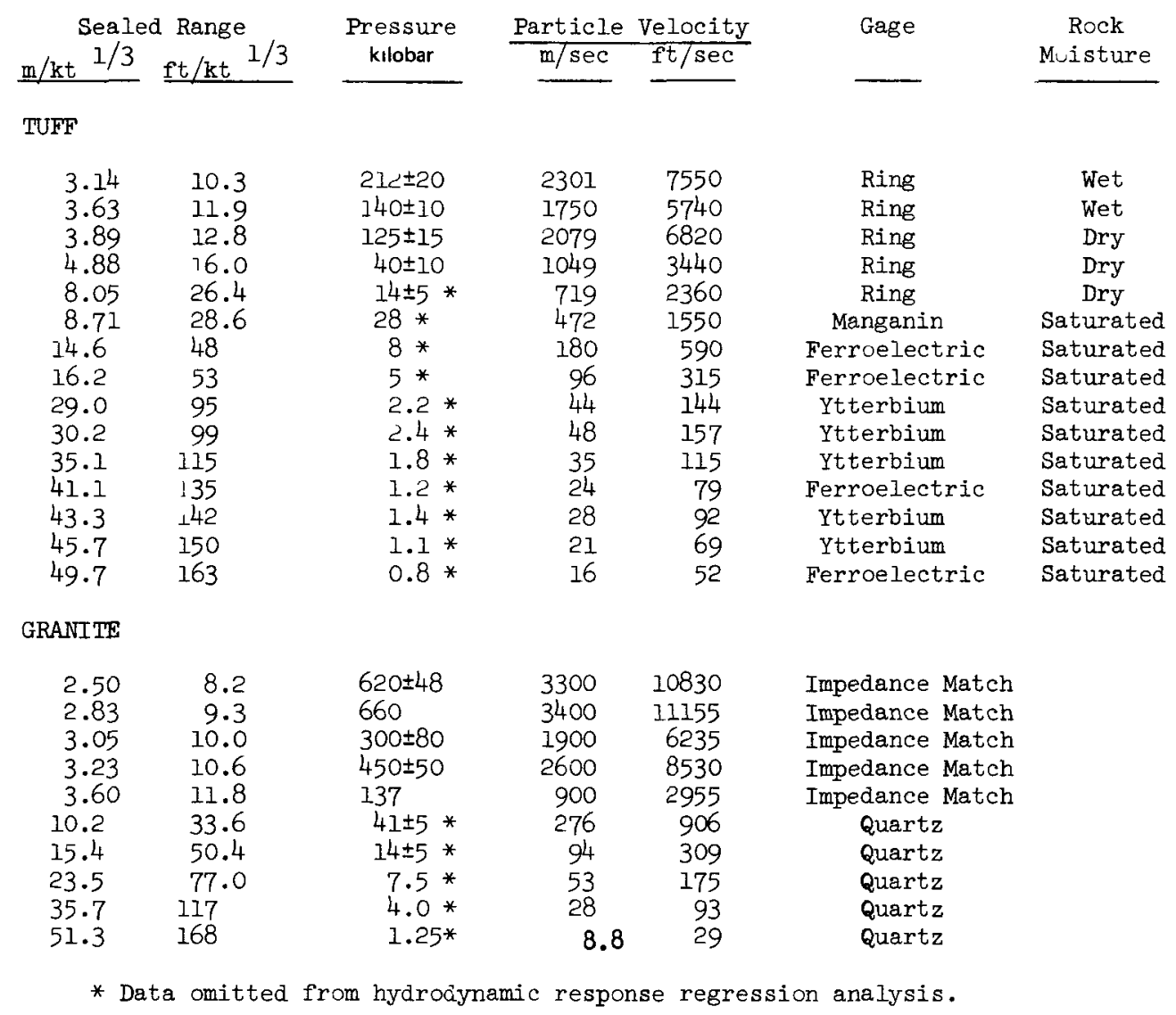


TABLE 6. 3 Scaled Free-Field Ground Motion--Alluvium

\begin{tabular}{|c|c|c|c|c|c|c|c|c|c|c|c|c|}
\hline \multirow{2}{*}{$\begin{array}{l}\text { Record } \\
\text { Number }\end{array}$} & \multicolumn{2}{|c|}{ Scaled } & \multicolumn{2}{|c|}{ Scaled Acceleration } & \multicolumn{3}{|c|}{ Particle Velocity } & \multicolumn{5}{|c|}{ Scaled Displa cement } \\
\hline & $\mathrm{m} / \mathrm{kt} \mathrm{Slant}_{\mathrm{l} / 3}$ & $\begin{array}{l}\text { Range } \\
\mathrm{ft} / \mathrm{kt} 1 / 3\end{array}$ & $\begin{array}{c}\text { Peak } \\
\text { g.kt } 1 / 3 \\
\end{array}$ & $\begin{array}{c}\text { Risetime } \\
\mathrm{sec} / \mathrm{kt} \mathrm{I}^{1 / 3} \\
\end{array}$ & \multicolumn{2}{|c|}{ Peak } & $\begin{array}{c}\text { Risetime } \\
\mathrm{sec} / \mathrm{kt} \quad 1 / 3\end{array}$ & Peak & in/kt $1 / 3$ & Risetime & $\begin{array}{ll}\begin{array}{l}\text { Resid } \\
\mathrm{cm} / \mathrm{kt}\end{array} & 1 / 3 \\
\end{array}$ & in/kt $1 / 3$ \\
\hline & SCOOTER: & $\begin{array}{l}0.5 \mathrm{kt} \text { TNT. } 38 \mathrm{ml} \\
\text { Sandia (Perret et al }\end{array}$ & $5 \mathrm{ft})$ deep in Area & IO NTS ALLUVIUM & -Boring & & & & & & & \\
\hline \multirow{10}{*}{$\begin{array}{c}\text { Shot leve } \\
\text { A-50 } \\
\text { A-100 } \\
\text { A-150 } \\
\text { HV-150 } \\
\text { A-200 } \\
\text { HV-200 } \\
\text { A-300 } \\
\text { HV-300 }\end{array}$} & I array & & & & & & & & & & & \\
\hline & 19.2 & 63 & 14437 & 0.0029 & $>360$ & $>1200$ & 0.0049 & -- & -- & -- & -- & -- \\
\hline & 38.4 & 126 & 390 & 0.0365 & 16.2 & 53 & 0.0403 & $>134$ & $>53$ & -- & -- & -- \\
\hline & 57.6 & 189 & 21.5 & 0.0189 & 5.85 & 19.2 & 0.1084 & 69.4 & 27.3 & 0.2659 & +48.0 & +18.9 \\
\hline & & & & -- & 6.98 & 22.9 & 0.1096 & 90.2 & 35.5 & 0.3213 & +70.4 & +27.7 \\
\hline & 76.8 & 252 & 3.91 & 0.0214 & 2.61 & 8.55 & 0.1474 & 37.4 & 14.7 & 0.2923 & +0.960 & $\begin{array}{l}+0.378 \\
+\end{array}$ \\
\hline & & & -- & -- & 2.51 & 8.24 & 0.1474 & 38.7 & 15.2 & 0.3125 & +3.20 & +1.26 \\
\hline & 115 & 378 & 0.63 & 0.0428 & 0.77 & 2.53 & 0.2003 & 13.7 & 5.39 & 0.3452 & +12.2 & +4.79 \\
\hline & & & -- & -- & 1.05 & 3.44 & 0.1902 & 18.6 & $7 \cdot 32$ & 0.3414 & 0.0 & 0.0 \\
\hline & FISHER: 12 & $\begin{array}{l}2.4 \mathrm{kt} \text { at } 363 \mathrm{~m}(1199 \\
\text { sandia (Perret 1965) }\end{array}$ & ft) in Area 3 NTS A & LLUVIUM-Borin & & & & & & & & \\
\hline 6-UR & 39.8 & 130 & - & -- & 9.91 & 32.5 & 0.613 & 59.8 & 23.5 & 0.1275 & +2.74 & +1.08 \\
\hline 8-UR & 79.0 & 259 & -- & -- & 0.762 & 2.50 & 0.0423 & 5.16 & 2.03 & 0.1590 & +0.82 & +0.32 \\
\hline 4-UR & 119 & 389 & & -- & 0.125 & 0.41 & 0.0324 & 0.955 & 0.376 & $0.1<10$ & $+\quad 0.22$ & +0.086 \\
\hline 2-AR & 237 & 778 & 0.926 & -- & -- & -- & -- & -- & -- & - & -- & -- \\
\hline $2-U R$ & & & -- & -- & 0.183 & 0.60 & 0.0307 & 1.01 & 0.397 & 0.1529 & 0.0 & 0.0 \\
\hline \multirow[t]{2}{*}{ 7-AY-S } & 158 & 517 & 5.09 & -- & 0.61 & 2.0 & -. & 3.76 & 1.48 & -- & -1.43 & -0.56 \\
\hline & HOGNOSE: & "L" kt at $239 \mathrm{~m} 17$ & $\mathrm{ft}$ ) in Area 3 NTS & ALLUVIUM_Borir & & & & & & & & \\
\hline 4-AR & 76.2 & 250 & 1.10 & 0.057 & 0.610 & 2.10 & 0.0820 & 8.97 & 3.53 & 0.3145 & +7.62 & +3.00 \\
\hline 4-UR & & & & -- & 0.174 & 0.57 & 0.0445 & 1.27 & 0.50 & 0.1095 & +0.32 & +0.13 \\
\hline 2-AR & 110 & 360 & 1.66 & 0.008 & 0.174 & 0.57 & 0.0365 & 1.91 & 0.750 & 0.1215 & -0.89 & -0.35 \\
\hline 2-UR & & & & -- & 0.204 & 0.67 & 0.0350 & 1.27 & 0.500 & 0.1190 & +0.38 & +0.15 \\
\hline $6-\mathrm{AR}$ & 150 & 493 & 0.72 & 0.009 & 0.119 & 0.39 & 0.0620 & 0.800 & 0.315 & 0.1020 & $-\quad 1.65$ & -0.65 \\
\hline 6-UR & & & & -- & 0.128 & 0.42 & 0.0630 & 0.864 & 0.340 & 0.1055 & +0.38 & +0.15 \\
\hline \multirow{3}{*}{$\begin{array}{l}\text { 8-AR } \\
\text { 8-UR }\end{array}$} & 281 & 923 & 0.24 & 0.012 & 0.049 & 0.16 & 0.0600 & 0.406 & 0.160 & 0.1000 & - & $\therefore$ \\
\hline & & & & & 0.055 & 0.18 & 0.0600 & 0.318 & 0.125 & 0.0900 & -- & -- \\
\hline & HAYMAKER: & : $46 \mathrm{kt}$ at $408 \mathrm{~m} \mathrm{ll}$ & $10 \mathrm{ft}$ ) in Area $3 \mathrm{NTS}$ & ALLUVIUM-Bor & & & & & & & & \\
\hline 2-AR & $77 \cdot 7$ & 255 & 7.99 & 0.0276 & 0.732 & 2.40 & 0.0472 & 4.96 & 1.95 & 0.1002 & +4.25 & +1.67 \\
\hline 2-UR & & & - & -- & 0.701 & 2.30 & 0.0466 & 4.61 & 1.81 & 0.0996 & +1.70 & +0.67 \\
\hline 4-UR & 154 & 504 & -- & -- & 0.189 & 0.62 & 0.0307 & 0.659 & 0.260 & 0.0586 & +0.11 & +0.04 \\
\hline $1-A V-S$ & 114 & 373 & 8.96 & -- & 1.05 & 3.43 & -- & 12.2 & 4.80 & - & -0.35 & -0.14 \\
\hline
\end{tabular}


TABLE 6.4 Scaled Free-Field Ground Motion--Alluvium

\begin{tabular}{|c|c|c|c|c|c|c|c|c|c|c|c|c|}
\hline \multirow[t]{2}{*}{$\begin{array}{l}\text { Record } \\
\text { Number }\end{array}$} & \multicolumn{2}{|r|}{$\begin{array}{l}\text { Scaled } \\
\text { Slant Range }\end{array}$} & \multicolumn{2}{|c|}{$\begin{array}{l}\text { Scaled Acceleration } \\
\text { Peak } \quad \text { Risetime }\end{array}$} & \multicolumn{3}{|c|}{$\begin{array}{l}\text { Particle Velocity } \\
\text { Peak }\end{array}$} & \multicolumn{5}{|c|}{ Scaled Displacement } \\
\hline & $\mathrm{m} / \mathrm{kt}^{1 / 3}$ & $\mathrm{ft} / \mathrm{kt} 1 / 3$ & $\mathrm{~g} \cdot \mathrm{kt} 1 / 3$ & $\mathrm{sec} / \mathrm{kt} 1 / 3$ & $\mathrm{~m} / \mathrm{sec}$ & $\mathrm{ft} / \mathrm{sec}$ & $\mathrm{sec} / \mathrm{kt}^{1 / 3}$ & $\mathrm{~cm} / \mathrm{kt}^{1 / 3}$ & $\mathrm{in} / \mathrm{kt}^{1 / 3}$ & $\mathrm{sec} / \mathrm{kt}^{1 / 3}$ & $\mathrm{~cm} / \mathrm{kt}^{1 / 3}$ & in $/ \mathrm{kt}^{1 / 3}$ \\
\hline \multicolumn{13}{|c|}{$\begin{array}{l}\text { MERLIN: } \begin{array}{l}10 \mathrm{kt}, 296 \mathrm{~m}(972 \mathrm{ft}) \text { deep in Area } 3 \mathrm{NTS} \text { ALLUVIUM-Boring } \\
\text { Sandia (Perret } 1971)\end{array}\end{array}$} \\
\hline \multicolumn{13}{|c|}{ Shot level array } \\
\hline $3-U R$ & 49.4 & 162 & -- & -- & 3.26 & 10.7 & 0.0939 & 20.2 & 7.96 & 0.1504 & +17.9 & +7.03 \\
\hline 4-AR & 98.7 & 324 & 3.52 & 0.0102 & 0.363 & 1.19 & 0.0495 & 2.97 & 1.17 & 0.1342 & +1.35 & +0.532 \\
\hline 4-UR & & & -- & -- & 0.241 & 0.790 & 0.0472 & 1.94 & 0.76 & 0.1328 & +1.08 & +0.426 \\
\hline 5-AR & 155 & 509 & 0.908 & 0.0120 & 0.122 & 0.400 & 0.0319 & 0.952 & 0.375 & 0.1494 & -- & -- \\
\hline 5-UR & & & -- & & 0.082 & 0.270 & 0.0338 & 0.646 & 0.254 & 0.1508 & +0.235 & +0.093 \\
\hline 6-AR & 226 & 741 & 0.367 & 0.0204 & 0.070 & 0.230 & 0.0328 & 0.693 & 0.273 & 0.0740 & +0.118 & +0.046 \\
\hline $6-U R$ & & & -- & -- & 0.064 & 0.210 & 0.0338 & 0.517 & 0.204 & 0.0740 & +0.141 & +0.056 \\
\hline 7-AR & 353 & 1158 & 0.259 & 0.0264 & 0.058 & 0.190 & 0.0430 & 0.4 .11 & 0.162 & 0.0726 & -- & -- \\
\hline \multicolumn{13}{|c|}{ Vertical arrays } \\
\hline $1-\mathrm{AVI}$ & 27.9 & 91.6 & 2162 & 0.0263 & 22.6 & 74 & -- & -- & -- & -- & -- & -- \\
\hline $1-A V 2$ & 46.0 & 151 & 16.9 & 0.0537 & 4.30 & 14.1 & 0.0897 & 35.1 & 13.8 & 0.1628 & +29.4 & +11.6 \\
\hline $1-\mathrm{AV} 3$ & 67.0 & 220 & 7.50 & 0.0217 & 0.963 & 3.16 & 0.0736 & 10.7 & 4.20 & 0.1582 & +9.28 & +3.65 \\
\hline 1-AV4 & 80.9 & 266 & 5.10 & 0.0208 & 0.716 & 2.35 & 0.0638 & 8.31 & 3.27 & 0.1716 & +0.59 & +0.23 \\
\hline 1-AV6 & 95.0 & 312 & 3.52 & 0.0435 & 0.561 & 1.84 & 0.0652 & 5.62 & 2.21 & 0.1591 & -5.29 & -2.08 \\
\hline 2-AV4 & 97.0 & 318 & 3.35 & 0.0430 & 0.576 & 1.89 & 0.0652 & 6.76 & 2.66 & 0.1702 & +5.29 & +2.08 \\
\hline I-AV7 & 109 & 358 & 2.59 & 0.0509 & 0.552 & 1.81 & 0.0773 & 5.71 & 2.25 & 0.1582 & +1.06 & +0.42 \\
\hline 1-AV9 & 123 & 404 & 2.01 & 0.0523 & 0.719 & 2.36 & 0.0703 & 6.08 & 2.39 & 0.1531 & +0.35 & +0.14 \\
\hline I-AVIOO & 130 & 427 & 1.88 & 0.0402 & 0.674 & 2.21 & 0.0731 & 5.49 & 2.16 & 0.1379 & +1.53 & +0.60 \\
\hline \multirow[t]{2}{*}{ S-IAV2 } & 136 & 448 & 3.39 & 0.0161 & 0.707 & 2.32 & 0.0628 & 5.37 & 2.11 & 0.1175 & -7.56 & -2.97 \\
\hline & VULCAN: & $\begin{array}{l}25 \mathrm{kt} \text { at } 322 \mathrm{~m}(105) \\
\text { LRL/Nortronics (Ra }\end{array}$ & $\begin{array}{l}\text { ft) in Area } 2 \text { NTS } \\
\text { dolph et al 1966) }\end{array}$ & UVIUM-Boring & & & & & & & & \\
\hline 7-AV & 37.4 & 123 & $>64$ & 0.0363 & -- & - & -- & -- & - & -- & -- & - \\
\hline $7-U V$ & & & -- & -- & 16.5 & 54 & 0.0482 & 96.9 & 38.2 & 0.158 & -- & -- \\
\hline 6-AV & 58.2 & 191 & 8.01 & 0.0267 & -- & -- & -- & -- & -- & -- & -- & -- \\
\hline $6-U V$ & & & -- & -- & 3.05 & 10 & 0.0886 & 17.1 & 6.73 & 0.1539 & -- & -- \\
\hline $5-\mathrm{AV}$ & 79.0 & 259 & 6.14 & 0.0171 & -. & -- & -- & $=$ & -- & -- & -- & -- \\
\hline $5-U V$ & & & - & -- & 1.10 & 3.6 & 0.1235 & 7.40 & 2.91 & 0.2117 & -- & -- \\
\hline 4-AV & 89.4 & 293 & 8.77 & 0.0103 & 1.80 & 5.9 & 0.1026 & -- & -- & -- & -- & -- \\
\hline 8-AV & 105 & 344 & 3.22 & 0.0133 & 1.13 & 3.7 & 0.0619 & - & -- & -- & -- & -- \\
\hline $15-\mathrm{AV}-\mathrm{S}$ & 110 & 360 & .2 .63 & 0.0103 & -- & -- & -- & - & -- & -- & -- & -- \\
\hline $15-U V-S$ & & & -- & -- & 0.853 & 2.8 & 0.0612 & 8.65 & 3.41 & 0.1566 & -- & -- \\
\hline
\end{tabular}


TABLE 6.5 Scaled Free-Field Ground Motion--Alluvium

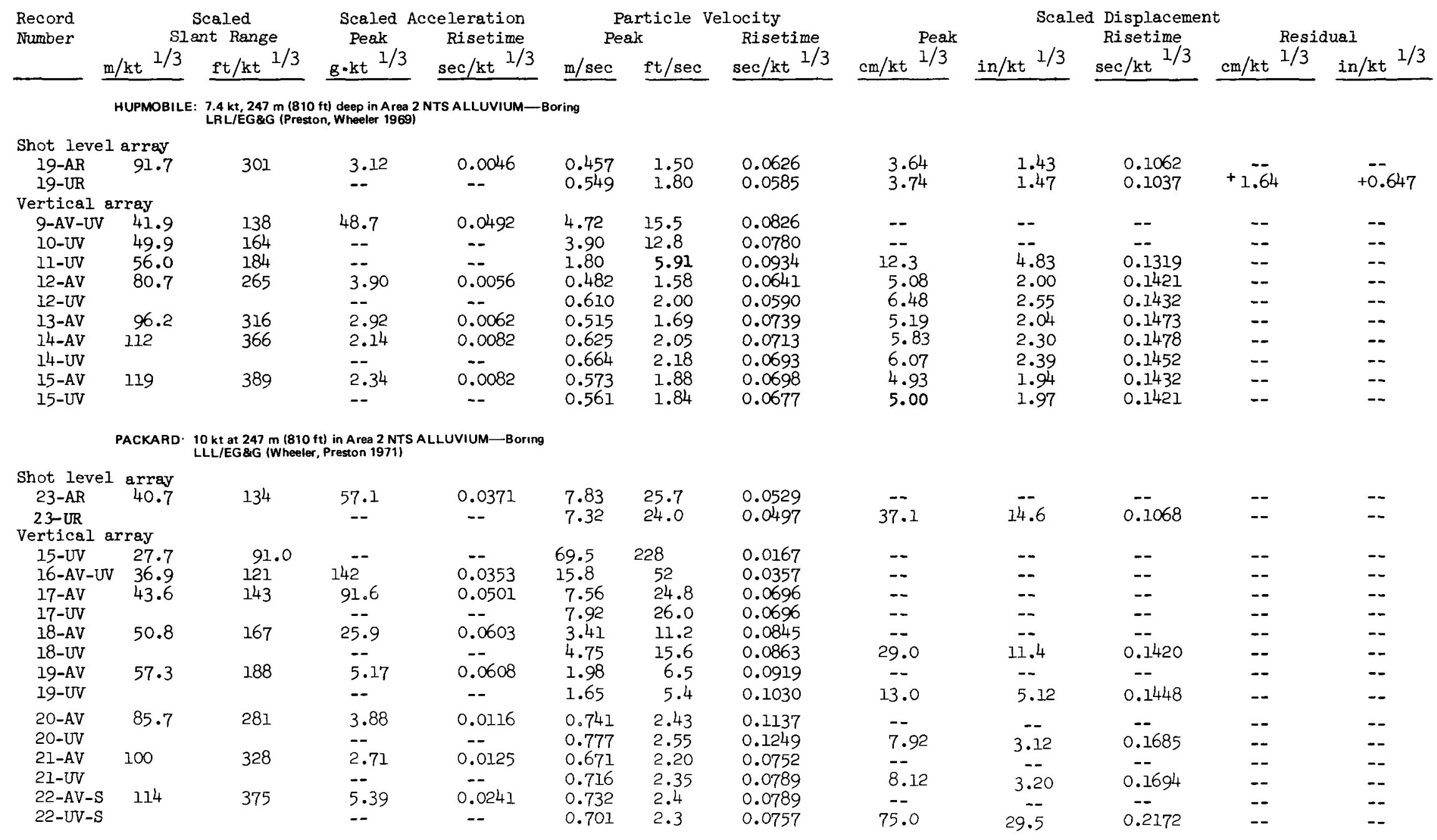


TABLE 6.6 Scaled Free-Field Ground Motion--Tuff Record
Number

Scaled Acceleration

Peak Risetime $\mathrm{m} / \mathrm{kt}^{1 / 3} \mathrm{ft} / \mathrm{kt}^{1 / 3}$

RAINIER: $1.7 \mathrm{kt}, 274 \mathrm{~m}(896 \mathrm{ft})$
Sandia (Perret 1961$)$

$\begin{array}{ccc}\text { Shot level } & \text { array } & \\ \text { AHP-2 } & 37.8 & 124 \\ \text { AHP-3 } & 50.8 & 167 \\ \text { AHP-3X } & 50.8 & 167 \\ \text { AHP-4 } & 63.8 & 210 \\ \text { AHP-5 } & 76.6 & 251 \\ \text { AHP-6 } & 128 & 420 \\ \text { AHP-7 } & 230 & 755 \\ \text { AR } & 346 & 1135 \\ \text { Vertical } & \text { array } & \\ \text { AVS-1 } & 93.5 & 307 \\ \text { AVS-1X } & 94.7 & 317 \\ \text { AVS-2 } & 114 & 374 \\ \text { AVS-3 } & 171 & 562 \\ \text { AVS-4 } & 178 & 585 \\ \text { AVS-6-S } & 229 & 751 \\ & \text { SRI (Swift, Sachs 1959a) } \\ \text { OAP-320 } & 148 & 486 \\ \text { OAP-250 } & 166 & 544 \\ \text { OAP-180 } & 184 & 603\end{array}$

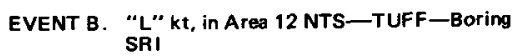

\begin{tabular}{|c|c|c|c|c|}
\hline ov55 & 113 & 372 & -- & -- \\
\hline ovv4 & 130 & 425 & -- & -- \\
\hline 3VH5 & 244 & 799 & -- & -- \\
\hline $3 \mathrm{VH}_{4}$ & 263 & 864 & -- & -- \\
\hline 3 VV2 & 293 & 963 & -- & -- \\
\hline
\end{tabular}

$650 \mathrm{UH}$
$900 \mathrm{UH}$ 61 Sandia not reportad

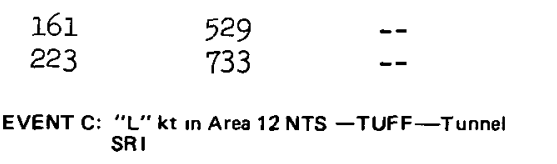

VR-9 128
340 420
1115

$--$

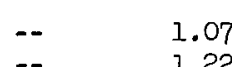

$\begin{array}{lll}2.65 & 8.7 & 0.025 \\ 2.80 & 9.2 & 0.032 \\ 0.805 & 2.64 & 0.010\end{array}$

$\begin{array}{lll}1.05 & 3.45 & 0.018\end{array}$

$\begin{array}{lll}0.24 & 0.80 & 0.017\end{array}$

Particle Velocity

Risetime

$\mathrm{cm/ \textrm {kt } ^ { 1 / 3 }}$ in/ $\mathrm{kt}^{1 / 3}$

caled Displacement

Risetime
$\mathrm{sec} / \mathrm{kt}^{1 / 3}$
$\mathrm{~cm} / \mathrm{kt}^{1 / 3}$ in/kt $1 / 3$

4

42.6
5.72
14.3
2.64
6.09
7.49
6.81
1.92
13.5
13.3
11.9
17.6
21.7
30.4
--
--
--

16.8
2.25
5.64
1.04
2.40
2.95
2.68
0.75
5.31
5.22
4.68
6.93
8.55
12.0
.-
--
--

0.031

0.017

0.032

0.021

0.029

0.113

0.414

0.109

0.129
0.128

0.136

0.323

1.074

1.074
0.2564

$\begin{array}{ll}-- & - \\ -- & -\end{array}$

$-$

$--$

$+3.4$

$+2.1$

$-1.7$

+2.2
+1.3
+

$+20+7.9$

$+\overline{12.8}+\overline{5} .0$

$+0.85+0.34$

$+14.3+5.6$

$-$

$--\quad-$

$-$

$--$

$--$

5.11

13.0

12.4
1.82

4.89

0.715

2.86

1.13
0.511

0.082

0.085

0.038

0.035

0.089

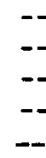

--

$-$

$--$

$-$

$--$

1.07
$-\quad 1.22$

$3.5 \quad 0.0461$

8.03

3.16

0.2167

$+6.21$

$+2.44$

0.0880

1.2 .6

4.94

$+9.31$

$+3.67$

$\begin{array}{lll}- & 0.999 \quad 3.28\end{array}$

0.0407
0.259

5.31

2.09

0.1041

0.0

0.0

0.0 
TABLE 6.7 Scaled Free-Field Ground Motion--Tuff

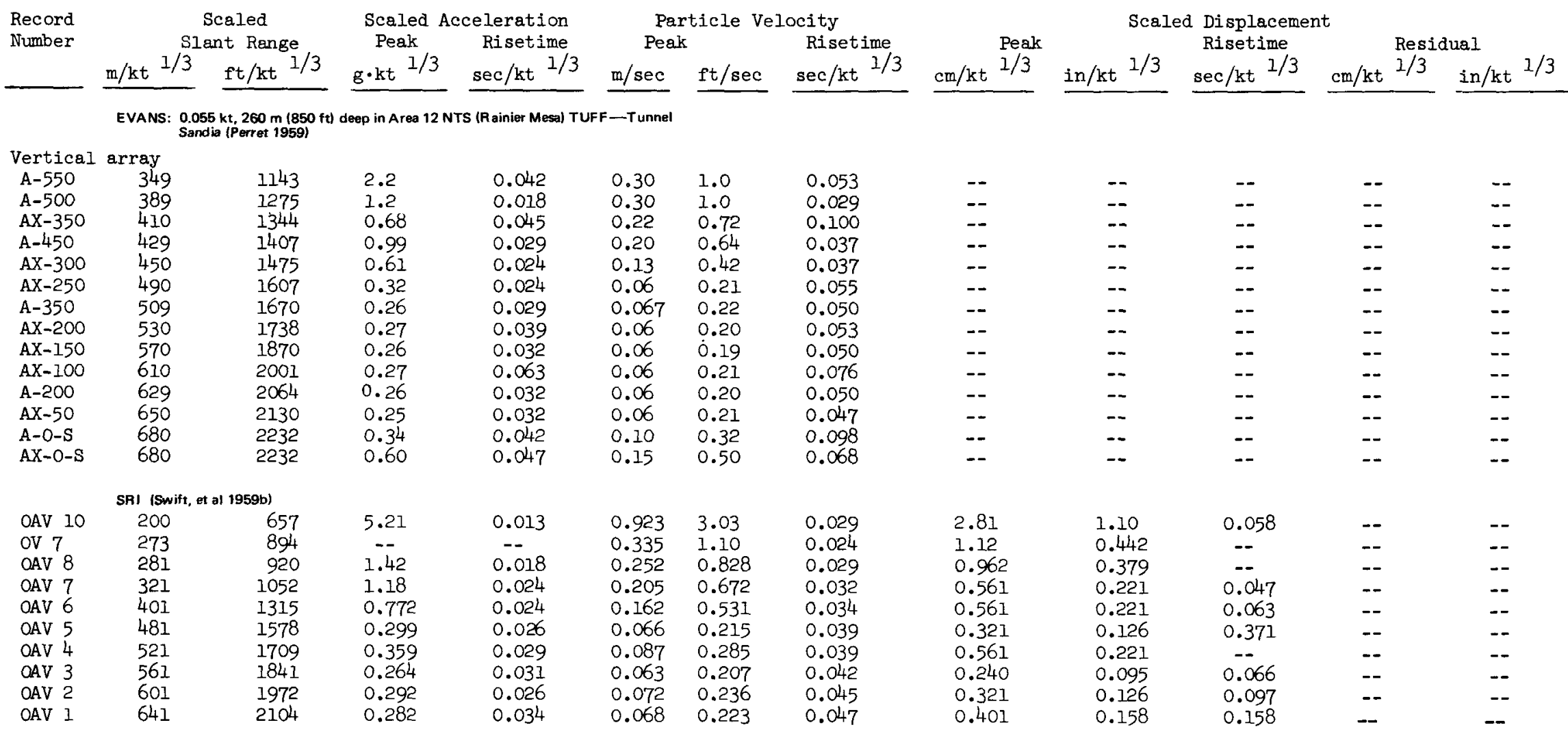


TABLE 6.8 Scaled Free-Field Ground Motion--Tuff

Record
Number

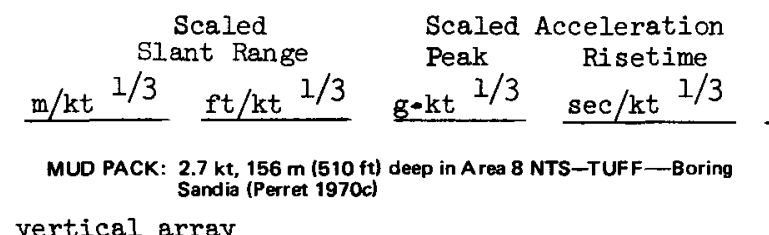

Off-set vertical array

\begin{tabular}{|c|c|c|}
\hline $\begin{array}{l}\text { NS-AVI-S } \\
\text { NS-AV?-S }\end{array}$ & 111 & 365 \\
\hline $\begin{array}{l}\mathrm{NS}-\mathrm{A} \sqrt{2}-\mathrm{S} \\
\mathrm{B} 5-1 \overline{\mathrm{UR}}\end{array}$ & 43.6 & 143 \\
\hline $\mathrm{B} 5-2 \mathrm{UR} 2$ & 49.3 & 162 \\
\hline B5-3UR 3 & 77.3 & 254 \\
\hline B5 $-4 \overline{\mathrm{UR}} 3$ & 187 & 614 \\
\hline NI-I UR I & 73.8 & 242 \\
\hline $\mathrm{Nl}-2 \overline{\mathrm{UR}}^{2}$ & 82.3 & 270 \\
\hline $\mathrm{N} 1-3 \overline{\mathrm{UR}} 3$ & 100 & 328 \\
\hline $\mathrm{NI}-4 \mathrm{UR} 3$ & 132 & 434 \\
\hline 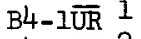 & 125 & 411 \\
\hline B4-2 $\overline{U R} 2$ & 130 & 426 \\
\hline $\mathrm{B} 4-3 \overline{\mathrm{UR}} 3$ & 142 & 465 \\
\hline $\mathrm{B} 2-1 \overline{\mathrm{UR}}$ & 188 & 618 \\
\hline $\mathrm{B} 2-2 \overline{\mathrm{UR}}$ & 192 & 629 \\
\hline $\mathrm{B} 2-3 \overline{\mathrm{UR}}$ & 201 & \\
\hline
\end{tabular}

DISCUS THROWER: $21 \mathrm{kt}, 338 \mathrm{~m}(1106 \mathrm{ft})$ deep in Area $8 \mathrm{NTS}-T$ TUFF-Boring

\begin{tabular}{|c|}
\hline $\begin{array}{l}\text { 4S-AVI-S } \\
\text { 4S-UV-S } \\
\text { 4E-UV } 3 \\
5 B-\overline{U R} 1\end{array}$ \\
\hline 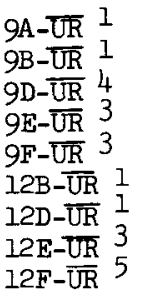 \\
\hline
\end{tabular}

$\begin{array}{lllll}5.78 & 0.0180 & 1.63 & 5.35 & 0.0905 \\ 4.89 & 0.0165 & 1.42 & 4.65 & 0.0898 \\ 9.93 & 0.0007 & 1.20 & 3.94 & 0.0539 \\ 4.68 & 0.0029 & 0.408 & 1.34 & 0.0582 \\ 1.35 & 0.0065 & 0.113 & 0.37 & 0.0582 \\ -- & -. & 0.061 & 0.20 & 0.0531 \\ 3.79 & 0.0057 & 0.378 & .1 .24 & 0.0517 \\ 1.57 & 0.0129 & 0.201 & 0.66 & 0.0481 \\ 0.738 & 0.0086 & 0.104 & 0.34 & 0.0409 \\ 0.460 & 0.0108 & 0.064 & 0.21 & 0.0553 \\ 0.752 & 0.0180 & 0.189 & 0.62 & 0.0632 \\ 0.460 & 0.0230 & 0.134 & 0.44 & 0.0661 \\ 0.306 & 0.0165 & 0.134 & 0.44 & 0.0603 \\ 0.251 & 0.0661 & 0.052 & 0.17 & 0.0754 \\ 0.125 & 0.0632 & 0.119 & 0.39 & 0.0847 \\ 0.153 & 0.0136 & 0.079 & 0.26 & 0.0819\end{array}$

\begin{abstract}
400
\end{abstract}
122

34.4

177

177
178

180

183
189

189
485

485
485

486
487

400

113
147
581
584
591
599
621
1591
1592
1594
1599

4.50
--
--
436
2.07
4.41
--
--
--
0.317
0.372
0.331
0.441

0.0294
--
--
0.0022
0.0069
0.0185
--
--
--
0.0221
0.0087
0.0040
0.0072

$\begin{array}{rl}3.35 & 11.0 \\ 3.41 & 11.2 \\ -25.6 & -84\end{array}$

\subsection{5}

0.2215

0.0018
0.0051

0.0402

$0.460 \quad 1.51$

$0.351 \quad 1.15$

0.0308

0.0109

$\begin{array}{lll}0.223 & 0.730 & 0.0178 \\ 0.223 & 0.998 & 0.0120\end{array}$

$0.304 \quad 0.998$

0.0120

0.0250
0.0188

$\begin{array}{lll}0.037 & 0.120 & 0.0188 \\ 0.038 & 0.125 & 0.0232\end{array}$

$\begin{array}{lll}0.038 & 0.125 & 0.0232 \\ 0.040 & 0.130 & 0.0294\end{array}$

Note: Superscripts indicate rock at gage station as follows: 1. tuff, 2. shale, 3. carbonate, 4 . tuff-carbonate interface, 5. argillite. 
TABLE 6.9 Scaled Free-Field Ground Motion--Wet Tuff

\begin{tabular}{|c|c|c|c|c|c|c|c|c|c|c|c|c|}
\hline \multirow{3}{*}{$\begin{array}{l}\text { Record } \\
\text { Number }\end{array}$} & \multirow{2}{*}{\multicolumn{2}{|c|}{$\begin{array}{l}\text { Scaled } \\
\text { Slant Range }\end{array}$}} & \multirow{3}{*}{ 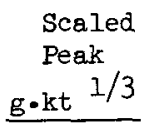 } & \multirow{3}{*}{$\begin{array}{c}\text { Acceleration } \\
\text { Risetime } \\
\text { sec/kt } 1 / 3 \\
\end{array}$} & \multicolumn{3}{|c|}{ Particle Velocity } & \multicolumn{5}{|c|}{ Scaled Displacement } \\
\hline & & & & & \multicolumn{2}{|c|}{ Peak } & \multirow{2}{*}{$\begin{array}{c}\begin{array}{c}\text { Risetime } \\
\mathrm{sec} / \mathrm{kt}\end{array} \\
\end{array}$} & \multirow{2}{*}{$\begin{array}{ll}\begin{array}{l}\text { Peak } \\
\mathrm{cm} / \mathrm{kt}\end{array} \\
\end{array}$} & \multirow[b]{2}{*}{ in/kt $1 / 3$} & \multirow{2}{*}{$\begin{array}{c}\text { Risetime } \\
\text { sec/kt } 1 / 3\end{array}$} & \multicolumn{2}{|c|}{ Residual } \\
\hline & $\underline{\mathrm{m} / \mathrm{kt}^{1 / 3}}$ & $\mathrm{ft} / \mathrm{kt} 1 / 3$ & & & $\mathrm{~m} / \mathrm{sec}$ & $\mathrm{ft} / \mathrm{sec}$ & & & & & $\mathrm{cm} / \mathrm{kt}^{1 / 3}$ & in/kt $1 / 3$ \\
\hline \multicolumn{13}{|c|}{$\begin{array}{c}\text { EVENT N: "'l' kt - WET TUFF-Boring } \\
\text { Sandia }\end{array}$} \\
\hline \multicolumn{13}{|c|}{ Vertical array } \\
\hline B2AV-22 & 35.7 & 117 & $>4275$ & $>0.0008$ & -- & -- & -- & -- & - & -- & -- & -- \\
\hline B2AV-20 & 42.9 & 141 & $>2992$ & $>0.0016$ & -- & -- & -- & -- & -- & -- & -- & -- \\
\hline B2AV-15, & 57.1 & 187 & $>1539$ & $>0.0025$ & -- & -- & -- & -- & -- & -- & $=$ & -- \\
\hline B2AV-9 1 & 82.1 & 269 & 761 & 0.0043 & 11.0 & 36.1 & 0.0051 & -- & -- & -- & -- & -- \\
\hline BLAV-9 1 & 82.1 & 269 & 846 & 0.0040 & 10.8 & 35.4 & 0.0046 & -- & -- & -- & -- & -- \\
\hline $\mathrm{B} \perp \mathrm{AV}-41$ & 99.9 & 328 & 547 & 0.0055 & 10.4 & 34.1 & 0.0094 & -- & -- & -- & -- & -- \\
\hline BIUV-4 1 & & & -- & -- & 8.8 & 28.9 & 0.0094 & 21.1 & 8.29 & 0.0825 & -2.34 & -0.92 \\
\hline BIAV-2 & 107 & 351 & 111 & 0.0099 & 6.0 & 19.7 & 0.0158 & -- & -- & -- & -- & -- \\
\hline BIUV-2 & & & -- & -- & 4.55 & 14.9 & 0.0158 & 16.8 & 6.63 & 0.0918 & -5.73 & -2.25 \\
\hline BIAV-1 & 111 & 363 & 36.8 & 0.0150 & 5.5 & 18.0 & 0.0304 & -- & -- & -- & -- & -- \\
\hline BIUV-1 & & & -- & -- & 4.0 & 13.1 & 0.0304 & 18.9 & 7.46 & 0.0947 & -2.92 & -1.15 \\
\hline Shot lev & el array & & & & & & & & & & & \\
\hline BI7AR $\frac{1}{1}$ & 582 & 1909 & 3.39 & 0.0117 & 0.31 & 1.02 & 0.0175 & -- & -- & -- & -- & -- \\
\hline Bl7UR $^{\perp}$ & & & -- & -- & 0.50 & 1.64 & 0.0199 & 0.713 & 0.281 & 0.0327 & -- & -- \\
\hline \multicolumn{13}{|c|}{$\begin{array}{l}\text { EVENT L: "L" } \mathrm{kt} \text { in Area } 12 \text { NTS - WET TUFF - Tunnel } \\
\text { Sandia unreported }\end{array}$} \\
\hline UR3OF & 46.7 & 153 & 117 & 0.0056 & 5.33 & 17.5 & 0.0123 & 22.1 & 8.68 & 0.0812 & +14.3 & +5.62 \\
\hline AR $40 F$ & 62.3 & 204 & 62.6 & 0.0118 & 4.27 & 14.0 & 0.0179 & -- & -- & -- & -- & -- \\
\hline UR $4 O F$ & & & -- & -- & 3.51 & 11.5 & 0.0174 & 13.6 & 5.36 & 0.0628 & +5.19 & +2.04 \\
\hline AR55F & 85.6 & 281 & 36.2 & 0.0082 & 3.17 & 10.4 & 0.0215 & -- & - & -- & -- & -- \\
\hline UR55F & & & -- & -- & 2.41 & $7 \cdot 9$ & 0.0143 & 8.69 & 3.42 & 0.0506 & +0.91 & +0.36 \\
\hline AR7OF & 109 & 358 & 20.2 & 0.0056 & 2.13 & 7.0 & 0.0199 & -- & -- & -- & -- & -- \\
\hline UR7OF & & & -- & -- & 2.13 & 7.0 & 0.0291 & 7.40 & 2.91 & 0.0613 & +1.30 & +0.511 \\
\hline ARIIOF & 171 & 562 & 26.2 & 0.0230 & 1.89 & 6.2 & 0.0266 & - & -- & -- & -- & -- \\
\hline URIIOF & & & -- & -- & 1.66 & 5.4 & 0.0271 & 3.80 & 1.50 & 0.0593 & -0.13 & -0.05 \\
\hline \multicolumn{13}{|c|}{$\begin{aligned} \text { EVENT M: " } L \text { " } k t \text { in A rea } 12 \text { NTS--WET TUFF -T Tunnel } \\
\text { Sandia unreported }\end{aligned}$} \\
\hline 200AR & 30.2 & 99.1 & 7336 & 0.0011 & -- & -- & - & -- & -- & -- & -- & -- \\
\hline 25OAR & 38.3 & 126 & 4380 & 0.0032 & 35.1 & 115 & 0.0036 & 19.2 & 7.56 & 0.0110 & -- & -- \\
\hline 30OAR & 46.2 & 152 & 2409 & 0.0030 & 27.4 & 90 & 0.0047 & - & -- & -- & -- & -- \\
\hline 35OAR & 48.7 & 160 & 856 & 0.0026 & 16.8 & 55 & 0.0050 & -- & -- & -- & -- & -- \\
\hline
\end{tabular}

Superscript 1 indicates gage stations below water table. 
TABLE 6.10 Scaled Free-Field Ground Motion--Wet Tuff

\begin{tabular}{|c|c|c|c|c|c|c|c|c|c|c|c|c|}
\hline \multirow{2}{*}{$\begin{array}{l}\text { Record } \\
\text { Number }\end{array}$} & \multicolumn{2}{|c|}{$\begin{array}{l}\text { Scaled } \\
\text { Slant Range }\end{array}$} & \multicolumn{2}{|c|}{ Scaled Acceleration } & \multicolumn{3}{|c|}{ Particle Velocity } & \multicolumn{5}{|c|}{ Scaled Displacement } \\
\hline & $\mathrm{m} / \mathrm{kt}^{1 / 3}$ & $\mathrm{ft} / \mathrm{kt}^{1 / 3}$ & $\mathrm{gekt}^{1 / 3}$ & $\begin{array}{c}\text { Risetime } \\
\text { sec/kt }\end{array}$ & $\mathrm{m} / \mathrm{sec}$ & $\mathrm{ft} / \mathrm{sec}$ & $\begin{array}{l}\text { Risetime } \\
\text { sec/kt }\end{array}$ & $\begin{array}{rl}\text { Peak } & \\
\mathrm{cm} / \mathrm{kt} & 1 / 3\end{array}$ & in $/ \mathrm{kt}^{1 / 3}$ & $\begin{array}{l}\text { Risetime } \\
\mathrm{sec} / \mathrm{kt} \\
1 / 3\end{array}$ & $\mathrm{~cm} / \mathrm{kt} \begin{array}{l}\text { Res } \\
1 / 3\end{array}$ & in $/$ kt $1 / 3$ \\
\hline \multicolumn{13}{|c|}{$\begin{array}{l}\text { EVENT D: "L-1" " kT in A Area } 2 \text { NTS-WET TUFF-Boring } \\
\text { Sandia unreported }\end{array}$} \\
\hline \multicolumn{13}{|c|}{ Vertical array } \\
\hline V5-AV & 118 & 386 & 13.3 & 0.0061 & 1.92 & 6.3 & 0.0852 & 20.9 & 8.21 & 0.1632 & -- & -- \\
\hline V5-UV & & & -- & -- & 1.89 & 6.2 & 0.0872 & 21.1 & 8.31 & 0.1652 & +1.03 & +0.405 \\
\hline $\mathrm{V} 4-\mathrm{AV}$ & 124 & 406 & 11.8 & 0.0041 & 1.95 & 6.4 & 0.0781 & 22.1 & 8.72 & 0.1683 & -- & -- \\
\hline V4-UV & & & -- & -- & 1.77 & 5.8 & 0.0760 & 17.8 & 6.99 & 0.1551 & 0 & 0 \\
\hline V3-AV & 130 & 426 & 10.9 & 0.0061 & 2.07 & 6.8 & 0.0416 & 21.1 & 8.31 & 0.1612 & -- & $=-$ \\
\hline V3-UV & & & -.- & -- & 2.26 & 7.4 & 0.0405 & 22.1 & 8.72 & 0.1531 & -2.06 & -0.811 \\
\hline V2-AV & 136 & 447 & 9.86 & 0.0061 & 2.53 & 8.3 & 0.0426 & 22.9 & 9.02 & 0.1581 & -- & -- \\
\hline V2-UV & & & -- & -- & 2.44 & 8.0 & 0.0365 & 20.6 & 8.11 & 0.1480 & -1.54 & -0.608 \\
\hline Vl-AV & 142 & 467 & 11.3 & 0.0243 & 2.68 & 8.8 & 0.0426 & 19.6 & 7.70 & 0.1480 & -- & -- \\
\hline VI-UV & & & -- & -- & 2.90 & 9.5 & 0.0426 & 19.6 & $7 \cdot 70$ & 0.1521 & -4.63 & -1.82 \\
\hline \multicolumn{13}{|c|}{ Offset yertical array } \\
\hline $211-\overline{U R} 1$ & 200 & 655 & -- & -- & 1.52 & 5.0 & 0.0203 & 6.39 & 2.51 & 0.0993 & +0.824 & +0.324 \\
\hline $\mathrm{Z} 14-\overline{\mathrm{UR}} ?$ & 193 & 634 & -- & -- & 1.46 & 4.8 & 0.0120 & 5.87 & 2.31 & 0.0852 & +2.27 & +0.892 \\
\hline $\mathrm{Z22- \overline { \textrm {UR } }} 3$ & 184 & 603 & -- & -- & 2.65 & 8.7 & 0.0101 & 4.94 & 1.95 & 0.0710 & +4.02 & +1.58 \\
\hline $\mathrm{z} 26-\overline{\mathrm{UR}} 3$ & 184 & 604 & $-=$ & -- & 1.89 & 6.2 & 0.0207 & 3.84 & 1.51 & 0.0801 & +1.75 & +0.689 \\
\hline $\mathrm{Z} 34-\overline{\mathrm{UR}} 4$ & 194 & 636 & -- & -- & 0.427 & 1.4 & 0.0034 & 1.54 & 0.608 & 0.1032 & +0.515 & +0.203 \\
\hline \multicolumn{13}{|c|}{ Shot level array } \\
\hline X24-UR 3 & 298 & 978 & -- & -- & 1.52 & 5.0 & 0.0245 & 2.37 & 0.933 & 0.1050 & +0.927 & +0.365 \\
\hline \multicolumn{13}{|c|}{$\begin{array}{c}\text { COMMODORE: } 250 \mathrm{kt}, 749 \mathrm{~m}(2449 \mathrm{ft}) \text { deep in A rea } 2 \text { NTS - WET TUFF-Boring } \\
\text { Sandia unreported }\end{array}$} \\
\hline \multicolumn{13}{|c|}{ Vertical array } \\
\hline M5-AV & 95.2 & 312 & 11.8 & 0.0048 & 4.60 & 15.1 & 0.1006 & -- & -- & - & -- & -- \\
\hline M5-UV & & & -- & -- & 5.24 & 17.2 & 0.0998 & 68.7 & 27.0 & 0.2221 & -- & -- \\
\hline $\mathrm{M} 4-\mathrm{UV}$ & 100 & 328 & - & -- & 4.48 & 14.7 & 0.0982 & 58.0 & 22.8 & 0.2164 & -- & -- \\
\hline $\mathrm{M} 3-\mathrm{AV}$ & 105 & 345 & 9.94 & 0.0097 & 4.51 & 14.8 & 0.0949 & -- & -- & -- & -- & -- \\
\hline M3-UV & & & -- & -- & 3.35 & 11.0 & 0.1006 & 39.0 & 15.3 & 0.2164 & -- & -- \\
\hline Ml-AV & 115 & 377 & 18.0 & 0.0145 & 4.82 & 15.8 & 0.0636 & - & -- & -- & -- & -- \\
\hline Ml-UV & & & -- & -- & 5.00 & 16.4 & 0.0620 & 66.2 & 26.1 & 0.2084 & -55.2 & -21.7 \\
\hline \multicolumn{13}{|c|}{ Offset yertical array } \\
\hline $\mathrm{ZII- \overline { \textrm {UR } }} 1$ & 168 & $\begin{array}{l}551 \\
535\end{array}$ & -- & -- & $\begin{array}{l}2.32 \\
2.32\end{array}$ & 7.6 & 0.0137 & 8.42 & 3.31 & 0.1142 & 0 & 0 \\
\hline $\mathrm{Z} 14-\overline{\mathrm{UR}} \mathrm{2}$ & 163 & 535 & -- & -- & 2.32 & 7.6 & 0.0145 & 7.60 & 2.99 & 0.0893 & +2.45 & +0.965 \\
\hline $\mathrm{Z22}-\overline{\mathrm{UR}} 3$ & 156 & 511 & -- & -- & 4.21 & 13.8 & 0.0217 & 7.77 & 3.06 & 0.0708 & +0.817 & +0.322 \\
\hline Z26-UR 3 & 156 & 511 & -- & -- & 2.93 & 9.6 & 0.0257 & 6.54 & 2.57 & 0.0901 & +3.84 & +1.51 \\
\hline $234-\overline{U R} 4$ & 162 & 533 & -- & -- & 0.975 & 3.2 & 0.0080 & 2.94 & 1.16 & 0.0869 & +1.72 & +0.676 \\
\hline $\begin{array}{l}\text { Shot lev } \\
\text { X24-UR } 3\end{array}$ & $\begin{array}{l}\text { el array } \\
280\end{array}$ & 918 & -- & -- & 0.975 & 3.2 & 0.0386 & 1.84 & 0.724 & 0.0949 & +0.409 & +0.161 \\
\hline$\lambda<4-U \Lambda \Omega$ & 200 & & & - & 0.912 & $3 . c$ & . & 1.04 & $0.1<4$ & $0.09+9$ & 80.409 & \\
\hline
\end{tabular}

응 Superscripts indicate rock at gage station as follows: 1 dry tuff, 2 welded tuff, 3 tuff below water table, 4 carbonate rock. 
TABLE 6.11 Scaled Free-Field Ground Motion--Wet Tuff

\begin{tabular}{|c|c|c|c|c|c|c|c|c|c|c|c|c|}
\hline \multirow{3}{*}{$\begin{array}{l}\text { Record } \\
\text { Number }\end{array}$} & \multicolumn{2}{|c|}{ Scaled } & \multicolumn{2}{|c|}{ Scaled Acceleration } & \multicolumn{3}{|c|}{ Particle Velocity } & \multicolumn{5}{|c|}{ Scaled Displacement } \\
\hline & \multirow{2}{*}{\multicolumn{2}{|c|}{$\begin{array}{l}\text { Slant Range } \\
\mathrm{m} / \mathrm{k}+1 / 3 \mathrm{ft} / \mathrm{kt} 1 / 3\end{array}$}} & \multirow{2}{*}{$\begin{array}{c}\text { Peak } \\
\text { g.kt } 1 / 3 \\
\end{array}$} & \multirow{2}{*}{$\begin{array}{c}\text { Risetime } \\
\text { sec/kt } 1 / 3 \\
\end{array}$} & \multicolumn{2}{|c|}{ Peak } & \multirow{2}{*}{$\begin{array}{l}\text { Risetime } \\
\text { sec/kt } 1 / 3 \\
\end{array}$} & \multicolumn{2}{|c|}{ Peak } & Risetime & \multicolumn{2}{|c|}{ Residual } \\
\hline & & & & & $\mathrm{m} / \mathrm{sec}$ & $\mathrm{ft} / \mathrm{sec}$ & & $\mathrm{cm} / \mathrm{kt}^{1 / 3}$ & $\mathrm{in} / \mathrm{kt}^{1 / 3}$ & $\mathrm{sec} / \mathrm{kt}^{1 / 3}$ & $\mathrm{~cm} / \mathrm{kt}^{1 / 3}$ & $\mathrm{in} / \mathrm{kt} \mathrm{t}^{1 / 3}$ \\
\hline \multicolumn{13}{|c|}{$\begin{array}{l}\text { EVENT F: "L-l" kt in Area } 2 \text { NTS-WET TUFF_Boring } \\
\text { Sarkia unreported }\end{array}$} \\
\hline \multicolumn{13}{|c|}{ Vertical array } \\
\hline $\mathrm{X} 3-\mathrm{UV}$ & 123 & 404 & -- & -- & 2.65 & 8.7 & 0.0669 & 30.6 & 12.0 & 0.1644 & +7.52 & +2.96 \\
\hline $\mathrm{X} 2-\mathrm{UV}$ & 129 & 424 & -- & -- & 3.35 & 11.0 & 0.0501 & 37.1 & 14.6 & 0.1725 & +5.01 & +1.97 \\
\hline $\mathrm{X} \perp-\mathrm{AV}$ & 135 & 443 & 17.2 & 0.0103 & 3.35 & 11.0 & 0.0494 & 32.6 & 12.8 & 0.1751 & +5.01 & +1.97 \\
\hline $\mathrm{X} 1-\mathrm{UV}$ & & & -- & -- & 3.20 & 10.5 & 0.0494 & 31.1 & 12.2 & 0.1727 & -- & -- \\
\hline \multicolumn{13}{|c|}{ offset vertical array } \\
\hline $\mathrm{Z} I 1-\overline{\mathrm{AR}}$ & 195 & 640 & 21.3 & 0.0148 & 2.13 & 7.0 & 0.0182 & -- & -- & -- & -- & -- \\
\hline $\mathrm{Zll}-\mathrm{UR}$ & & & -- & -- & 2.26 & 7.4 & 0.0188 & 5.31 & 2.09 & 0.0506 & +1.50 & +0.592 \\
\hline $\mathrm{Z} 14-\overline{\mathrm{AR}}$ & 189 & 620 & 28.9 & 0.0122 & 2.38 & 7.8 & 0.0182 & -- & -- & -- & -- & -- \\
\hline $\mathrm{Z} 14-\overline{\mathrm{UR}}$ & & & -- & -- & 1.68 & 5.5 & 0.0150 & 5.01 & 1.97 & 0.0780 & +2.11 & +0.829 \\
\hline $\mathrm{Z22}-\overline{\mathrm{UR}}$ & 180 & 590 & -- & -- & 3.29 & 10.8 & 0.0061 & 4.46 & 1.76 & 0.0462 & +1.00 & +0.395 \\
\hline $\mathrm{Z} 26-\overline{\mathrm{UR}}$ & 180 & 591 & -- & -- & 2.50 & 8.2 & 0.0071 & 3.26 & 1.28 & 0.0276 & +0.251 & +0.099 \\
\hline $\mathrm{Z} 34-\overline{\mathrm{AR}}$ & 189 & 620 & 5.98 & 0.0034 & 0.396 & 1.3 & 0.0154 & -- & -- & -- & -- & -- \\
\hline $\mathrm{Z34-UR}$ & & & -- & -- & 0.579 & 1.9 & 0.0197 & 1.23 & 0.484 & 0.0367 & +0.401 & +0.158 \\
\hline \multicolumn{13}{|c|}{$\begin{array}{l}\text { EVENT G: "L-1" kt in Area } 2 \text { NTS-WET TUFF-Boring } \\
\text { Sandia unreported }\end{array}$} \\
\hline $\mathrm{Zll}-\overline{\mathrm{UR}}$ & 168 & 550 & -- & -- & 2.50 & 8.2 & 0.0276 & 8.66 & 3.41 & 0.1789 & +4.21 & +1.66 \\
\hline $\mathrm{Z} 14-\overline{\mathrm{UR}}$ & 163 & 535 & -- & -- & 2.23 & 7.3 & 0.0239 & 7.77 & 3.06 & 0.1580 & +1.87 & +0.737 \\
\hline $\mathrm{Z} 22-\overline{\mathrm{UR}}$ & 157 & 514 & -- & -- & 5.39 & 17.7 & 0.0071 & -- & -- & -- & -- & -- \\
\hline $\mathrm{Z} 26-\overline{\mathrm{UR}}$ & 158 & 520 & - & -- & 4.27 & 14.0 & 0.0081 & -- & -- & -- & -- & -- \\
\hline $\mathrm{Z} 34-\overline{\mathrm{UR}}$ & 170 & 558 & -- & -- & 0.853 & 2.8 & 0.0199 & -- & -- & -- & -- & - \\
\hline
\end{tabular}

Subscripts indicate rock at gage stations as follows: 1 dry tuff, 2 welded tuff, 3 tuff below water table, 4 carbonate rock. 
TABLE 6.12 Scaled Free-Field Ground Motion--Wet Tuff

\begin{tabular}{|c|c|c|c|c|c|c|c|c|c|c|c|c|}
\hline \multirow{2}{*}{$\begin{array}{l}\text { Record } \\
\text { Number }\end{array}$} & \multicolumn{2}{|c|}{ Scaled } & \multicolumn{2}{|c|}{ Scaled Acceleration } & \multicolumn{3}{|c|}{ Particle Velocity } & Peak & Scale & $\begin{array}{l}\text { Displacement } \\
\text { Risetime }\end{array}$ & \multicolumn{2}{|c|}{ Residual } \\
\hline & $\mathrm{m} / \mathrm{kt}^{1 / 3}$ & $\mathrm{ft} / \mathrm{kt}^{1 / 3}$ & $\mathrm{~g}: \mathrm{kt} 1 / 3$ & $\mathrm{sec} / \mathrm{kt}^{1 / 3}$ & $\mathrm{~m} / \mathrm{sec}$ & $\mathrm{ft} / \mathrm{sec}$ & $\sec / \mathrm{kt}^{1 / 3}$ & $\mathrm{~cm} / \mathrm{kt}^{1 / 3}$ & in/kt $1 / 3$ & $\mathrm{sec} / \mathrm{kt}^{1 / 3}$ & $\mathrm{~cm} / \mathrm{kt}^{1 / 3}$ & in/kt $1 / 3$ \\
\hline \multicolumn{13}{|c|}{$\begin{array}{c}\text { EVENT H: “L-I” kt in Area } 9 \text { NTS-WET TUFF一Boring } \\
\text { LLLEG\&G }\end{array}$} \\
\hline \multicolumn{13}{|c|}{ Vertical array } \\
\hline $16-\mathrm{AV}-\mathrm{UV}$ & 31.4 & 103 & 436 & 0.0225 & 34.7 & 114 & 0.0301 & -- & -- & -- & -- & -- \\
\hline $15-\mathrm{AV}$ & 43.0 & 141 & 163 & 0.0375 & -- & -- & -- & -- & -- & -- & -- & -- \\
\hline $14-\mathrm{AV}-\mathrm{UV}$ & 57.6 & 189 & 26.3 & 0.0032 & 7.41 & 24.3 & 0.0659 & 62.7 & 24.7 & 0.2140 & -- & -- \\
\hline $13-\mathrm{AV}$ & 72.1 & 236 & 18.4 & -- & 4.45 & 14.6 & 0.1001 & 45.8 & 18.0 & 0.1873 & -- & -- \\
\hline 13-UV & & & -- & -- & 4.33 & 14.2 & 0.1007 & 49.3 & 19.4 & 0.2235 & -- & -- \\
\hline 12-AV & 80.8 & 265 & 17.1 & 0.0061 & 5.06 & 16.6 & 0.1043 & 62.7 & 24.7 & 0.2280 & -- & -- \\
\hline II-AV & 86.6 & 284 & 14.7 & 0.0057 & 4.36 & 14.3 & 0.1037 & 50.5 & 19.9 & 0.2046 & -- & -- \\
\hline 10-AV & 92.4 & 303 & 14.2 & 0.0067 & 4.75 & 15.6 & 0.1089 & 61.5 & 24.2 & 0.2202 & -- & -- \\
\hline 10-UV & & & -- & -- & 3.81 & 12.5 & 0.1060 & 49.9 & 19.6 & 0.2202 & -- & -- \\
\hline \multicolumn{13}{|c|}{$\begin{aligned} \text { EVENT I: " } l " k t \text { in Area } 2 \text { NTS-WET TUFF-Boring } \\
\text { Sand ia/LLL unreported }\end{aligned}$} \\
\hline \multicolumn{13}{|c|}{ Offset vertical array } \\
\hline $23-14 \overline{\mathrm{UR}}_{1}^{1}$ & 188 & 618 & -- & -- & 0.445 & 1.46 & 0.0091 & 25.0 & 9.85 & 0.0699 & -3.6 & -1.4 \\
\hline $\mathrm{Z3}-18 \overline{\mathrm{UR}}_{2}^{1}$ & 187 & 615 & -- & -- & 0.442 & 1.45 & 0.0190 & 23.7 & 9.33 & 0.0837 & +16 & +6.4 \\
\hline $\mathrm{Z3}-20 \overline{\mathrm{U}}_{3}^{2}$ & 188 & 618 & -- & -- & 0.460 & 1.51 & 0.0130 & 25.9 & 10.2 & 0.0888 & +7.2 & +2.8 \\
\hline$z 3-24 \overline{\mathrm{UR}}^{3}$ & 192 & 631 & -- & -- & 0.442 & 1.45 & 0.0095 & 18.8 & 7.41 & 0.0736 & +1.8 & +0.7 \\
\hline \multicolumn{13}{|c|}{$\begin{aligned} & \text { CALABASH: } 110 \mathrm{kt}, 626 \mathrm{~m}(2050 \mathrm{ft}) \text { deep in Area } 2 \mathrm{NTS} \text {-WET TUFF_-Boring } \\
& \text { Sandia/LLL unreported }\end{aligned}$} \\
\hline $\mathrm{Z} 2-14 \overline{\mathrm{UR}}_{2}^{1}$ & 197 & 646 & -- & -- & 1.19 & 3.9 & 0.0159 & 41.6 & 16.4 & 0.0756 & +13 & +5.0 \\
\hline $\mathrm{Z} 2-18 \overline{\mathrm{UR}}_{2}^{2}$ & 193 & 632 & -- & -- & 0.975 & 3.2 & 0.0140 & 12.1 & 4.76 & 0.0597 & -- & -- \\
\hline $\mathrm{Z} 2-20 \overline{\mathrm{UR}}_{2}^{3}$ & 192 & 631 & -- & -- & 1.19 & 3.9 & 0.0121 & 2.93 & 1.15 & 0.0538 & -- & -- \\
\hline $\mathrm{Z} 2-24 \overline{U R}_{0}^{3}$ & 193 & 634 & $=-$ & -- & 1.89 & 6.2 & 0.0284 & 2.67 & 1.05 & 0.0547 & -- & -- \\
\hline $\mathrm{z} 3-20 \overline{\mathrm{UR}}^{2}$ & 304 & 997 & -- & -- & 1.16 & 3.8 & 0.0380 & 2.16 & 0.852 & 0.0860 & -- & - \\
\hline \multicolumn{13}{|c|}{$\begin{array}{l}\text { CARPETBAG: } 220 \mathrm{kt}, 663 \mathrm{~m}(2171 \mathrm{ft}) \text { deep in Area } 2 \text { NTS-WET TUFF-Boring } \\
\text { Sandia/LLL unreported }\end{array}$} \\
\hline $\mathrm{Z3}-14 \mathrm{UR}_{7}^{1}$ & 158 & 519 & -- & -- & 1.71 & 5.6 & 0.0232 & 3.91 & 1.54 & 0.0629 & +2.4 & +1.0 \\
\hline $23-18 \overline{\mathrm{UR}}^{1}$ & 154 & 505 & -- & -- & 0.64 & 2.1 & 0.0172 & 1.79 & 0.706 & 0.0394 & -- & -- \\
\hline $\mathrm{Z3}-20 \overline{\mathrm{UR}}^{2}$ & 153 & 502 & -- & -- & 1.68 & 5.5 & 0.0137 & 4.19 & 1.65 & 0.0480 & +1.5 & +0.6 \\
\hline $\mathrm{Z} 3-24 \overline{\mathrm{UR}}^{3}$ & 153 & 502 & -- & - & 2.32 & 7.6 & 0.0129 & 3.18 & 1.25 & 0.0444 & -- & -- \\
\hline
\end{tabular}

Superscripts indicate rock at gage stations as follows: 1 dry tuff, 2 welded tuff, 3 tuff below water table. 
TABLE 6.13 Scaled Free-Field Ground Motion--Wet Tuff

\begin{tabular}{|c|c|c|c|c|c|c|c|c|c|c|}
\hline \multirow{3}{*}{$\begin{array}{l}\text { Record } \\
\text { Number }\end{array}$} & \multirow{2}{*}{\multicolumn{2}{|c|}{$\begin{array}{c}\text { Scaled } \\
\text { Slant Range }\end{array}$}} & \multicolumn{2}{|c|}{ Scaled Acceleration } & \multicolumn{3}{|c|}{ Particle Velocity } & \multicolumn{3}{|c|}{ Scaled Displacement } \\
\hline & & & Peak & Risetime & Peg & & Risetime & & & Risetime \\
\hline & $\mathrm{m} / \mathrm{kt}^{1 / 3}$ & $\mathrm{ft} / \mathrm{kt}^{1 / 3}$ & $\mathrm{~g} \cdot \mathrm{kt}^{1 / 3}$ & $\mathrm{sec} / \mathrm{kt}^{1 / 3}$ & $\mathrm{~m} / \mathrm{sec}$ & $\mathrm{ft} / \mathrm{sec}$ & $\mathrm{sec} / \mathrm{kt}^{1 / 3}$ & $\mathrm{~cm} / \mathrm{kt}^{1 / 3}$ & in $/ \mathrm{kt}^{1 / 3}$ & $\mathrm{sec} / \mathrm{kt}^{1 / 3}$ \\
\hline \multicolumn{11}{|c|}{$\begin{array}{l}\text { EVENT O "L" "kt in Area } 12 \text { NTS (Raunter Mesa) WET TUFF-Tunnel } \\
\text { Sand } 1 \text { IDNA unreported }\end{array}$} \\
\hline \multicolumn{11}{|c|}{ Shot level array } \\
\hline AROO & 164 & 539 & 100 & 0.0093 & 3.87 & 12.7 & 0.0111 & -- & -- & -- \\
\hline UROO & & & -- & -- & 3.63 & 11.9 & 0.0111 & 20.9 & 8.22 & 0.1295 \\
\hline ARI3 & 183 & 599 & 42.4 & 0.0074 & 2.44 & 8.0 & 0.0149 & -- & -- & -- \\
\hline UR13 & & & -- & -- & 2.35 & 7.7 & 0.0158 & 6.01 & 2.37 & 0.0427 \\
\hline AR 40 & 224 & 736 & 43.1 & 0.0074 & 1.83 & 6.0 & 0.0088 & 4.36 & 1.72 & 0.0483 \\
\hline UR40 & & & -- & -- & 0.732 & 2.4 & 0.0046 & 1.41 & 0.557 & 0.2553 \\
\hline ARIlO & 319 & 1047 & 14.9 & 0.0097 & 1.13 & 3.7 & 0.0172 & -- & -- & -- \\
\hline UR110 & & & -- & -- & 0.914 & 3.0 & 0.0181 & 1.89 & 0.743 & 0.0404 \\
\hline \multicolumn{11}{|c|}{$\begin{array}{l}\text { EVENT P "L" " kIt in Area } 12 \text { NTS - WET TUFF-Tunnel } \\
\text { SRI/PI }\end{array}$} \\
\hline 27OURI & 48.9 & 160 & -- & -- & 23.2 & 76 & 0.0107 & -- & -- & -- \\
\hline 64OURI & 114 & 374 & -- & -- & 3.78 & 12.4 & 0.0134 & -- & -- & -- \\
\hline 640UR2 & 113 & 372 & -- & -- & 4.24 & 13.9 & 0.0116 & -- & -- & -- \\
\hline I110ARI & 197 & 646 & 30.5 & 0.0122 & -- & -- & -- & -- & -- & -- \\
\hline IIIOUR1 & & & -- & -- & 0.223 & 0.73 & 0.0290 & - & -- & -- \\
\hline \multicolumn{11}{|c|}{$\begin{array}{l}\text { EVENT R "L" kit in Area } 12 \text { NTS-WET TUFF-Tunnel } \\
\text { Sandia }\end{array}$} \\
\hline AR-35 & 45.4 & 149 & 802 & 0.0028 & -- & -- & -- & -- & -- & - \\
\hline UR-35 & & & -- & -- & 24.4 & 80 & 0.0041 & -- & - & -- \\
\hline UR-38 & 47.0 & 154 & -- & -- & 25.9 & 85 & 0.0024 & -- & -- & -- \\
\hline
\end{tabular}


TABLE 6.14 Scaled Free-Field Ground Motion--Granite

Record
Number

Scoled
Slant Range
$\underline{\mathrm{m} / \mathrm{kt}^{\mathrm{I} / 3}} \mathrm{ft} / \mathrm{kt}^{1 / 3}$

Scaled Acceleration

Peak Risetime

$\underline{\mathrm{m} / \mathrm{kt}^{1 / 3} \mathrm{ft} / \mathrm{kt}^{1 / 3}}$ \begin{tabular}{l} 
Risetime \\
$\mathrm{sec} / \mathrm{kt}^{\mathrm{I} / 3}$ \\
\hline
\end{tabular}
Particle Velocity

$\begin{array}{cll}\text { Peak } & \text { Risetime } \\ \mathrm{m} / \mathrm{sec} \quad \mathrm{ft} / \mathrm{sec} & \mathrm{sec} / \mathrm{kt}^{1 / 3}\end{array}$ $\underline{\mathrm{cm} / \mathrm{kt}^{1 / 3^{\text {Peak }}}}$ in/kt ${ }^{1 / 3}$
Scaled Displacement

Risetime Residual

$\mathrm{sec} / \mathrm{kt}^{1 / 3} \mathrm{~cm} / \mathrm{kt}^{1 / 3} \mathrm{in} / \mathrm{kt}^{1 / 3}$

HARD HAT: $5.9 \mathrm{kt}, 290 \mathrm{~m}(950 \mathrm{ft})$ deep in Area $15 \mathrm{NTS}$-GRANITE-Tunnel

Shot Level Array

$\begin{array}{cc}\text { Shot Level Array } \\ \text { 4-A } & 43.2 \\ 6-A & 51.6 \\ 6-U & \\ 8-A & 66.8 \\ 8-U & \\ 9-A & 85.2 \\ 9-U & \\ 11-A R & 102 \\ 11-U R & \\ 12-A R & 132 \\ 12-U R & \end{array}$

SRI (Swift 1965)

22VR-1 $\quad 168$

2ARS-1 251

2VRS-1 253

Vertical Array

$\begin{array}{ll}\text { OAV-6 } & 45.5 \\ O A V-5 & 54.0\end{array}$

$\begin{array}{ll}0 A V-5 & 54.0 \\ O A V-4 & 70.8\end{array}$

$\begin{array}{ll}O A V-3 & 87.7 \\ O A V-2 & 113\end{array}$

113
130

$\begin{array}{ll}O A V-1 & 130 \\ O A V-S & 160\end{array}$

$\begin{array}{ll}142 & 76 \\ 169 & 3516 \\ 219 & 8 \\ 279 & 1 \\ 334 & 83 \\ 434 & 59\end{array}$

$\begin{array}{ccc}7636 & 0.0006 & 17.2 \\ 3516 & 0.0012 & 18.5 \\ - & - & 15.6 \\ 891 & 0.0014 & 9.17 \\ \overline{1} & - & 9.14 \\ 19 & 0.0017 & 6.52 \\ - & - & 2.44 \\ 83.1 & 0.0024 & 1.83 \\ - & - & 1.58 \\ 59.1 & 0.0028 & 1.74 \\ - & - & 2.26\end{array}$

56.5
60.6
51.3
30.1
30.0
21.4
8.0
6.0
5.2
5.7
7.4

0.0007

0.0007

$0 . \overline{0} 039$

$0 . \overline{0} \overline{4} 8$

0.0069

0.0061

$\underline{\mathrm{cm} / \mathrm{kt} / 3}$

sec/nt

$\begin{array}{cl}8.99 & - \\ 1.97 & 3.54 \\ 11.9 & 0.77 \\ 9.98 & 4.70 \\ 7.87 & 3.93 \\ 3.51 & 3.10 \\ 2.53 & 1.38 \\ 0.984 & 0.996 \\ 2.78 & 0.387 \\ 3.65 & 1.10 \\ & 1.44\end{array}$

$0 . \overline{0089}$

$0 . \overline{39}$

0.033

0.041

$0.0 \overline{45}$

-

. .44

.045

$\begin{array}{ccl}-5.04 & - & 2.78 \\ 0.0044 & 0.418\end{array}$

$\begin{array}{ll}9.13 & 0.0039 \\ 1.37 & 0.0080\end{array}$

0.0080

0.013
0.0044

4.54

1.79

0.038

$0 . \overline{758}$

0.052

0.052
0.045

$\begin{array}{rc}3234 & 0.0019 \\ 2533 & 0.0022 \\ 361 & 0.0025 \\ 905 & - \\ 484 & 0.0033 \\ 204 & 0.0039 \\ 164 & 0.0044 \\ 96.5 & 0.012\end{array}$

$\begin{array}{ll}1.26 & 3.65\end{array}$

$\begin{array}{lll}21.4 & 70.1 & 0.0022 \\ 22.8 & 74.9 & 0.0028 \\ 10.1 & 33.3 & 0.0055\end{array}$

$\begin{array}{lll}21.4 & 70.1 & 0.0022 \\ 22.8 & 74.9 & 0.0028 \\ 10.1 & 33.3 & 0.0055\end{array}$

$\begin{array}{ll}10.1 & 33.3 \\ 22.2 & 72.9\end{array}$

$8.02 \quad 26.3$

0.0045

0.0055

0.0064

$\begin{array}{lll}3.93 & 12.9 & 0.0064 \\ 4.79 & 15.7 & 0.024\end{array}$

0.742

-


TABLE 6.15 Scaled Free-Field Ground Motion--Granite and Dolomite

\begin{tabular}{|c|c|c|c|c|c|c|c|c|c|c|c|c|}
\hline \multirow{2}{*}{$\begin{array}{l}\text { Record } \\
\text { Number }\end{array}$} & \multicolumn{2}{|c|}{ Scaled } & \multicolumn{2}{|c|}{ Scaled Acceleration } & \multicolumn{3}{|c|}{ Particle Velocity } & \multicolumn{5}{|c|}{ Scaled Displacement } \\
\hline & $\mathrm{m} / \mathrm{kt} \mathrm{I}^{S 3 \mathrm{ant}}$ & $\begin{array}{l}\text { Range } \\
\mathrm{ft} / \mathrm{kt}^{1 / 3}\end{array}$ & $\begin{array}{l}\text { Peak } \\
\mathrm{g} \cdot \mathrm{kt}^{\mathrm{I}} / 3\end{array}$ & $\begin{array}{l}\text { Risetime } \\
\text { sec/kt1/3 }\end{array}$ & $\mathrm{m} / \mathrm{sec}^{\mathrm{Pe}}$ & $\mathrm{ft} / \mathrm{sec}$ & $\begin{array}{l}\text { Risetime } \\
\mathrm{sec} / \mathrm{kt} / 3\end{array}$ & $\mathrm{~cm} / \mathrm{kt}^{1 / 3}$ & ak $\mathrm{in} / \mathrm{kt} 1 / 3$ & $\begin{array}{l}\text { Risetimg } \\
\mathrm{sec} / \mathrm{kt}\end{array}$ & $\mathrm{cm} / \mathrm{kt}^{1 / 3}{ }^{\text {Res }}$ & in $/ \mathrm{kt}^{1 / 3}$ \\
\hline \multicolumn{13}{|c|}{$\begin{array}{l}\text { SHOAL: } 12 \mathrm{kt}, 378 \mathrm{~m}(1205 \mathrm{ft}) \text { deep in Central Nevada-GRANITE-Tunnel } \\
\text { Sandia (Weart 1965) }\end{array}$} \\
\hline & & & VUF 2001 & & & & & & & & & \\
\hline \multicolumn{13}{|c|}{ Shot Level Array } \\
\hline PM-7 & 40.3 & 132 & 12,477 & 0.0006 & 67.1 & 220 & 0.0026 & - & - & - & - & - \\
\hline$P M-6$ & 66.6 & 218 & 641 & 0.0022 & 14.9 & 49.0 & 0.0044 & - & - & - & - & - \\
\hline $\mathrm{PX}-5$ & 111 & 363 & 140 & 0.0031 & 3.54 & 11.6 & 0.0052 & - & - & - & - & - \\
\hline PM- 4 & 173 & 568 & 38.9 & 0.0052 & 1.55 & 5.10 & 0.0072 & - & - & - & - & - \\
\hline$P M-3$ & 258 & 847 & 8.59 & 0.0055 & 0.640 & 2.10 & 0.0148 & 3.11 & 1.22 & 0.0891 & +1.66 & +0.655 \\
\hline$P M-2$ & 256 & 840 & 9.62 & 0.0043 & 0.436 & 1.43 & 0.0141 & 1.29 & 0.507 & 0.0555 & +0.166 & +0.066 \\
\hline PM-1 & 260 & 853 & 10.3 & 0.0037 & 0.546 & 1.79 & 0.0088 & 1.29 & 0.507 & 0.0529 & -0.133 & -0.052 \\
\hline \multicolumn{13}{|c|}{ Vertical Array } \\
\hline PM-8-8 & 108 & 355 & 481 & 0.0032 & 5.39 & 17.7 & 0.0041 & $>24.4$ & $>9.61$ & - & - & - \\
\hline PM-8-9 & 122 & 401 & 179 & 0.0038 & 3.86 & 12.7 & 0.0053 & 21.6 & 8.52 & $0 . I 682$ & -1.11 & -0.44 \\
\hline PM-8-10 & 136 & 446 & 108 & 0.0041 & 3.38 & 11.1 & 0.0061 & 26.1 & 10.3 & 0.1734 & +13.5 & +5.33 \\
\hline PM-8-11 & 154 & 504 & 93.9 & 0.0062 & 3.90 & 12.8 & 0.0104 & 34.9 & 13.8 & 0.1804 & +11.3 & +4.43 \\
\hline PM-8-12 & 160 & 525 & 140 & 0.0082 & 6.40 & 21.0 & 0.0133 & 44.9 & 17.7 & 0.1603 & +15.5 & +6.12 \\
\hline \multicolumn{13}{|c|}{$\begin{array}{l}\text { HANDCAR. } 12 \mathrm{kt}, 402 \mathrm{~m}(1319 \mathrm{ft}) \text { deep in Ares } 8 \mathrm{NTS} \text {-DOLOMITE-Boring } \\
\text { Sandia (Perret } 1970 \mathrm{l})\end{array}$} \\
\hline \multicolumn{13}{|c|}{ Offset Vertical Arrays } \\
\hline $\mathrm{BI}-\mathrm{SAV}$ & 175 & 575 & 9.75 & 0.0095 & 2.07 & 6.80 & 0.0376 & 15.2 & 5.98 & 0.1385 & +3.66 & +1.44 \\
\hline Bl-SAVI & 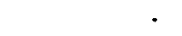 & & 9.62 & 0.0087 & 2.07 & 6.80 & 0.0358 & 16.0 & 6.29 & 0.1420 & +8.88 & +3.49 \\
\hline $\mathrm{B} 1-1 \overline{\mathrm{UR}^{1}}$ & 78.1 & 256 & 49.2 & 0.0026 & 3.69 & 12.1 & 0.0214 & 32.4 & 12.8 & 0.1463 & +26.6 & +10.5 \\
\hline $\mathrm{Bl}-2 \overline{\mathrm{UR}}^{2}$ & 70.2 & 230 & 109 & 0.0017 & 3.87 & 12.7 & 0.0105 & - & - & - & - & - \\
\hline $\mathrm{B} 2-1 \overline{\mathrm{UR}^{1}}$ & 107 & 350 & 58.4 & 0.0017 & 2.85 & 9.35 & 0.0144 & 11.6 & 4.59 & 0.1267 & +9.76 & +3.84 \\
\hline $\mathrm{B} 2-2 \overline{\mathrm{UR}^{2}}$ & 97.6 & 320 & 63.0 & 0.0017 & 4.42 & 14.5 & 0.0114 & 17.2 & 6.77 & 0.1018 & +15.8 & +6.20 \\
\hline $\mathrm{B} 2-3 \mathrm{UR}^{3}$ & 82.5 & 271 & 90.0 & 0.0017 & 3.11 & 10.2 & 0.0149 & 15.1 & 5.94 & 0.1070 & +12.0 & +4.72 \\
\hline $\mathrm{B} 4-1 \overline{\mathrm{UR}^{1}}$ & 128 & 422 & 23.1 & 0.0048 & 1.73 & 5.66 & 0.0144 & 6.59 & 2.59 & 0.0791 & +4.66 & +1.83 \\
\hline $\mathrm{B} 4-2 \mathrm{UR}^{2}$ & 123 & 404 & 19.0 & 0.0031 & 1.65 & 5.40 & 0.0183 & 6.26 & 2.46 & 0.0743 & +3.55 & +1.40 \\
\hline $\mathrm{B} 4-3 \overline{\mathrm{UR}}^{3}$ & 113 & 372 & 24.3 & 0.0044 & 1.66 & 5.44 & 0.0175 & 12.3 & 4.85 & 0.0721 & +8.88 & +3.49 \\
\hline$B 4-4 \mathbb{U R}^{3}$ & 93.6 & 307 & 65.0 & 0.0026 & 1.98 & 6.49 & 0.0070 & 2.05 & 0.808 & 0.0240 & -0.666 & -0.262 \\
\hline B5-1 $\overline{U^{2}}$ & 208 & 683 & 9.09 & 0.0087 & 0.354 & 1.16 & 0.0166 & 0.677 & 0.266 & 0.0428 & +0.666 & +0.262 \\
\hline $\mathrm{B} 5-2 \overline{\mathrm{UR}}^{2}$ & 206 & 675 & 7.28 & 0.0087 & 0.561 & & 0.0323 & & 0.590 & 0.0542 & +0.999 & +0.393 \\
\hline $\mathrm{B} 5-3 \mathrm{UR}$ & 198 & 650 & 7.37 & 0.0074 & 0.671 & 2.20 & 0.0170 & 1.86 & 0.734 & 0.0537 & +1.44 & +0.568 \\
\hline $\mathrm{B} 5-4 \mathrm{UR}^{3}$ & 186 & 612 & - & - & 1.23 & 4.03 & 0.0114 & 1.81 & 0.712 & 0.0280 & +0.666 & +0.262 \\
\hline $\mathrm{B} 6-1 \overline{\mathrm{UR}}^{3}$ & 412 & 1352 & 3.27 & 0.0175 & 0.201 & 0.660 & 0.0236 & 0.366 & 0.144 & 0.0555 & 0.0 & 0.0 \\
\hline
\end{tabular}

Superscripts indicate rock at gage stations as follows: I tuff, 2 shale, 3 carbonate. 
TABLE 6.16 Scaled Free-Field Ground Motion--Granite

\begin{tabular}{|c|c|c|c|c|c|c|c|c|c|c|c|c|}
\hline \multirow{3}{*}{$\begin{array}{l}\text { Record } \\
\text { Number }\end{array}$} & & Scaled & Scaled & celeration & \multicolumn{3}{|c|}{ Particle Velocity } & \multicolumn{3}{|c|}{ Scaled Displacement } & \multirow{2}{*}{\multicolumn{2}{|c|}{ Residual }} \\
\hline & & at Range & Peak & Risetime & & & Risetime & & & Risetime & & \\
\hline & $\mathrm{m} / \mathrm{kt}^{1 / 3}$ & $\mathrm{ft} / \mathrm{kt} \mathrm{t}^{1 / 3}$ & $\mathrm{~g} \cdot \mathrm{kt} \mathrm{t}^{1 / 3}$ & $\mathrm{sec} / \mathrm{kt}^{1 / 3}$ & $\mathrm{~m} / \mathrm{sec}$ & $\mathrm{ft} / \mathrm{sec}$ & $\mathrm{sec} / \mathrm{kt}^{1 / 3}$ & $\mathrm{~cm} / \mathrm{kt}^{1 / 3}$ & $\mathrm{in} / \mathrm{kt}^{1 / 3}$ & $\mathrm{sec} / \mathrm{kt}^{1 / 3}$ & $\mathrm{~cm} / \mathrm{kt}^{1 / 3}$ & $\mathrm{in} / \mathrm{kt}{ }^{1}$ \\
\hline
\end{tabular}

PILE DRIVER: $56 \mathrm{kt}, 463 \mathrm{~m}(1518 \mathrm{ft})$ deep in Area $15 \mathrm{NTS}-$ GRANITE-Tunnel
SRI (Hoffman, Sauer 1969$)$

Vertical Array

$\begin{array}{cccc}\text { Verticel } & \text { Array } & & \\ \text { 9UV } & 47.8 & 157 & - \\ \text { 8UV } & 55.8 & 183 & - \\ 6 \mathrm{AV} & 79.7 & 261 & 516 \\ \text { 6UV } & & & - \\ \text { 5AV } & 91.6 & 301 & 115 \\ 5 \mathrm{UV} & & & - \\ \text { 3AV } & 104 & 340 & 73 \\ \text { 3UV } & & & - \\ \text { 2AV } & 108 & 353 & 115 \\ 1 \mathrm{UV} & 112 & 366 & - \\ \text { OAV-S } & 121 & 397 & 325\end{array}$

$\begin{array}{cc}- & 29 \\ - & 36.6 \\ 0.0021 & 8.23 \\ - & 11.6 \\ 0.0044 & 3.66 \\ - & 4.57 \\ 0.0091 & 4.57 \\ - & 3.35 \\ 0.0089 & 4.57 \\ - & 4.88 \\ 0.0091 & 7.62\end{array}$

$\begin{array}{rr}95 & 0.0026 \\ 120 & 0.0024 \\ 27 & 0.0034 \\ 38 & 0.0029 \\ 12 & 0.0099 \\ 15 & 0.0091 \\ 15 & 0.0139 \\ 11 & 0.0128 \\ 15 & 0.0115 \\ 16 & 0.0183 \\ 25 & 0.0128\end{array}$

-
-
-
83.7
-
61.7
-
34.5
-
53.1
-

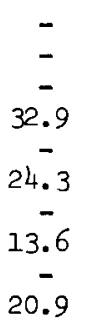

-
-
0.2381

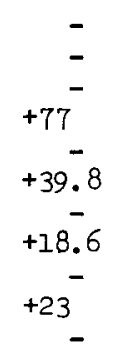

-
+
+30
-
+15.7
+7.3
+-
+9.1
-

Shot Level Array

1403 UR 159

$2403 \frac{\mathrm{UR}}{\mathrm{UR}} \quad 159$

1503 UR 225

2503 UR 225

$\begin{array}{ll}523 & - \\ 523 & - \\ 740 & - \\ 740 & -\end{array}$

-
-
-

2.93

\section{$9.6 \quad 0.0065$}

$\begin{array}{lll}1.65 & 5.41 & 0.0067\end{array}$

Sandia (Perret 1968b)

X-SLRAR-UR 25.3

Y-SLRUR 30.8

A-SLRUR $\quad 37.7$

$83.1 \quad 2.3 \times 10^{5 *}$

1.05

$3.44 \quad 0.0084$

3.86

3.86
12.8

1. 52

0.0105

2.16

5.04

0.0766

0.0371

0.2250

$0 . \overline{2159}$

0.2141

0.0004

30.5
67.1
35.4
14.6
65.2
33.5
15.2
3.05
6.25

100
220
116
48
$214 *$
110
50
10
20.5
37.5
14.7
18.8

0.0004

0.0007

0.0013

0.0008

0.0014

0.0021

0.0017

0.0022

0.0022

C-SLRAR

74.3

0.0015

11.4

16-SLRAR 123

0.0018

4.48
5.73

14.7
18.8

0.0055
0.0055

$\begin{array}{cc}- & - \\ - & - \\ - & - \\ - & - \\ - & - \\ 43.2 & 17.0 \\ - & - \\ - & - \\ - & - \\ - & -- \\ 10.4 & 4.10\end{array}$

-
$=$
$=$
0.0503
$=$
-
-
-
0.0452

* Saturated record peaks. 
TABLE 6.17 Scaled Free-Field Ground Motion--Volcanic Breccia and Lava

\begin{tabular}{|c|c|c|c|c|c|c|c|c|c|c|c|c|}
\hline \multirow[t]{2}{*}{$\begin{array}{l}\text { Record } \\
\text { Number }\end{array}$} & \multicolumn{2}{|c|}{ Scaled } & \multirow{2}{*}{$\begin{array}{l}\text { Scaled } \\
\text { Peak } \\
\mathrm{g}^{\circ} \mathrm{kt}^{1 / 3}\end{array}$} & \multirow{2}{*}{$\begin{array}{c}\text { celeration } \\
\text { Risetime } \\
\mathrm{sec} / \mathrm{kt}^{1 / 3}\end{array}$} & \multicolumn{3}{|c|}{ Particle Velocity } & \multicolumn{5}{|c|}{ Scaled Displacement } \\
\hline & $\mathrm{m} / \mathrm{kt}^{1 / 3}$ & $\mathrm{ft} / \mathrm{kt}^{1 / 3}$ & & & $\mathrm{~m} / \mathrm{sec}$ & $\mathrm{ft} / \mathrm{sec}$ & $\mathrm{sec} / \mathrm{kt}^{\mathrm{I} / 3}$ & ${\mathrm{~cm} / \mathrm{kt}^{1 / 3}}^{1 / 3}$ & in $/ \mathrm{kt}^{1 / 3}$ & $\sec / \mathrm{kt}^{1 / 3}$ & $\mathrm{~cm} / \mathrm{kt}^{1 / 3}$ & in $/ \mathrm{kt}^{1 / 3}$ \\
\hline \multicolumn{13}{|c|}{$\begin{array}{l}\text { LONGSHOT: } 81 \mathrm{kt}, 701 \mathrm{~m} \text { (2300 ftt) deep in Amchitka-VOLCANIC BRECCIA-Boring } \\
\text { WES (Day, Murrell 1967) }\end{array}$} \\
\hline \multicolumn{13}{|c|}{ Vertical Array } \\
\hline $6 \mathrm{~A}$ & 84.5 & 277 & 215 & 0.0025 & $7.99^{*}$ & $26.2^{*}$ & 0.0051 & - & - & - & - & - \\
\hline $6 \mathrm{~V}$ & & & - & - & 8.81 & 28.9 & 0.0046 & - & - & - & - & - \\
\hline $5 \mathrm{~A}$ & 98.6 & 324 & 225 & 0.0028 & 8.02 & 26.3 & 0.0051 & - & - & - & - & - \\
\hline $5 \mathrm{~V}$ & & & - & - & $7.04 *$ & $23.1^{*}$ & - & - & - & - & - & - \\
\hline $4 A-V$ & 113 & 370 & $132 *$ & 0.0049 & $7.71 *$ & $25.3^{*}$ & 0.0055 & - & - & - & _- & - \\
\hline $3 \mathrm{~A}$ & 127 & 416 & 103 & 0.0032 & 4.05 & 13.3 & 0.0058 & - & - & - & - & - \\
\hline $3 \mathrm{~V}$ & & & - & - & 4.85 & 15.9 & 0.0051 & - & - & - & - & - \\
\hline $9 \mathrm{~V}$ & 134 & 438 & - & - & 3.63 & 11.9 & 0.0083 & - & - & - & - & - \\
\hline $2 \mathrm{~A}$ & 155 & 508 & 108 & 0.0042 & 6.68 & 21.9 & 0.0125 & - & - & - & - & - \\
\hline $2 \mathrm{~V}$ & & & - & - & 3.99 & 13.1 & 0.0116 & - & - & - & - & - \\
\hline $8 \mathrm{~V}$ & 161 & 527 & - & - & 3.96 & 13.0 & 0.0136 & 26.2 & 10.3 & 0.141 & - & - \\
\hline$I \mathrm{AV}-\mathrm{S}$ & 162 & 532 & 114 & 0.0042 & 5.76 & 18.9 & 0.0079 & 39.6 & 15.6 & 0.145 & - & - \\
\hline $1 \mathrm{~V}-\mathrm{S}$ & & & - & - & 5.64 & 18.5 & 0.0067 & 51.8 & 20.4 & 0.174 & - & - \\
\hline \multicolumn{13}{|c|}{$\begin{array}{l}\text { MILROW: -1 Mt, } 1220 \mathrm{~m} \text { (4000 ft) deep in Amchitka-PILLOW LAVA-Boring } \\
\text { Sandia (Perret, Breding 1972) }\end{array}$} \\
\hline \multicolumn{13}{|c|}{ Vertical Array } \\
\hline II-2OAV-UV & 61.5 & 202 & 673 & 0.0023 & 11.2 & 36.9 & 0.0035 & - & - & - & - & _- \\
\hline Il-25AV hi & 76.7 & 252 & 335 & 0.0011 & - & - & - & - & - & - & - & - \\
\hline $\mathrm{Il}-25 \mathrm{AV}-\mathrm{UV}$ & & & 361 & 0.0012 & 8.35 & 27.4 & 0.0037 & 35.3 & 13.9 & 0.1393 & +25.9 & +10.2 \\
\hline II-30AV 10 & 91.9 & 302 & 273 & 0.0014 & 10.1 & 33.2 & 0.0063 & - & - & - & - & - \\
\hline $\mathrm{II}-30 \mathrm{AV}-\mathrm{UV}$ & & & 272 & 0.0014 & 9.57 & 31.4 & 0.0052 & 46.5 & 18.3 & 0.0081 & +47.2 & +18.6 \\
\hline $\mathrm{Il}-35 \mathrm{AV}-\mathrm{UV}$ & 107 & 351 & 245 & 0.0024 & 5.09 & 16.7 & 0.0017 & 25.9 & 10.2 & 0.1366 & +16.8 & +6.60 \\
\hline I2-37AV hi & 113 & 371 & 181 & 0.0016 & - & - & - & - & - & - & - & - \\
\hline $\mathrm{I} 2-37 \mathrm{AV}-\mathrm{UV}$ & & & 196 & 0.0018 & 6.71 & 22.0 & 0.0016 & 36.8 & 14.5 & 0.1051 & +14.0 & +5.50 \\
\hline $\mathrm{I} 2-39 \mathrm{AV}$ & 119 & 391 & 207 & 0.0037 & 9.69 & 31.8 & 0.0092 & - & - & - & - & - \\
\hline I2-39UV & & & - & - & 8.87 & 29.1 & 0.0128 & 49.3 & 19.4 & 0.1027 & +17.3 & +6.80 \\
\hline SO-AV hi & 122 & 400 & 355 & 0.0037 & - & - & - & - & - & - & - & - \\
\hline SO-AV-UV & & & 303 & 0.0035 & 8.44 & 27.7 & 0.0140 & 43.2 & 17.0 & 0.1051 & +11.9 & +4.70 \\
\hline
\end{tabular}



TABLE 6. 19 Scaled Free-Field Ground Motion--Shale and Rhyolite

\begin{tabular}{|c|c|c|c|c|c|c|c|c|c|c|c|c|}
\hline \multirow{3}{*}{$\begin{array}{l}\text { Re cord } \\
\text { Number }\end{array}$} & \multicolumn{2}{|c|}{ Scaled } & \multirow{3}{*}{$\begin{array}{l}\text { Scal } \\
\text { Peak } \\
\mathrm{g} \cdot \mathrm{kt}^{1 / 3}\end{array}$} & \multirow{3}{*}{$\begin{array}{l}\text { Acceleration } \\
\text { Risetime } \\
\mathrm{sec} / \mathrm{kt}^{1 / 3}\end{array}$} & \multicolumn{3}{|c|}{ Particle Velocity } & \multicolumn{5}{|c|}{ Scaled Displacement } \\
\hline & & at Range & & & \multicolumn{2}{|c|}{ Peak } & Risetime & \multicolumn{2}{|c|}{ Peak } & \multirow{2}{*}{$\begin{array}{l}\text { Risetime } \\
\text { sec/ } \mathrm{kt}^{1 / 3}\end{array}$} & \multicolumn{2}{|c|}{ Resi dual } \\
\hline & $\mathrm{m} / \mathrm{kt}^{1 / 3}$ & $\mathrm{ft} / \mathrm{kt}^{1 / 3}$ & & & $\mathrm{~m} / \mathrm{sec}$ & $\mathrm{ft} / \mathrm{sec}$ & $\mathrm{sec} / \mathrm{kt} t^{1 / 3}$ & $\mathrm{~cm} / \mathrm{kt}^{\mathrm{I} / 3}$ & $\mathrm{in} / \mathrm{kt}^{1 / 3}$ & & $\mathrm{~cm} / \mathrm{kt}^{1 / 3}$ & $\mathrm{in} / \mathrm{kt}^{1 / 3}$ \\
\hline \multicolumn{13}{|c|}{$\begin{array}{l}\text { GASBUGGY: } 29 \mathrm{kt}, 1290 \mathrm{~m} \text { (14240 ft) deep in San Juan Basin —LEWIS SHALE一Boring } \\
\text { Sandia (Perret 1970a) }\end{array}$} \\
\hline \multicolumn{13}{|c|}{ Offset Vertical Array } \\
\hline $\mathrm{U} 41-\overline{\mathrm{UR}}^{\mathrm{I}}$ & 152 & 499 & 83.0 & 0.0029 & 2.42 & 7.94 & 0.0052 & 2.23 & 0.878 & 0.0218 & +0.846 & +0.333 \\
\hline $\mathrm{U} 46-\overline{\mathrm{UR}}_{2}^{2}$ & 156 & 510 & 63.6 & 0.0036 & 1.96 & 6.43 & 0.0052 & 1.70 & 0.670 & 0.0277 & +1.04 & +0.410 \\
\hline $\mathrm{U} 36-\mathrm{UR}^{3}$ & 166 & 544 & 45.5 & 0.0039 & 1.59 & 5.21 & 0.0062 & 1.36 & 0.537 & 0.0192 & +0.895 & +0.352 \\
\hline$U 32-\overline{U R}^{4}$ & 181 & 594 & 40.9 & 0.0029 & 1.33 & 4.36 & 0.0049 & 1.23 & 0.482 & 0.0156 & +0.586 & +0.231 \\
\hline $\mathrm{S} I-\mathrm{AV}$ & 422 & 1383 & 19.2 & 0.0133 & 1.67 & 5.48 & 0.0218 & 5.57 & 2.19 & 0.0687 & +0.488 & +0.192 \\
\hline
\end{tabular}

BOXCAR-1.2 Mt, $1165 \mathrm{~m}$ ( $3822 \mathrm{ft}$ ) deep in Area 20 NTS-RHYOLITE-Boring $1.2 \mathrm{Mt}, 1165 \mathrm{~m}(3822 \mathrm{f}$
Sandia unreported

Shot Level Array

$\begin{array}{cccccccc}\text { Shot Le vel } & \text { Array } & & & & \\ \text { U8-AR } & 231 & 756 & 21.3 & 0.0141 & 1.77 & 5.8 & 0.0191 \\ \text { U8-UR } & & & - & - & 1.80 & 5.9 & 0.0188 \\ \text { U24-AR } & 685 & 2247 & 1.28 & 0.0028 & 0.107 & 0.35 & 0.0085 \\ \text { U24-UR } & & & - & - & 0.101 & 0.33 & 0.0094 \\ \text { SO-AVhi } & 109 & 358 & 78.6 & 0.0015 & 6.10 & 20.0 & 0.0245 \\ \text { SO-AV10 } & & & 81.8 & 0.0019 & 6.89 & 22.6 & 0.0245 \\ \text { S0-UV } & & & - & - & 6.40 & 21.0 & 0.0245\end{array}$

$-\overline{3}$
2.
$0 . \overline{1} 39$
-
$30 . \overline{8}$

$0 . \overline{93}$
$\overline{-}$
0.055
$-\overline{-}$
$12 . \overline{1}$

0.
0.0475
-
0.0254
-
-
0.0922

$\begin{array}{rr}- & - \\ - & - \\ - & \overline{0} \\ -\overline{0} & - \\ +6.69 & +2 . \overline{6} 3\end{array}$

Superscripts indicate rock at gage station as follows: 1. Pictured Cliffs sandstone, 2. Lewis Shale, 3. 0jo Alamo sandstone, 4 . Nacimiento shale and sandstone. 
TABLE 6.20 Scaled Free-Field Ground Motion--Bedded Salt

\begin{tabular}{|c|c|c|c|c|c|c|c|c|c|c|c|c|}
\hline \multirow{3}{*}{$\begin{array}{l}\text { Record } \\
\text { Number }\end{array}$} & \multicolumn{2}{|c|}{ Scaled } & $\mathrm{Scal}$ & Acceleration & \multicolumn{3}{|c|}{ Particle Velocity } & \multicolumn{5}{|c|}{ Scaled Displacement } \\
\hline & & nt Range & Peak & Risetime & & & Risetime & & & Risetime & & idual \\
\hline & $\mathrm{m} / \mathrm{kt}^{1 / 3}$ & $\mathrm{ft} / \mathrm{kt}^{1 / 3}$ & $g \cdot k t^{1 / 3}$ & $\mathrm{sec} / \mathrm{kt}^{1 / 3}$ & $\mathrm{~m} / \mathrm{sec}$ & $\mathrm{ft} / \mathrm{sec}$ & $\mathrm{sec} / \mathrm{kt}^{1 / 3}$ & $\mathrm{~cm} / \mathrm{kt}^{1 / 3}$ & $\mathrm{in} / \mathrm{kt}^{1 / 3}$ & $\mathrm{sec} / \mathrm{kt}^{1 / 3}$ & $\mathrm{~cm} / \mathrm{kt}^{1 / 3}$ & $\mathrm{in} / \mathrm{kt}^{1 / 3}$ \\
\hline
\end{tabular}
GNOME: $3.1 \mathrm{kt}, 366 \mathrm{~m}(1200 \mathrm{ft}$ ) deep in BEDDED SALT-Tunnel

$\begin{array}{cc}\text { Vertical } & \text { Array } \\ 18 \mathrm{~A} & 80.2 \\ 23 \mathrm{~A} & 154 \\ 24 \mathrm{~A} & 184 \\ 25 \mathrm{~A} & 206 \\ 26 \mathrm{~A} & 226 \\ 27 \mathrm{~A} & 237 \\ 20 \mathrm{~A}-\mathrm{S} & 247\end{array}$

Shot Level

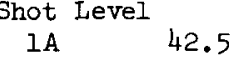

$\begin{array}{ll}\text { 2A-hi } & 52.1\end{array}$

2A-10

$3 \mathrm{~A}$

$4 \mathrm{~A}-\mathrm{hi}$

$4 A-10$

4U-hi

$4 U-10$

$\begin{array}{ll}5 \mathrm{~A} & 119 \\ 5 \mathrm{U} & \end{array}$

6A-hi 157

$6 \mathrm{~A}-10$

TA 204

$\begin{array}{ll}\text { TA } & 204 \\ 2 I A & 327\end{array}$

SRI (Swift 1962)

$\begin{array}{llr}2 & A R & 552 \\ 3 & A R & 1103 \\ 4 & A R & 2208\end{array}$

$5 A R \quad 6481$

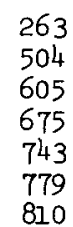

$$
\begin{array}{r}
554 \\
117 \\
64.2 \\
36.5 \\
40.8 \\
26.2 \\
36.5
\end{array}
$$

$$
\begin{aligned}
& 0.012 \\
& 0.011 \\
& 0.016 \\
& 0.013 \\
& 0.023 \\
& 0.030
\end{aligned}
$$

$\begin{array}{rr}18.0 & 59.1 \\ 6.7 & 22.0 \\ 3.5 & 11.5 \\ 3.2 & 10.5 \\ 4.4 & 14.4 \\ 4.8 & .15 .7 \\ 5.6 & 18.4\end{array}$

$0 . \overline{0} 13$

0.020

0.033

0.039

0.047

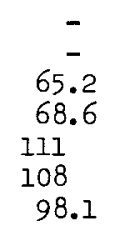
$-$
27.0
42.7
38.6

0.030

70.1230

0.0013
0.0019

$31.1 \quad 102$

17

15,602
5,687

3,645

$0 . \overline{0021}$

$0 . \overline{0043}$

13.0

$\overline{496}$

496
452

-

389

175

-

-

$0 . \overline{0071}$

$0 . \overline{0} 02$

87.5
65.6

37.9

12. 7

-

$0 . \overline{0} 117$

$0 . \overline{0191}$

$\begin{array}{rr}10.5 & 125 \\ 10.3 & 34.4\end{array}$

$10.3 \quad 33.8$

$9.3 \quad 30.5$

$\begin{array}{ll}9.5 & 31.2 \\ 4.8 & 15.7\end{array}$

$9.0 \quad 29.5$

$4.7 \quad 15.4$

$\begin{array}{ll}4.2 & 13.8\end{array}$

$4.4 \quad 14.4$

2.8

3.0
4.49

9.19
9.84

9.84
14.7

0.0034

0.0040

0.0049

0.0069

-

$0 . \overline{0} 082$

-

0.0138

0.0165

0.0233

98.1

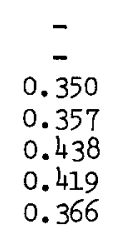

0.419
0.366

-
-
$=$
$=$
$=$
$=$
$=$
$=$
-
7.54
7.54
8.37
4.46
5.21
-

-
-
-
-
-
-
-
-
-
2.97
2.97
3.29
1.75
2.05
-

-
-
-
-
-
-
-
-
-
-
0.0501
-
0.0494
-

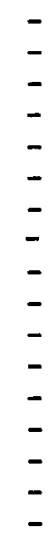

0.0288

0.0336

0.0453

0.0720
1.28
0.508
0.123

0.505
0.200
0.049
0.0624
0.0514
0.0665 
TABLE 6. 21 Scaled Free-Field Ground Motion--Dome Salt

\begin{tabular}{|c|c|c|c|c|c|c|c|c|c|c|c|c|}
\hline \multirow{3}{*}{$\begin{array}{l}\text { Record } \\
\text { Number }\end{array}$} & \multirow{2}{*}{\multicolumn{2}{|c|}{$\begin{array}{l}\text { Scaled } \\
\text { Slant Range }\end{array}$}} & \multicolumn{2}{|c|}{ Scaled Acceleration } & \multicolumn{3}{|c|}{ Particle Velocity } & \multicolumn{5}{|c|}{ Scaled Displacement } \\
\hline & & & Peak & Risetime & & & Risetime & & & Risetime & & idual \\
\hline & $\mathrm{m} / \mathrm{kt}^{1 / 3}$ & $\mathrm{ft} / \mathrm{kt} \mathrm{t}^{1 / 3}$ & $\mathrm{~g} \cdot \mathrm{kt}^{1 / 3}$ & $\mathrm{sec} / \mathrm{kt}^{1 / 3}$ & $\mathrm{~m} / \mathrm{sec}$ & $\mathrm{ft} / \mathrm{sec}$ & $\sec / k t^{1 / 3}$ & $\mathrm{~cm} / \mathrm{kt}^{1 / 3}$ & in $/ \mathrm{kt}^{1 / 3}$ & $\mathrm{sec} / \mathrm{kt} \mathrm{t}^{\mathrm{I} / 3}$ & $\mathrm{~cm} / \mathrm{kt}^{1 / 3}$ & $\mathrm{in} / \mathrm{kt}^{1 / 3}$ \\
\hline \multicolumn{13}{|c|}{$\begin{array}{l}\text { SALMON: } 5.3 \mathrm{kt}, 828 \mathrm{~m}(2717 \mathrm{ft}) \text { deep in Tatum SALT DOME-Boring } \\
\text { Sandia (Perret } 1968 \mathrm{a})\end{array}$} \\
\hline \multicolumn{13}{|c|}{ Offset Vertical Array } \\
\hline 14C-27ARH & 95.1 & 312 & 1813 & 0.0041 & 14.0 & 46.1 & 0.0047 & 12.5 & 4.93 & 0.0338 & +8.61 & +3.39 \\
\hline $14 \mathrm{C}-22 \mathrm{AR}$ & 129 & 424 & 697 & 0.0058 & 7.52 & 24.7 & 0.0067 & 7.32 & 2.88 & 0.0330 & +5.16 & +2.03 \\
\hline $14 \mathrm{C}-22 \overline{\mathrm{UR}}$ & & & - & - & 8.17 & 26.8 & 0.0066 & 8.55 & 3.36 & 0.0350 & +6.54 & +2.57 \\
\hline $14 \mathrm{C}-32 \mathrm{AR}$ & 129 & 424 & 697 & 0.0057 & 7.70 & 25.3 & 0.0071 & 7.78 & 3.06 & 0.0340 & +7.31 & +2.88 \\
\hline $14-20 \mathrm{AR}$ & 158 & 519 & 471 & 0.0070 & 5.49 & 18.0 & 0.0083 & 5.68 & 2.24 & 0.0338 & +1.98 & +0.779 \\
\hline $6-27$ ARH & 183 & 599 & 288 & 0.0079 & 3.90 & 12.8 & 0.0094 & 4.28 & 1.68 & 0.0341 & +2.58 & +1.02 \\
\hline $6-27 \mathrm{URH}$ & & & - & - & 5.48 & 18.0 & 0.0087 & 4.69 & 1.85 & 0.0307 & +2.46 & +0.971 \\
\hline $14 \mathrm{C}-36 \overline{\mathrm{UR}}$ & 184 & 604 & 282 & - & 3.85 & 12.6 & 0.0099 & 4.21 & 1.66 & 0.0328 & +1.15 & +0.452 \\
\hline $6-20 \overline{\mathrm{UR}}$ & 223 & 730 & 176 & - & 3.05 & 10.0 & 0.0115 & 3.54 & 1.40 & 0.0350 & +2.47 & +0.971 \\
\hline $14 \mathrm{C}-39 \underline{\mathrm{AR}}$ & 230 & 756 & 163 & 0.0101 & 2.68 & 8.79 & 0.0118 & 3.02 & 1.19 & 0.0339 & +0.172 & +0.068 \\
\hline $14 \mathrm{C}-39 \mathrm{UR}$ & & & - & - & 2.67 & 8.76 & 0.0110 & 2.75 & 1.08 & 0.0333 & +0.516 & +0.203 \\
\hline $11-2 T \mathrm{TRH}$ & 357 & 1170 & - & - & 1.16 & 3.81 & 0.0166 & 1.57 & 0.616 & 0.0367 & +0.459 & +0.181 \\
\hline $11-20 \underline{\mathrm{UR}}$ & 375 & 1229 & - & - & 1.15 & 3.77 & 0.0178 & 1.58 & 0.621 & 0.0390 & +0.746 & +0.294 \\
\hline $11-34 \overline{U R}$ & 378 & 1241 & 24.1 & - & 0.990 & 3.25 & 0.0192 & 1.33 & 0.524 & 0.0387 & +0.430 & +0.169 \\
\hline 5-27URH & 427 & 1400 & 7.48 & 0.0117 & 0.652 & 2.14 & 0.0186 & 1.07 & 0.422 & 0.0399 & +0.516 & +0.203 \\
\hline \multicolumn{13}{|c|}{ SAI (Eisler, Hoffman 19ఱ9) } \\
\hline \multicolumn{13}{|c|}{ Shot Level Array } \\
\hline $2 \mathrm{~V} \mathrm{RI}$ & 192 & 629 & - & - & 2.6 & 8.5 & 0.0109 & 3.27 & 1.29 & 0.0334 & +1.26 & +0.497 \\
\hline $26 \mathrm{~V} \mathrm{RI}$ & 198 & 650 & - & - & 3.9 & 12.8 & 0.0109 & 4.53 & 1.78 & 0.0330 & - & - \\
\hline $13 \mathrm{~V} \mathrm{RI}$ & 258 & 846 & - & - & 2.6 & 8.5 & 0.0152 & 3.21 & 1.26 & 0.0358 & +1.03 & +0.406 \\
\hline $14 \mathrm{~V} \mathrm{RI}$ & 282 & 924 & - & - & 0.8 & 2.62 & 0.0161 & 1.03 & 0.406 & 0.0364 & +0.287 & +0.113 \\
\hline \multicolumn{13}{|c|}{ Vertical Array } \\
\hline $15 \mathrm{AV}-6$ & 74.2 & 243 & 1621 & 0.0017 & 15.0 & 49.2 & 0.0029 & 5.74 & 2.26 & 0.0086 & - & - \\
\hline $15 \mathrm{VV}-4$ & 91.5 & 300 & - & - & 22.0 & 72.2 & 0.0046 & 18.1 & 7.11 & 0.0356 & - & - \\
\hline $15 \mathrm{VV}-3$ & 143 & 468 & - & - & 8.20 & 26.9 & 0.0057 & 7.63 & 3.00 & 0.0293 & - & - \\
\hline $15 \mathrm{VV}-\mathrm{I}$ & 231 & 757 & - & - & 1.35 & 4.43 & 0.0115 & 1.43 & 0.565 & 0.0499 & - & - \\
\hline $16 u v-6$ & 388 & 1274 & - & - & 1.04 & 3.41 & 0.0115 & 1.20 & 0.474 & 0.0287 & - & - \\
\hline $16 \mathrm{AV}-5$ & 405 & 1330 & 41.8 & 0.0092 & 1.05 & 3.44 & 0.0109 & - & - & - & - & - \\
\hline $16 \mathrm{AV}-4$ & 423 & 1387 & 41.5 & 0.0086 & 1.12 & 3.67 & 0.0115 & 1.95 & 0.768 & 0.0338 & - & - \\
\hline $16 \mathrm{VV}-4$ & & & - & - & 1.04 & 3.41 & 0.0115 & 2.08 & 0.820 & 0.0327 & - & - \\
\hline $16 \mathrm{AV}-3$ & 436 & 1430 & 27.9 & 0.0109 & 1.20 & 3.94 & 0.0138 & 1.84 & 0.723 & 0.0344 & - & - \\
\hline $16 \mathrm{AV}-2$ & 449 & 1473 & 17.8 & 0.0103 & 1.07 & 3.51 & 0.0161 & 2.12 & 0.835 & 0.0705 & - & - \\
\hline $16 v v-2$ & & & - & - & 1.29 & 4.23 & 0.0178 & 2.70 & 1.06 & 0.0665 & - & - \\
\hline $16 \mathrm{AV}-1$ & 458 & 1502 & 26.9 & 0.0120 & 1.22 & 4.00 & 0.0149 & 3.56 & 1.40 & 0.0809 & - & - \\
\hline $16 \mathrm{AV}-\mathrm{VV}-\mathrm{S}$ & 475 & 1559 & 48.8 & 0.0195 & 3.60 & 11.8 & 0.0275 & 20.1 & 7.90 & 0.0992 & - & - \\
\hline
\end{tabular}




\section{REFERENCES}

Bass, R. C. , Close-In Shock Studies, Project 1. 4 Ferris Wheel Series, Flat Top Event, POR3005, Sandia Laboratory, October 1965.

Bass, R. C., Additional Hugoniot Data for Geologic Materials, SC RR-66-848, Sandia Laboratory, Albuquerque, New Mexico, October 1966.

Bass, R. C., Chabai, A. J., and Hawk, H. L., Project Shoal, Hydrodynamic and Plastic Shock Studies, VUF 1003, Sandia Laboratory, Albuquerque, New Mexico, March 1966.

Bass, R. C., Hawk, H. L., and Chabai, A. J., Hugoniot Data For Some Geologic Materials, SC-4903(RR), Sandia Laboratory, Albuquerque, New Mexico, June 1963.

Chabai, A. J., and Bass, R. C., Measurements on a Spherical Shock Wave in a Granite Medium, SC-4741(RR), Sandia Laboratory, Albuquerque, New Mexico, December 1963.

Chabai, A. J., Bass, R. C., and Hawk, H. L., Close In Phenomenon of Buried Explosions, DASA 1382 Defense Documentation Center, Cameron Station, Alexandria, Virginia, May 1963.

Day, J. D. and Murrell, D. W., Ground and Water Shock Measurements, Project 1.01 Vela Uniform Program, Long Shot Event, VUF 2701, U. S. Army Engineer Waterways Experiment Station, March 1967.

Eisler, J. D., and Hoffman, H. V., Free-Field Particle Motion from a Nuclear Explosion in Salt, Part II, Vela Uniform Program, Project Dribble, Salmon Event, VUF 3013, Stanford Research Institute, May 1969.

Hoffman, H. V., and Sauer, F. M. , Free-Field and Surface Motions, Project 1. 1, Operation Flint Lock, Pile Driver Event, POR 4000, Stanford Research Institute, June 1969.

Lombard, D. B. , The Hugoniot Equation of State of Rocks, UCRL-6311, Lawrence Radiation Laboratory, Livermore, California, February 1961.

Perret, W. R., Surface and Subsurface Strong Motion Measurements, Projects 26. 2 and 26.10, Operation Hardtack II, Evans Event, ITR 1703, Sandia Corporation, August 1959.

Perret, W. R., Subsurface Motion from a Confined Underground Detonation-Part I, Project 26. 4b, Operation Plumbbob, Rainier Event, WT-1929, Sandia Corporation, May 1961.

Perret, W. R. , Free-Field Ground Motion Studies in Granite, Project 3. 3, Operation Nougat, Hard Hat Event, POR1803, Sandia Corporation, April 1963.

Perret, W. R., Ground Motion Near Nuclear Explosions in Desert Alluvium, Projects 1.1 and 1.2, Vela Uniform Program, Operation Nougat, Fisher, Ringtail, Hognose, and Haymaker Events, VUF 2000, Sandia Laboratories, March 1965 (CFRD).

Perret, W. R., Free-Field Particle Motion from a Nuclear Explosion in Salt, Part I, Vela Uniform Program, Project Dribble, Salmon Event, VUF 3012, Sandia Laboratory, June 1968.

Perret, W. R., Free-Field Ground Motion in Granite, Project 1. 2a, Operation Flint Lock, Pile Driver Event, POR4001, Sandia Laboratory, September 1968. 
REFERENCE (cont)

'Perret, W. R., Gasbuggy Seismic Source and Surface Motion, Plowshare Program, Gasbuggy Event, PNE-1002, Sandia Laboratories, April 1970.

Perret, W. R., Ground Motion in a Multilayered Earth, Part I, Nuclear Explosion in Hardrock, Project 1.1/1.2, Operation Whetstone, Handcar/Painted Pony Event, POR 2800, Sandia Laboratories, June 1970.

Perret, W. R. , Ground Motion in a Multilayered Earth, Part II, Nuclear Explosion in Tuff, Project 1.1/1.2, Operation Whetstone, Mud Pack Event, POR2900, Sandia Laboratories, June 1970.

Perret, W. R. , Free-Field and Surface Motion from a Nuclear Explosion in Alluvium: Merlin Event, SC-RR-69-334, Sandia Laboratories, November 1971.

Perret, W. R. , 'Seismic-Source Energies of Underground Nuclear Explosions", Bulletin of the Seismological Society, 62, pp. 763-774, June 1972.

Perret, W. R., Ground Motion in the Vicinity of the Cannikin Nuclear Explosion, SLA-73-0043, Sandia Laboratories, September 1973.

Perret, W. R., and Breding, D. R., Ground Motion in the Vicinity of an Inderground Nuclear Explosion in the Aleutian Islands: Milrow Event, SC-RR-71-0668, Sandia Laboratories, May 1972.

Periet, W. R., Chabai, A. J., Reed, J. W., and Vortman, L. J., Project Scooter, Plowshare Program, SC-4602(RR), Sandia Corporation, October 1963.

l'erret, W. R., and Kimball, K. B., Ground Motion Induced by a Contained Nuclear Explosion, Project 1.1a/1.2a, Operation Flint Lock, Discus Thrower Lvent, POR6400, Sandia Laboratories, March 1971.

Preston, R. G., and Wheeler, V. L., Response of the Iine-of-Sight Pipe to Ground Shock in the ITupmobile Nuclear Liffects Test, L'CRL-50662, Lawrence Radiation Laboratory, August 1969 (CFRD).

Randolph, P. L., Preston, R. G., and Wheeler, V. L., Preliminary Report: Ground-Motion and lostshot-Collapse Studies in the Vulcan Event, LCID 15051, Lawrence Radiation Laboratory, August 1966 (CFRD).

Rice, M. I1., McQueen, R. G., and Walsh, J. M., "Compression of Solids by Strong Shock Waves," Solid State Physics, Vol. 6, pp. 1-63, Academic Press, New York, 1958.

Swift, L. M., Intermediate Range Earth Notion Measurements, l'lowshare Program, Gnome livent, PNE-111F, Stanford Research Institute, October 1962.

Swift, L. \., Measurement of Close-In Larth Motion, Project 1.2, Operation Nougat, Hard Hat Event, VUF 2101, Stanford Research Institute, May 1965 (CFRD).

Swift, I. N1., and Sachs, D. C., Surface Motion from an L'nderground Detonation, Project 26.4a, Operation Plumbbob, Rainier Lvent, WT-1528, Stanford Research Institute, April 1959.

Swift, L. M., Sachs, D. C., and Wells, W. M., Earth Motion Measurements, Part 1, Seismic Studies and Cavity Studies, Project 26.1, Operation Hardtack II, Evans Event, WT-1702, Stanford Research Institute, January 1959. 
Weart, W. D., Particle Motion near a Nuclear Detonation in Halite, Projects 44.1 and 1.1, Plowshare Program, Gnome Event, PNE-108F, Sandia Corporation, February 1963.

Weart, W. D., Free-Field Earth Motion and Spalling Measurements in Granite, Project 1.1, Vela Uniform Program, Shoal Event, VUF 2001, Sandia Corporation, February 1965.

Wheeler, V. E., and Preston, R. G., Response of the Pipe and Ground in the Packard Nuclear Effects Test, UCRL-51112, Lawrence Livermore Laboratory, August 1971. 
DISTRIBUTION:

U.S. Energy Research \& Development Agency Division of Technical Information (11)

P.O. Box 62

Oak Ridge, TN 37830

U.S. Energy Research \& Development Agency Director for Military Applications (2)

Washington, DC 20545

U.S. Lnergy Research \& Development Agency Division of Applied Technology (2)

Washington, DC 20545

U.S. Energy Research \& Development Agency Albuquerque Operations Office (2)

P. O. Box 5400

Albuquerque, NIM 87115

U.S. Energy Research \& Development Agency Nevada Operations Office (14)

P. O. Box 14100

Las Vegas, NV 89114

Attn: Library (2)

E. M. Douthett (10)

R. W. Newman

P. IIalstead

Los Alamos Scientific Laboratory (13)

P.O. Box 1663

Los Alamos, NM 87544

Attn: Report Librarian (4)

A. H. Davis

1R. R. Brownlee

A. N. Cox

R. C. Campbell

D. E. Eilers

R. Sharp, Jr.

K. II. Olsen

C. Keller

T. Scolman

I'niversity of California

Lawrence Livermore Laboratory (12)

P. O. Box 808

Livermore, CA 94550

Attn: Library (3)

V. E. Wheeler

J. R. Hearst

G. C. Werth

D. Springer

B. Crowley

I.. Ramspott

A. 11 . Holzer

L. Germain

L. Jackson
U.S. Geological Survey

Special Projects Branch (5)

Denver Federal Center

Denver, CO 80225

Attn: Library (2)

W. Twenhofel (2)

F. A. Mckeown

U. S. Geological Survey

Crustal Studies Branch (2)

345 Middlefield Road

Menlo Park, CA 94025

Attn: J. Healy

Library

U.S. Department of Commerce

USGS Special Projects

3060 South Highland Drive

Las Vegas, NV 89102

Attn: K. W. King

National Academy of Science (2)

2100 Constitution Avenue, NW

Washington, DC 20418

Attn: Earth Sciences Division

J. W. Berg, Jr.

Headquarters

Defense Nuclear Agency (2)

Washington, DC 20305

Attn: T. Stong

C. B. McFarland

Test Command (5)

Defense Nuclear Agency

Kirtland Air Force Base East

Albuquerque, NII 87115

Attn: Library (2)

B. Grote

C. Keller

J. LaComb

Director, Defense Advance Research

Projects Agency (3)

Washington, DC 20301

Attn: C. Romney (2)

Director

Army lingineer Waterways Experiment Station (4)

P.O. Box 631

Vicksburg, MS 39180

Attn: Library

C. Arbuthnot

L. Ing ram

D. Day 
DISTRIBUTION: (cont)

Air Force Weapons Laboratory (WLIL) (4) Kirtland Air Force Base, NM 87117

Attn: Library (2)

Massachusetts Institute of Technology

Cambridge, MA 02139

Attn: Department of Earth Sciences (2) F. Press M. N. Toksoz

TRW Systems

Space Technology Laboratories (4)

Redondo Beach, CA 90278

Attn: Library

B. Sussholz (3)

El Paso Natural Gas Co.

El Paso, TX 79901

Attn: P. L. Randolph

California Division of Mines \& Geology

1416 Ninth St. - Room 118

Sacramento, CA 95814

Attn: W. M. Wells (2)

Massachusetts Institute of Technology

Dept of Civil Engineering

Cambridge, MA 02129

Attn: R. K. McGuire

R\&D Associates (2)

Santa Monica, CA 90403

Attn: H. Cooper

J. G. Lewis

Pacifica Technology, Inc. (2)

P. O. Box 148

Del Mar, CA 92014

Attn: R. Bjork

J. Kent

University of Wisconsin-Milwaukee

Dept of Geological Sciences

Milwaukee, WI 5320

Attn: D. E. Willis, Chairman

EG\&G, Inc.

P. O. Box 204

San Ramon, CA 94583

Attn: R. G. Preston

Holmes \& Narver, Inc. (3)

P. O. Box 17902

Los Angeles, CA 90017

Attn: R. P. Kennedy

E. A. Wais

Library

Agbabian-Jacobsen Associates

8939 South Sepulveda Blvd

Los Angeles, CA 90045

Attn: R. B. Vail, Jr.
Physics International Company (2) 2700 Merced Street

San Leandro, CA 94557

Attn: F. M. Sauer

C. Vincent

Systems, Science and Software (3)

P.O. Box 1620

LaJolla, CA 92037

Attn: R. E. Duff

T. Cherry

J. Barthel

General K. E. Fields

561 Lake Avenue

Greenwich, CT 06830

2 W. J. Howard

1000 G. A. Fowler

1100 C. D. Broyles

1110 J. D. Kennedy

1110 L. R. Hill

1111 W. D. Weart (5)

1111 W. R. Perret (10)

1111 L. J. Vortman

1111 R. C. Bass (10)

1111 H. D. Garbin

1111 G. E. Larsen

1111 L. D. Tyler

1112 J. D. Plimpton

1115 J. L. Benson

1116 J. W. Wistor

1120 G. E. Hansche

1123 B. C. Benjamin

1123 K. B. Kimball

1123 H. R. Holmes

1123 D. R. Breding

1130 H. E. Viney

1131 B. C. Edwards

1133 C. W. Gulick

1133 W. C. Vollendorf

1150 J. R. Banister

1150 C. R. Mehl

1150 M. L. Merritt

1150 D. M. Tendall

8000 T. B. Cook, Jr.

8266 E. A. Aas (2)

8300 B. F. Murphey

9000 R. A. Bice

9415 R. J. Beyatte

3141 L. S. Ostrander (5)

3151 W. F. Carstens (3) For: ERDA/TIC (Unlimited Release) 